\title{
INVESTIGATION OF DRIVER SPEED CHOICE AND CRASH CHARACTERISTICS DURING LOW VISIBILITY EVENTS
}

\author{
A Thesis \\ Presented to \\ the faculty of the School of Engineering and Applied Science \\ University of Virginia \\ in partial fulfillment \\ of the requirements for the degree \\ Master of Science \\ by \\ Kathryn L. McCann
}

May

2016 
APPROVAL SHEET

The thesis

is submitted in partial fulfillment of the requirements

for the degree of

Master of Science

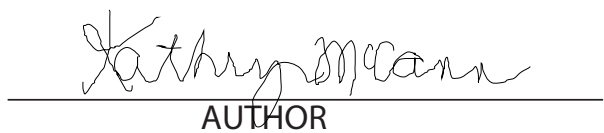

The thesis has been read and approved by the examining committee:

\section{Michael D. Fontaine}

\begin{tabular}{c}
\hline $\begin{array}{l}\text { Advisor } \\
\text { T. Donna Chen }\end{array}$ \\
\hline Brian Smith \\
\hline
\end{tabular}

Accepted for the School of Engineering and Applied Science:

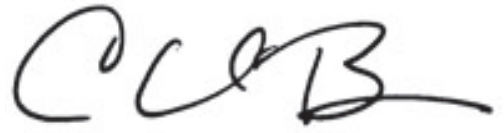

Craig H. Benson, Dean, School of Engineering and Applied Science

May

2016 


\section{ACKNOWLEDGMENTS}

I am extraordinarily grateful to have had the opportunity to pursue a master's degree at the University of Virginia and cannot even begin to thank everyone who helped me along the way.

Foremost, I would like to express my gratitude to my advisor, Dr. Michael D. Fontaine. I have learned so much from his enthusiasm, guidance, knowledge, and support. He made sure I was on track from the very beginning and encouraged me to submit my work at different times along the way. I cannot imagine having a better advisor.

I am grateful to all the teachers and mentors I have had and to my thesis examination committee members for their support, suggestions, and encouragement.

I have been surrounded by the most enthusiastic and helpful people throughout this project. Everyone who I have worked with from VDOT's Southwest and Northwest Regional Operations divisions were always on hand to quickly share data and answer questions. The VSL technical committee pushed me to explore the data in new ways with their questions and feedback. It was truly a pleasure to work with all of you.

I would like to thank Paula Crouch who suggested that I accompany her to VTRC one day in the summer before my senior year and to Dr. Jose Gomez who met with me that day and made it possible for me spend a few weeks learning about the Research Council before I went back to school. This experience started the journey to completing this degree and illuminated the possibilities I had in front of me.

Finally, I want to thank my family and friends, particularly my parents who have always encouraged and supported me. 


\section{ABSTRACT}

Fog can create a significant safety hazard for motorists. If motorists drive faster than current visibility permits, severe multiple-vehicle crashes may occur. In Virginia, sections of I77 and I-64 in mountainous parts of the state experience significant reoccurring fog events. These locations have also experienced several chain reaction crashes involving more than 50 vehicles during fog. These crashes were typically caused by drivers traveling too fast for available visibility conditions.

In order to improve safety on the I-77 corridor, the Virginia Department of Transportation has constructed a variable speed limit (VSL) system which will post dynamic speed limits based on the available visibility. Before the system is activated, it is important to understand existing driver speed choice behavior during low visibility conditions. It is possible that posting a VSL speed based only on stopping sight distance (SSD) could create significant speed variance and decrease safety if drivers are currently driving much faster than conditions warrant. In this study, crash, speed, and visibility data were examined at several locations on I64 and I-77 where there were recurring fog events.

Crash history at I-77 revealed that crashes in low visibility were more likely to be severe and involve more than 2 vehicles than crashes during clear conditions. Mean speed analysis found that observed mean speeds exceed safe speeds in all low visibility conditions and at all sites. In the worst visibility conditions, drivers are exceeding the safe speed by more than 20 $\mathrm{mph}$. Standard deviation analysis found that speed variance did not increase as visibility decreased on I-77, but at several locations in I-64 standard deviation was different during low visibility compared to clear conditions.

Models were developed better understand the relationship between speed and visibility. The models developed showed that while motorists are slowing down in low visibility, there is a still a significant differential between observed speeds and the safe speed calculated from the SSD. The models show that on I-64 speeds are much less sensitive to changes in visibility compared to I-77. A possible explanation for the differences between I-77 and I-64 are the presence of illuminated in-pavement markers on I-64 that provides motorists with and sense of safety that causes them to driver faster than visibility conditions dictate. It's also possible that mean speeds in low visibility are higher on I-64 because of the regular commuter traffic who are more comfortable driving during foggy conditions.

The model for I-77 was used to develop the initial VSL control algorithm. A primary concern of the VSL system operators was that it will not be respected by motorists and result in increased speed variance in foggy conditions. The model was used to help bridge the gap between current driver behavior and safe speed. It is recommended that future VSL system deployments use existing driver behavior in the initial algorithms as well. Speed and crash data on I-77 should be analyzed after the VSL system is deployed to determine the operational and safety effects. If the system on I-77 is deemed to be successful, a similar system should be developed for I-64 using the current driver behavior models as part of the initial algorithm. 


\section{TABLE OF CONTENTS}

Acknowledgments $\quad$ iii

Abstract iv

Table of Contents $\quad$ v

List of Tables vii

List of Figures $\quad$ viii

CHAPTER 1: INTRODUCTION

1.1 Purpose and Scope $\quad 1$

1.2 Thesis Organization $\quad 2$

CHAPTER 2: LITERATURE REVIEW

2.1 Introduction 3

2.2 Crash characteristics in Fog 3

2.3 Driver Behavior in fog $\quad 4$

2.4 Weather controlled Variable Speed Limit Applications 5

2.4.1 Visibility Controlled VSL Systems 5

2.4.1.1 Alabama - I-10 Jubilee Parkway 5

2.4.1.2 Nevada - I-80 5

2.4.1.3 Oregon I-5 and US-97 6

2.4.1.4 Tennessee - I-75 6

2.4.1.5 Utah - I-215 7

2.4.1.6 Netherlands - A16 Motorway 8

2.4.2 Snow, Rain, and Ice Controlled VSL Systems 9

2.4.2.1 Maine - I-95 and I-295 Advanced Traveler Information System 9

2.4.2.2 New Jersey - Turnpike VSL 10

2.4.2.3 Washington - I-90 TravelAid ITS 10

2.4.2.4 Wyoming - I-80 11

2.4.2.5 Finland - Highway E18 12

2.4.2.6 Sweden - E6 Motorway 13

$\begin{array}{ll}\text { 2.4.3 Summary of Past VSL Deployments } & 14\end{array}$

2.5 Gaps in past research $\quad 18$

CHAPTER 3: SITE CHARACTERISTICS 19

3.1 Introduction $\quad 19$

3.2 I-77 in Fancy Gap, Virginia 19

3.2.1 Site Description $\quad 19$

3.2.2 ATSMS Overview 20

3.2.2.1 Road Weather Information System Stations 20

3.2.2.2 Variable Speed Limit Signs 22

3.2.2.3 Algorithm Development 23

3.3 I-64 in Afton, Virginia 23

3.3.1 Site Description $\quad 23$

CHAPTER 4: METHODOLOGY 2

4.1 Data Collection and Processing $\quad 26$

$\begin{array}{ll}\text { 4.1.1 Visibility Data } & 26\end{array}$

4.1.1.1 I-77 in Fancy Gap, Virginia 26 
4.1.1.2 I-64 in Afton, Virginia 27

4.1.2 Crash Data 27

4.1.3 Speed and Volume Data 28

4.1.3.1 I-77 in Fancy Gap, Virginia 28

4.1.3.2 I-64 in Afton, Virginia 28

4.1.4 Categorization of Data by Stopping Sight Distance Safe Speed 29

4.2 Data Analysis $\quad 29$

4.2.1 Visibility Profiles $\quad 29$

4.2.2 Crash Analysis $\quad 30$

4.2.2.1 Crash Frequency and Characteristics $\quad 30$

4.2.2.2 Crash Rate Analysis $\quad 30$

4.2.3 Driver Speed Choice Behavior 30

4.2.3.1 Speed Analysis $\quad 30$

4.2.3.2 Modeling of Mean Speed as a Function of Visibility 31

CHAPTER 5: RESULTS

5.1 Introduction $\quad 32$

5.2 I-77 in Fancy Gap, Virginia

5.2.1 Visibility Profiles $\quad 32$

5.2.2 Crash Analysis 33

5.2.2.1 Crash Frequency and Characteristics 33

5.2.2.2 Crash Rate 38

5.2.3 Driver Behavior $\quad 39$

5.2.3.1 Speed Analysis $\quad 39$

5.2.3.2 Speed/Visibility Models 43

5.3 I-64 in Afton, Virginia 46

5.3.1 Visibility Profiles $\quad 46$

5.3.2 Crash Analysis $\quad 47$

5.3.2.1 Crash Frequency $\quad 47$

5.3.3 Driver Behavior $\quad 48$

5.3.3.1 Speed Analysis $\quad 48$

5.3.3.2 Modeling Speed $\quad 54$

5.3.3.3 Generalized Linear Model $\quad 58$

$\begin{array}{ll}5.4 \text { Summary of Results } & 61\end{array}$

5.5 Application of Speed Models to I-77 VSL Algorithm Development 62

CHAPTER 6: CONCLUSIONS AND RECOMMENDATIONS 64

6.1 Conclusions and Discussion $\quad 64$

6.1.1 Crash Analysis $\quad 64$

6.1.2 Driver Speed Choice $\quad 64$

6.2 Recommendations $\quad 66$

6.3 Future Research 67

REFERENCES $\quad 68$

$\begin{array}{ll}\text { APPENDICES } & \mathbf{7 0}\end{array}$

$\begin{array}{ll}\text { Appendix A: Publications \& Presentations } & 70\end{array}$

Appendix B: Additional Tables $\quad 71$ 


\section{LIST OF TABLES}

Table 1: Summary of Visibility Controlled VSL Systems 16

Table 2: Summary of Snow, Rain , \& Ice Controlled VSL Systems 17

Table 3: I-77 ATSMS Components 20

Table 4: Safe Speeds by Visibility Bin 29

Table 5: Crash Severity by Visibility Bin, 2010-2014 35

Table 6: Number of Vehicles Involved in Crashes by Visibility Bin, 2010-2014 36

Table 7: Crash Type by Visibility Bin, 2010-2014 37

Table 8: Crash Rate by Visibility Condition, 2010-2014 38

Table 9: I-77 Mean Speed by Visibility Bin 39

Table 10: I-77 Speed Differential between Lanes by Visibility Bin 39

Table 11: I-77 Speed Profile Characteristics 41

Table 12: I-77 Model Parameters 44

Table 13: I-64 Mean Speed by Visibility Bin $\quad 50$

Table 14: I-64 Lane Speed Differential by Visibility Bin 5

Table 15: I-64 Speed Profile Characteristics $\quad 52$

Table 16: I-64 Model Parameters

Table 17: ANOVA Table for I-64 Generalized Linear Model $\quad 59$

Table 18: I-64 Generalized Linear Model Compare Means $\quad 60$ 


\section{LIST OF FIGURES}

Figure 1: I-77 Study Area $\quad 20$

Figure 2: Map of RWIS Visibility Stations $\quad 21$

Figure 3: Vaisala Forward Scatter Visibility Sensor $\quad 21$

Figure 4: Planned VSL Sign Locations 22

Figure 5: (a) Variable Speed Limit Cutout Sign, (b) Full Color Dynamic Message Sign 23

Figure 6: I-64 Study Area $\quad 24$

Figure 7: Fog Lights on Afton Mountain 24

Figure 8: Map with Data Collection Locations 26

Figure 9: (a) Viasala Navigator Interface and (b) Sample Data Exported to Excel 27

Figure 10: I-77 Average Annual Visibility Profile 33

Figure 11: I-77 Speed Profiles $\quad 42$

Figure 12: I-77 Models for (a) MP 5.3, (b) MP 6.6, and (c) MP 7.7 45

Figure 13: I-77 Low Visibility Event 46

Figure 14: I-64 Visibility Profile, July to December 2014

Figure 15: I-64 Speed Profiles (a) MP 98.4 EB, (b) MP 98.4 WB, (c) MP 102.1 EB, and (d) MP

102.1 WB 53

Figure 16: I-64 Models for MP's 98.4 EB, 98.4 WB, 99.9 WB, 101.1 EB

Figure 17: I-64 Model for 99.9 EB

Figure 18: I-64 Model for MP 101.1 EB

Figure 19: I-64 Model for MP 102.1 EB

Figure 20: I-64 Model for 102.1 WB $\quad 57$

Figure 21: I-64 Westbound Low Visibility Event $\quad 58$

Figure 22: Algorithm Model $\quad 62$ 


\section{CHAPTER 1: INTRODUCTION}

Reduced visibility created by fog can create a significant safety hazard, particularly on high speed roads. From 2001 to 2008, there was an average of approximately 20,000 policereported crashes during fog annually in the United States (Hamilton, Tefft, Arnold, \& Grabowski, 2014). Fog crashes also account for around 2\% of all fatal crashes that have occurred between 1990 and 2012 (Hamilton et al., 2014). Past studies have shown that crashes in fog tend to involve multiple vehicles and have a higher percentage of fatalities and injuries than crashes in clear conditions (Hamilton et al., 2014). Fog is often unpredictable and fast setting, which can make it difficult for transportation agencies to address safety issues created by fog. Until recently, there have been relatively few engineering countermeasures that could address safety during foggy conditions.

In Virginia, there are several interstate locations that experience recurring fog events which have led to severe multi-vehicle crashes. In most cases, police reports indicated that drivers were traveling too fast for conditions. For example, dense and unpredictable fog on I-77 near the Virginia-North Carolina border creates dangerous driving conditions for motorists, which is exacerbated by a steep downhill grade. On March 30, 2013, there was a 95-car, chain reaction crash with 3 fatalities during a fog event (NY Daily News, 2013).

Variable speed limit (VSL) systems are a type of intelligent transportation system (ITS) technology that dynamically sets speed limits based on roadway conditions. Weather controlled VSL systems use atmospheric data to calculate a safe driving speed that is displayed on VSL signs. Typically, these systems are used to improve safety in winter weather or low visibility. Several variable speed limit systems have been installed in the United States and abroad including systems in the Netherlands, Tennessee, Alabama, Utah, and Nevada that are visibility controlled (Goodwin, 2003b; Hogema \& van der Horst, 1994; Jensen, 1995; Perrin, Martin, \& Cottrell, 2003; Robinson, 2002). Very little quantitative analysis has been performed to evaluate the success of these systems, although most systems were deemed to qualitatively improve safety.

An Active Traffic and Safety Management System (ATSMS) has recently been installed on I-77 in Fancy Gap, Virginia with the goal of improving safety and operations during low visibility events. A primary component of the ATSMS is a variable speed limit system that will calculate a safe speed given the conditions and display it to motorists on full color dynamic message signs. This ATSMS will serve as a pilot for weather controlled variable speed limit systems in Virginia. An understanding of driver behavior in foggy conditions is useful in the development of a VSL control algorithm. If a speed limit is not respected by motorists, it may lead to an increase in speed variance and additional safety concerns. If the I-77 ATSMS is successful, an additional system is also planned for deployment on I-64 at Afton Mountain.

\subsection{PURPOSE AND SCOPE}

This thesis aims to evaluate the safety and driver behavior at I-77 in Fancy Gap and on I64 over Afton Mountain to aid in the development of the variable speed limit algorithm for the ATSMS on I-77. The specific objectives of this project are to: 
- Determine the impact of low visibility on safety by examining crash data and other safety surrogate measures during fog at these two sites.

- Determine how driver speed and speed compliance varies as a function of weather conditions at both sites.

- Using this information on driver behavior in fog, develop recommendations for the I77 VSL control algorithm.

The project objectives will be accomplished by collecting traffic, visibility, and crash data on I-77 in Fancy Gap, Virginia before the ATSMS is installed and on I-64 in Afton, Virginia.

\subsection{THESIS ORGANIZATION}

The remaining chapters are organized as follows:

- Chapter 2 is a literature review of driver behavior in low visibility conditions and past deployments of weather controlled variable speed limit systems

- Chapter 3 is an overview of the I-77 Active Traffic and Safety Management System

- Chapter 4 describes the methodology used to evaluate safety and driving behavior on I-77 and I-64

- Chapter 5 discusses the results of the analysis outlined in the previous chapter and summarizes the VSL algorithm developed for I-77

- Chapter 6 provides conclusions and recommendations based on the analysis at both sites 


\section{CHAPTER 2: LITERATURE REVIEW}

\subsection{INTRODUCTION}

Past literature was reviewed to gather information on crash characteristics and driver behavior in fog, and on the successes and failures of previous deployments of VSL systems. This chapter further discusses the available research on these topics and identifies key gaps in the knowledge base that will be explored in this thesis.

\subsection{CRASH CHARACTERISTICS IN FOG}

A two decade review of crashes in low-visibility throughout the United States revealed several trends safety (Hamilton et al., 2014). The crash analysis used fatal crashes from 1990 to 2012 from the Fatality Analysis Reporting System (FARS) and all crash severity crashes from the National Automotive Sampling System General Estimates Systems (NASS-GES) between 1990 and 2008 (Hamilton et al., 2014). Results from the crash analysis found that in general, the raw number of fatal crashes in fog had decreased over the collection period (Hamilton et al., 2014). It is particularly interesting that fog crashes are decreasing as a percentage of overall crashes. This could be from improvements in weather monitoring and driver alert systems during this period as well as improvements in vehicle safety. Crash history also supports the common belief that fog crashes are often multi-vehicle collisions. According to the report, 20\% of fatal crashes involving 10+ vehicles and $4.5 \%$ of crashes involving 6 to 9 vehicles occur in fog (Hamilton et al., 2014). Both percentages are much greater than the overall representation of fatal crashes in fog compared to all fatal crashes which is around 2\% (Hamilton et al., 2014). This emphasized the safety concerns in low visibility as these crashes often involved more vehicles than the average fatal crash. The report concludes that while fog crashes are a small percentage of overall crashes, crashes are more likely to occur in low visibility conditions than in clear conditions and that these crashes are more likely to be serious and involve multiple vehicles than crashes that occur in clear conditions (Hamilton et al., 2014).

There are several limitations with this crash analysis. This study looks almost exclusively at fatal crashes and how fatal crashes in fog compare to fatal crashes in all conditions. This assumes that crashes at all severity levels follow the same trends as the trend in fatal crashes. Additionally, this analysis looks purely at percentages. The analysis would be stronger if crash rates were normalized by vehicles miles traveled. This would allow for comparison analysis over time and across weather conditions, since it is possible that vehicle travel may decline during limited visibility periods. Furthermore, there is no analysis by the severity of visibility reduction, and it cannot be assumed that crash trends are the same across all visibility levels.

A study of crashes in Florida from 2003 to 2007 looked at various factors that might contribute to fog and smoke crashes such as lighting, posted speed, number of lanes, median type, and driver age (Abdel-Aty, Ekram, Huang, \& Choi, 2011). Odds ratios were calculated to examine crash type and severity for fog and smoke crashes compared to crashes in clear conditions (Abdel-Aty et al., 2011). This analysis revealed that crashes in fog or smoke were more likely to have a fatality or severe injury and involve multiple vehicles than crashes in clear 
conditions (Abdel-Aty et al., 2011). Head-on crashes were found to be the most likely crash type for fog or smoke crashes, however this dataset included undivided roadways as well as divided highways (Abdel-Aty et al., 2011). This study also did not examine the severity of the visibility reduction.

Several other studies looked at raw numbers of crashes in fog compared to crashes in clear conditions; however no analysis was performed with regard to crash cause or characteristics (Goodwin, 2002, 2003b). One study of crashes in fog as well as other adverse weather conditions focused on economic impacts and mitigation techniques, but did not look at contributing factors (Pisano, Goodwin, \& Rossetti, 2000).

\subsection{DRIVER BEHAVIOR IN FOG}

Fog related crashes are random events and occur infrequently. Therefore, to evaluate safety, it is useful to look at alternate safety indicators such as speed and driver behavior. A driver simulator study of behavior in fog revealed that drivers are not able to accurately perceive their speed due to the decrease in contrast in their surroundings (Snowden, Stimpson, \& Ruddle, 1998). This leads to speeds that are much higher than the appropriate safe speed for the conditions. Another driving simulator study found that headways decreased in the worst fog conditions (Kang, Ni, \& Andersen, 2008).

A study was conducted at Clemson University using university students with an average of less than five years of driving experience (Brooks et al., 2011). The simulation study was designed to test the drivers ability to stay in their lane and maintain their speed (Brooks et al.,

2011). The study tested each driver in varying degrees of low visibility from 1630 feet to 20 feet (Brooks et al., 2011). It was concluded from the study that drivers would choose a speed that allowed them to stay in their lane effectively; however, driver speeds were often greater than a safe stopping sight distance speed given the visibility (Brooks et al., 2011). This study has several limitations. Only one driver age was tested: young drivers with an average of less than five years of driving experience. It cannot be assumed that drivers of all experience level would behave the same way in fog. This study was conducted on a driving simulator which has inherent limitations compared to a study conducted on the roadway. It's difficult to say whether or not driving behavior is the same when tested on a simulator and the participant knows that they are being evaluated and that there is no real danger. Additionally, it's unclear if the representation of low visibility is realistic on a simulation screen.

Another simulator study found that in low-visibility conditions, driver behavior could be categorized into two groups, drivers who chose not to maintain visual contact with the vehicle ahead and drivers who maintain visual contact with a lead vehicle (Broughton, Switzer, \& Scott, 2007). While the sample size for this study was small, the analysis showed that $75 \%$ of the vehicles chose to maintain visual contact with the lead vehicle, even if the speed and headway associated with this following behavior compromised safety (Broughton et al., 2007). This car following behavior in low visibility could be a major contributing factor to the high proportion of rear-end crashes in low visibility conditions. 
Severe crashes in low visibility raised awareness of the critical safety concerns on I-84 in Southeast Idaho. A study of driving behavior in low visibility was conducted between December 1995 and April 1996 (Liang, Kyte, Kitchener, \& Shannon, 1998). Speed, visibility, and traffic volume data was collected at one location on I-84 during two days of low visibility and one day of clear conditions (Liang et al., 1998). The study found that there was a reduction in mean speed during low visibility conditions from $66 \mathrm{MP}$ to $61 \mathrm{MPH}$ but an increase in speed variance (Liang et al., 1998). This suggests that drivers naturally reduce their speed if they perceive a need to do so even without any external information or warning systems. This study was limited to only one data collection location and only two days of low visibility. More data would improve the reliability of this analysis. Additionally, there was no information about the severity of the low visibility event.

\subsection{WEATHER CONTROLLED VARIABLE SPEED LIMIT APPLICATIONS}

\subsubsection{Visibility Controlled VSL Systems}

\subsubsection{Alabama - I-10 Jubilee Parkway}

The Alabama DOT implemented a low visibility warning system following a 1995 crash on I-10 on the bridge over the Mobile Bay involving 193 vehicles. The VSL system spans an eight mile segment of I-10 and includes six weather sensors at one mile intervals along the corridor, twenty-five closed circuit cameras to monitor traffic, twenty-four variable speed limit signs, five dynamic message boards, and radar vehicle detection devices every $1 / 3$ mile (Goodwin, 2003a).

The system is manually activated and controlled by the traffic management center (Goodwin, 2003a; Kimley-Horn, 2014). Appropriate speed limits are determined using the AASHTO stopping sight distance formula: visibility below 660 feet corresponds to a speed limit of $55 \mathrm{MPH}$, visibility below 450 feet corresponds to a speed limit of $45 \mathrm{MPH}$, visibility below 280 feet corresponds to a speed limit of $35 \mathrm{MPH}$, and visibility below 175 feet will result in a road closure (Goodwin, 2003a). Visibility readings are taken from the weather stations and verified using the cameras of someone on patrol in the field (Kimley-Horn, 2014). This VSL system is regulatory and law enforcement officers are notified when speeds are reduced (Goodwin, 2003a). The Alabama DOT feels that the presence of officers on the corridor help enforce the speed without having to pull over vehicles (Kimley-Horn, 2014). Control operators observed decreased speeds and the Alabama DOT reported that safety on the bridge improved as a result of the low-visibility warning system, but no quantitative analysis of system effectiveness was found (Goodwin, 2003a).

\subsubsection{Nevada - I-80}

Localized fog is a primary safety concern on I-80 as it travels by a coal-fired power generation facility through a canyon with a river in Northern Nevada (Robinson, 2002). Two variable speed limit signs were installed in each direction approaching the area of concern on the corridor (Robinson, 2002). RWIS stations collect weather and visibility data while speed loop detectors are used to collect real-time traffic data (Robinson, 2002). A computer algorithm is 
used to determine the appropriate speed on the corridor using the visibility, $85^{\text {th }}$ percentile speed, and pavement conditions (Robinson, 2002). The speed limits are considered to be regulatory and enforced by state police (Robinson, 2002). Despite the fact that the system was designed to be fully automated, the reliability of the visibility sensors limited the success of the system upon activation and prevented it from being operated in an automated mode (Robinson, 2002). There is no reported evaluation of the effectiveness of the system to date.

\subsubsection{Oregon I-5 and US-97}

Oregon implemented a fully automated variable speed limit system on I-5 and US-97 in 2014 (Kimley-Horn, 2014). Speed limits are displayed on full color DMS's spaced at 1.5 mile intervals along each corridor (Kimley-Horn, 2014). The weather controlled component of this system takes visibility, grip factor, and current vehicle speed as inputs to determine the posted speed, which is advisory at this time (Kimley-Horn, 2014). Dual loop sensors and Wavetronix side-fire radar units collect speed and volume data throughout each corridor (Kimley-Horn, 2014). The grip factor and the visibility are determined using lasers from a Vaisala DSC111 sensor (Kimley-Horn, 2014). If the visibility is greater than 500 feet and the grip factor is greater than 0.70 , then the clear conditions speed limit is posted (Kimley-Horn, 2014). Reduced visibility is considered to be less than 500 feet and not classified into further bins (Kimley-Horn, 2014). While the system is fully automated, the algorithm has built in error detection and it can be overridden by an operator if necessary (Kimley-Horn, 2014) A smoothing algorithm dictates the speed posted to adjacent signs and a time parameter is set to determine the refresh rate of the speed limit (Kimley-Horn, 2014). Speed analysis has not been performed to evaluate the effects of the VSL system and ODOT has not reported any qualitative effects.

\subsubsection{Tennessee - I-75}

The implementation of a variable speed limit system on I-75 in southeast Tennessee was prompted by a 99 car crash due to extremely dense fog coming off the Hiwassee River (Goodwin, 2003a). The low visibility warning system spans nineteen miles of I-75 and consists of six static signs with flashing beacons, two highway advisory radio transmitters, ten dynamic message signs, and ten variable speed limit signs (Goodwin, 2003a). Data is collected from two environmental sensors, eight visibility sensors, and forty-four vehicle detectors and sent to a central computer systems accessed by the Tennessee DOT and Tennessee Department of Safety (Goodwin, 2003a). An automated system observes the visibility and alerts personnel when the low-visibility threshold is met and warning messages are displayed on the VSL and DMS signs (Jensen, 1995). Highway patrol troopers that have been alerted and stationed in the area then verify conditions by manually by counting delineators that have been located based on the visibility thresholds (Goodwin, 2003a). Operators then must manually activate the system which is programmed to respond to the appropriate visibility scenario (Jensen, 1995). Visibility classified as clear keeps the speed limit at $65 \mathrm{mph}$, while moderate and severe reduces the speed limit to $50 \mathrm{mph}$ and $35 \mathrm{mph}$ respectively (Jensen, 1995). When the visibility is classified as critical (less than 240 feet), automatic gates close the on-ramps to the interstate and detour traffic to a pre-designated route (Jensen, 1995). 
The Tennessee DOT pointed to a reduction of crashes as the measure of improved safety due to the implementation of the system. There were more than 200 fog related crashes between 1973 and 1994, and only one crash occurred in fog between 1994 and 2003 (Goodwin, 2003a). While there has not been any known formal evaluation of the system, local law enforcement agencies state that there has been an observed decrease in vehicle speeds during the moderate scenario, which was displayed $90 \%$ of the time that the system was activated during the 12 month evaluation period (Jensen, 1995; Robinson, 2002).

\subsubsection{Utah - I-215}

The Adverse Visibility Information System Evaluation (ADVISE) system was installed in phases between 1995 and 2000 on a two mile section of I-215 that crosses the Jordan Valley River in Salt Lake Valley, Utah (Perrin et al., 2003). ADVISE consists of a variable message sign to display recommended speed or appropriate advisory messages, four fog sensors that record visibility, and six loop detectors that record speed data (Perrin et al., 2003). The displayed speed limit is calculated using an algorithm that takes the weighted average of the two lowest visibility readings and compares to the established thresholds for visibility and the corresponding speed limit (Perrin et al., 2003). It is unclear if the system is automated or must be activated by controllers.

ADVISE was installed in phases which allowed for the collection of visibility and speed data before the variable speed limits were operational. Baseline data was collected when the fog and loop detectors were installed but before the VSL signs were in place (Perrin et al., 2003). After ADVISE was fully constructed, data was collected for two years and compared to the baseline data to measure effectiveness of ADVISE (Perrin et al., 2003). The variable speed limits from ADVISE are considered advisory and are not enforceable by the police (Perrin et al., 2003).

Analysis of the before and after speeds found that the there was a decrease in the spread of vehicle speeds due to the presence of ADVISE. This suggests improved safety along the corridor. However, the mean speed increased by $15 \%$, which indicates that cautious drivers sped up rather than aggressive drivers slowing down to the meet the recommended speed (Perrin et al., 2003). The study reports that between phases of the project, the interstate was changed from three lanes to four lanes. It is possible that driver speeds increased during the after period because drivers perceived that they could drive safely at a higher speed with the change in the facility. A graph of the mean speeds before and after the installation of ADVISE shows that even in clear conditions the after speeds are greater than the before speeds. It is particularly interesting that speed variance decreased during this study. This is very different from the analysis of the other VSL systems. Again, it is possible that the addition of an extra travel lane impacted variance in this way. While Perrin et al. did not discuss compliance in their study, a visual examination of the scatter plot of mean speeds does not point to good compliance during reduced visibility. In fact, the plots show a small decrease in speeds (approximately $65 \mathrm{MPH}$ to $58 \mathrm{MPH})$ as visibility decreases from $250 \mathrm{~m}$ (820 feet) to $60 \mathrm{~m}$ (200 feet). According to the report, the variable messages signs should display a recommended safe speed of $30 \mathrm{MPH}$ when the visibility is less than $100 \mathrm{~m}$ (330 feet) (Perrin et al., 2003). 
Analysis of the effectiveness of ADVISE was limited to comparing vehicle speeds as a function of visibility before and after the installing of the system. There was no crash analysis or any analysis of compliance to posted speed.

\subsubsection{Netherlands - A16 Motorway}

In response to a 100 vehicle crash caused by dense fog on the A16 Motorway in 1990, the Dutch Ministry of Transport called on the TNO Human Factors Research Institute to perform a study on the effects of a fog-signaling system on driving behavior. The fog-signaling system was installed on a $12 \mathrm{~km}$ section of the A16 Motorway in the Netherlands and it became operational in November of 1991 (Hogema \& van der Horst, 1994). The system consists of 37 VSL matrix signs on gantries above the roadway at an average interval of $700 \mathrm{~m}(2,300 \mathrm{feet})$ (Hogema \& van der Horst, 1994). One to three visibility sensors were assigned to the nearest downstream gantries (Hogema \& van der Horst, 1994). Recommended speed thresholds as a function of the visibility were established such that in visibility greater than $140 \mathrm{~m}$ (460 feet), no speed limit reduction would be shown $(100 \mathrm{~km} / \mathrm{h}, 62 \mathrm{mph})$; in visibility between $70 \mathrm{~m}$ and $140 \mathrm{~m}$ (230 to 460 feet), the speed limit would be reduced to $80 \mathrm{~km} / \mathrm{h}(50 \mathrm{mph})$; and in visibility less than $70 \mathrm{~m}$, the speed limit would be reduced to $60 \mathrm{~km} / \mathrm{h}(37 \mathrm{mph})$ (Hogema \& van der Horst, 1994).

Control data for the analysis was taken from an adjacent section of the A16 motorway and from the nearby A59 motorway (Hogema \& van der Horst, 1994). Loop detectors collected data for 2 years at the control locations and on the study section. The detectors recorded lane number, time of day, speed, and length of vehicles for passing traffic (Hogema \& van der Horst, 1994). Multiple linear regression was performed to determine which independent variables had the most significant effects on mean speed: visibility, lane, and flow (Hogema \& van der Horst, 1994).

The Human Factors Research Institute concluded that the mean speed in fog decreased more when the fog-signaling system was present than when it was not present. For visibility greater than $35 \mathrm{~m}$ (115 feet), means speeds were 8 to $10 \mathrm{~km} / \mathrm{h}$ (5 to $6 \mathrm{mph})$ greater when the system was not present (Hogema \& van der Horst, 1994). This trend existed for both the fast and slow lanes on the motorway. However, in visibility less than $35 \mathrm{~m}$, drivers tended to drive slower when the system was not present than when it was present (Hogema \& van der Horst, 1994). When the system was not present, the drivers tended to drive at a speed less than $60 \mathrm{~km} / \mathrm{h}$ (37 mph) which is the minimum threshold established for the fog-signaling system (Hogema \& van der Horst, 1994). This adverse effect of the system could be remedied by establishing a lower minimum recommended speed for extreme conditions (Hogema \& van der Horst, 1994). The speed analysis showed the same general trend of speed as a function of visibility with and without the system. The trend showed that vehicle speeds decreased as visibility decreased and the rate of this decrease was approximately the same in both lanes of traffic when comparing the speeds with and without the system.

The study did not look at any crash data as a measure of effectiveness. Additionally the analysis was performed by looking at control roadways rather than comparing after effects to any before data on the same section of roadway. It is possible that the control roads experienced 
different weather conditions and traffic, which could raise questions about the comparison results.

\subsubsection{Snow, Rain, and Ice Controlled VSL Systems}

\subsubsection{Maine - I-95 and I-295 Advanced Traveler Information System}

The Maine Advanced Traveler Information System consists of multiple safety oriented traffic control devices including variable speed limit signs along I-95/Maine Turnpike (Belz \& Garder, 2010). The weather reduced speed limit concept was not new to the Maine Turnpike; the previous system had $45 \mathrm{MPH}$ advisory speed limit signs with flashing beacons that would be activated in poor weather conditions (Belz \& Garder, 2010). The new variable speed limit signs could be set to any speed and would be activated due to weather, roadway incidents and accidents, and other emergency situations (Belz \& Garder, 2010). Authority to activate the variable speed limit system is limited to the Maine State Police who notify the traffic control operators (Belz \& Garder, 2010).

To determine the effectiveness of the system, speed data was collected manually by radar gun over a three year period during inclement winter weather (Belz \& Garder, 2010). Despite the ability to post any speed, only a $45 \mathrm{mph}$ advisory speed was posted during the study period (Belz \& Garder, 2010). The average speed and $85^{\text {th }}$ percentile speed were calculated on each collection day and paired with a snow intensity measure of none, very light, light, moderate, or heavy (Belz \& Garder, 2010). The snow intensity for the speed data analysis was determined visually, so categorization may be inconsistent. Based on the average speeds in different snow intensities, it was determined that the variable speed limit signs had little to no effect drivers speeds (Belz \& Garder, 2010). A survey of driver perception of the system was conducted and sixty-two responses were received (Belz \& Garder, 2010). The survey results indicated a mixed review of the system, with $56 \%$ percent saying the system was useful, but only $45 \%$ claiming to adhere to the recommended speed (Belz \& Garder, 2010). Ultimately, it was recommend that improvements to the system include the use of recommended speed limits other than $45 \mathrm{mph}$, the installation of additional variable speed limit signs, police enforcement of reduced speed limits, and the use of an algorithm to determine the appropriate speed limit based on sight distance and roadway surface friction (Belz \& Garder, 2010).

Evaluation of the effectiveness of the variable speed limit system was limited to speed data collection. During the three year period, data was collected during thirteen days and snow events were present during eleven of these days; the $45 \mathrm{mph}$ speed limit was still on display during the two days classified as having no snow event (Belz \& Garder, 2010). Comparison analysis between clear and snowy conditions is limited by the availability of data. Furthermore, there was no control scenario set up for comparison of the system without variable speed limits. Quantitative analysis on the old $45 \mathrm{mph}$ signs with flashing beacons was not mentioned or used in this report. Because only a reduced $45 \mathrm{mph}$ speed limit was displayed during the collection periods, it is not possible to analyze the effectiveness of the variable aspect of the speed limit system. It is not surprising that the recorded speeds were higher during the times that the snow intensity was classified as none or light because the drivers could see that there was no reason to reduce speed to $45 \mathrm{mph}$. The $45 \mathrm{mph}$ speed limit is considered advisory and not enforceable by 
the police, giving the driver no incentive to reduce speed especially when the driver can determine that the safe speed is much higher than the posted $45 \mathrm{mph}$ limit. Activation of the system is determined by state police and no weather data was collected via sensors. The analysis was further limited by the collection of speed samples at only one location not allowing for analysis across the corridor. No crash analysis was conducted for this study and the survey received only 62 responses, raising questions about its statistical significance.

\subsubsection{New Jersey - Turnpike VSL}

The New Jersey Turnpike Authority has been using variable speed limits to improve safety on the turnpike since the Advance Traffic Management System was installed in the 1960's (Robinson, 2002). The system is made up of more than 120 variable messages sign and 113 dynamic message signs spread throughout a 150 mile corridor (Goodwin, 2003a). Operators in the traffic management center monitor weather data from thirty environmental sensor stations and manually lower speed limits in five mph increments from the regular posted speed down to $30 \mathrm{mph}$ when necessary (Goodwin, 2003a). The reduced speeds are considered regulatory and enforced by state police officers (Goodwin, 2003a). There has not been a formal test of the effectiveness of the variable speed limit system on the turnpike; however, the New Jersey Turnpike Authority asserts that the system improves daily operations and safety along the corridor (Robinson, 2002).

The system is limited by the necessity of manual control and absence of an algorithm to determine the appropriate speed based on the weather conditions. Effectiveness of the system cannot be determined without quantitative analysis of speed and crash data. Because the system is so old and unique, it would be impossible to look at any before data on the turnpike and difficult to compare to any control road for comparison analysis.

\subsubsection{Washington - I-90 TravelAid ITS}

Fog, snow, and ice often lead to dangerous driving conditions on I-90 through the Cascade Mountains in Washington State. The Washington State DOT decided to implement a variable speed limit system to improve safety on a 40 mile segment of I-90 with a high volume of truck traffic, severe grade and curvature, and a high amount of unfamiliar seasonal traffic (Goodwin, 2003a). Thirteen dynamic message signs with variable speed limit signs were constructed to display advisory messages and reduced speed limits (Goodwin, 2003a). Appropriate speed limits and messages were determined from data collected via six environmental sensor stations (ESS) and twenty-two radar vehicle detectors (Goodwin, 2003a). Safe speeds were calculated by a central computer algorithm and confirmed by operators who manually activate the speed management system (Goodwin, 2003a).

Speed data was collected at two locations along the corridor for 12 months following of the variable speed limits signs (Ulfarsson et al., 2002). A location near a VSL sign would be used as the experimental site, while a location six miles away and outside the VSL area would be used as a control site for the analysis (Ulfarsson et al., 2002). A comparison of the mean speeds at each site showed that when the VSL signs were active the average speed in the eastbound direction at the VSL data collection site was $100 \mathrm{~km} / \mathrm{h}$ compared to $119 \mathrm{~km} / \mathrm{h}$ at collection site 
outside the VSL area (Ulfarsson et al., 2002). In the westbound direction, the average speed was $117 \mathrm{~km} / \mathrm{h}$ at the collection site within the VSL area and $121 \mathrm{~km} / \mathrm{h}$ outside the VSL area (Ulfarsson et al., 2002). Eastbound, the speed standard deviation was $16.7 \mathrm{~km} / \mathrm{h}$ when the VSL was on compared to $11.8 \mathrm{~km} / \mathrm{h}$ when the VSL was off. In the westbound direction the speed standard deviation was $12.8 \mathrm{~km} / \mathrm{h}$ with the VSL system and $11.9 \mathrm{~km} / \mathrm{h}$ without the system (Ulfarsson et al., 2002). Hypothesis testing revealed that the mean speeds and standard deviation of speed were statistically significantly different when the system was off compared to on (Ulfarsson et al., 2002). The value of the displayed speed limit is not used or stated for this analysis and no compliance evaluation was performed.

Because vehicle speeds were only collected at one experimental location along the corridor, it is difficult to draw conclusions about the effectiveness of the entire system. The report did not break down mean speed by posted reduced speed or by weather condition and severity. Therefore no conclusion could be drawn about driver compliance with reduced speed or about what weather conditions produced the best compliance or speed reduction.

\subsubsection{Wyoming - I-80}

In February of 2009, the Wyoming Department of Transportation installed VSL signs along a 52 mile section of I-80 between Rawlins and Laramie (Buddemeyer, Young, \& DorseySpitz, 2011). This corridor has a reported average ADT of 10,800 with $60 \%$ heavy truck traffic (Buddemeyer et al., 2011). Severe weather in the region often created impassible conditions on the interstate. During the winter between 2007 and 2008, this stretch of I-80 was closed 29 times for an average of 8 hours at a time (Buddemeyer et al., 2011). Closing the interstate is a heavy economic burden on the state and surrounding communities as it is a heavy freight route through the region. Crash analysis performed by the University of Wyoming in 2006 reinforced the notion that hazardous conditions caused by the severe weather were responsible for a large portion of the crashes (Buddemeyer et al., 2011). The Wyoming Department of Transportation decided to implement a VSL system in conjunction with research done by the University of Wyoming (Buddemeyer et al., 2011).

Prior to the installation of the VSL system in 2009, the corridor had one road weather information system (RWIS) and two dynamic message signs: one at each end of the 52 mile corridor (Buddemeyer et al, 2010). To gather performance data, ten Wavetronix sensors were added to collect speed and volume data along the study section (Buddemeyer et al, 2010). As part of the VSL system, speed radar feedback signs were posted at each end of the corridor and four DMS boards relaying basic information about the VSL system were spread out along the roadway (Buddemeyer et al, 2010). Dual indicated VSL signs were installed at the six interchanges along the 52 mile corridor with an average spacing between adjacent signs of 6.7 miles. Each VSL sign was equipped with a flashing beacon and a cut out for the word "REDUCED" to appear on a yellow background when the reduced speed limit was in place (Buddemeyer et al, 2010). Upon the commencement of its operation in 2009, a computer operated system for determining the appropriate reduced speed had not been set up, so the reduced speed was recommended by the Wyoming Highway Patrol (Buddemeyer et al, 2010). 
The University of Wyoming devoted much of its analysis of this VSL system to determining the most significant factors on driver speed (Buddemeyer et al., 2011). It was concluded that surface status, subsurface temperature, wind speed, dew point, and visibility had the biggest impact on speed. Furthermore, the University of Wyoming looked at the effect the VSL signs had on lowering driver speed (Buddemeyer et al., 2011). Using a linear regression model with weather data from the RWIS and speed data collected from February 2009 to April 2009 , it was concluded that there was a reduction in driver speeds of 0.47 to $0.75 \mathrm{mph}$ for every $1 \mathrm{mph}$ of reduced posted speed (Buddemeyer et al., 2011). No model fit value was reported for any of the analysis.

Analysis of this VSL system was limited by the availability of weather data across the corridor. With only one RWIS station, accurate information could not be obtained that was representative of the entire corridor. The analysis of compliance with posted reduced speed used a model rather than comparison with any speed data collected before the installation of the VSL signs. It is possible that this analysis approach was selected due to the limited "before" data available with only one RWIS station and no permanent traffic collection methods.

The University of Wyoming and the Wyoming Department of Transportation selected only speed compliance as a measure of effectiveness for this VSL system. While weather related crashes were listed as a contributing factor in the need for this installation, no post installation crash analysis was performed on the corridor.

\subsubsection{Finland - Highway E18}

Winter weather is often responsible for dangerous road conditions throughout Finland. While it is the standard in Finland for the speed limit to be decreased by a fixed amount during winter months, often the speed limit is still much higher than the safe speed given the conditions (Rämä, 1999). The Technical Research Centre of Finland conducted a study to determine the effect of a variable speed limit system on driver behavior in inclement weather (Rämä, 1999).

The field test was conducted on a $14 \mathrm{~km}$ stretch of Highway E18 in southern Finland. This limited access highway was equipped with five information boards and thirty-six variable speed limit signs (Rämä, 1999). Two unmanned weather stations were used to collect weather data which was sent in five minute intervals to a central computer (Rämä, 1999). Road surface condition and precipitation data was used to classify the conditions as poor, moderate or good and automatically display the speed limits appropriately. It was pre-determined that the winter speed limit could be reduced from $100 \mathrm{~km} / \mathrm{h}$ to $80 \mathrm{~km} / \mathrm{h}$ in moderate and poor conditions while the summer speed limit could be reduced from $120 \mathrm{~km} / \mathrm{h}$ in good conditions to $100 \mathrm{~km} / \mathrm{h}$ and 80 $\mathrm{km} / \mathrm{hr}$ in moderate and poor conditions respectively (Rämä, 1999). A control road located 100 $\mathrm{km}$ west of the field test site was used to compare the effect of the variable speed limit system on E18 (Rämä, 1999). This road had $100 \mathrm{~km} / \mathrm{h}$ speed limit during the winter months and a 120 $\mathrm{km} / \mathrm{h}$ speed limit the rest of the year (Rämä, 1999). Data was collected on the experimental road and the control road using loop detectors at automatic data collection stations (Rämä, 1999).

For the analysis, data from the experimental road and control road was matched using road and weather classification as well as day of the week and time of day. Speed analysis 
showed that during good conditions in the winter when the speed limit was set to $100 \mathrm{~km} / \mathrm{h}$ the mean speeds were $98 \mathrm{~km} / \mathrm{h}$ on the experimental road and $104 \mathrm{~km} / \mathrm{h}$ on the control road (Rämä, 1999). During poor conditions when the speed limit was further reduced to $80 \mathrm{~km} / \mathrm{h}$ on the experimental road, the mean speed decreased by $9.7 \mathrm{~km} / \mathrm{h}$ on the experimental road and $6.3 \mathrm{~km} / \mathrm{h}$ on the control road (Rämä, 1999). This suggests that in poor conditions that drivers decrease speed both when advisory speeds are posted and when they are not; however, the mean speed was $3.4 \mathrm{~km} / \mathrm{h}$ lower when the VSL signs were present than when they were not. During adverse weather conditions, the standard deviation of speeds decreased when the variable speed limit system was in use on the experimental road, and increased on the control road as compared to each road when the weather conditions were good (Rämä, 1999). Reduced standard deviation of speed is an implied safety measure as crashes are less likely to occur when the spread of speeds is less. The field study did some analysis on headways and found that the variable speed limit system decreased percentage of headways less than 1.5 seconds by 1 to $6.6 \%$; however, because of the low traffic volumes, the proportion of headways under 1.5 seconds was relatively low to begin with at 18 to $20 \%$ (Rämä, 1999).

The system was deemed successful by the Technical Research Centre of Finland given the overall reduction in means speeds and standard deviation of speeds (Rämä, 1999). The system was considered to be most effective when the adverse weather conditions were difficult to detect by eye (Rämä, 1999). The system could be improved by improving the algorithm for determining the displayed speed limits. For this field test, the lowest displayed speed limit was $80 \mathrm{~km} / \mathrm{h}$ but sometimes the safe speed in the given weather condition is much lower than 80 $\mathrm{km} / \mathrm{hr}$. Overall, it was concluded that the system encouraged safer driver behaviors but was not economically justified on low-volume roadways (Rämä, 1999).

In determining the effectiveness of the system, before and after data couldn't be analyzed because the variable message system had been in place since the experimental road was constructed (Rämä, 1999). The control road was located $100 \mathrm{~km}$ from the experimental road which draws concern about the continuity of conditions between the two locations with respect to weather, roadway geometry, and traffic. Furthermore, that data for the analysis was matched based on road and weather conditions on the experimental road and control road. Since no before data was available, crashes were not looked at as a measure of effectiveness for this study.

\subsubsection{Sweden - E6 Motorway}

A field test was conducted to evaluate the effectiveness of weather controlled variable speed limit systems in Sweden on the E6 Motorway. Recommended speed limits on the E6 Motorway were based on roadway surface conditions (Lind, 2007). RWIS stations collected atmospheric condition information at the site and was sent to the Traffic Information Centre where operators would monitor and activate the VSL system (Jarlebring, 2009). Variable speed limit signs were installed on a $55 \mathrm{~km}$ segment of the E6 Motorway and could be manually activated and lowered from $120 \mathrm{~km} / \mathrm{h}$ to $60 \mathrm{~km} / \mathrm{h}$ in 10 or $20 \mathrm{~km} / \mathrm{h}$ increments (Lind, 2007). Precipitation and slippery surface conditions are the principal weather concerns on the roadway; therefore, temperature, moisture, wind speed, and wind direction were used to classify conditions into categories based on the expected friction coefficient of the roadway (Lind, 2007). Each condition classification was assigned a safe speed based on the expected coefficient of friction: 
$110 \mathrm{~km} / \mathrm{h}$ speed limit for moderate rain or light snowfall, $100 \mathrm{~km} / \mathrm{hr}$ for heavy rain or moderate snowfall, $80 \mathrm{~km} / \mathrm{hr}$ for very heavy rain or heavy ice formation, or $60 \mathrm{~km} / \mathrm{h}$ for cloudburst or very heavy ice formation (Lind, 2007).

Speed data was collected and used as a measure of effectiveness of the variable speed limit system. The speed limit was $110 \mathrm{~km} / \mathrm{h}$ during a 6 month baseline period prior to VSL installation. After the VSL system was installed and turned on, the static speed limit was raised to $120 \mathrm{~km} / \mathrm{h}$ (Lind, 2007). Speed data after the installation of the VSL system was grouped by the displayed variable speed limit and subsequent surface condition at the time. The baseline speeds were matched with the corresponding surface conditions and sorted into each of the speed limit/surface condition groups (Lind, 2007). Analysis of the before and after speeds indicated that the driver speeds decreased by 12 to $20 \mathrm{~km} / \mathrm{h}$ when the variable speed limit system was present during icy and very slippery roadway surface conditions (Lindkvist \& Landerfors, 2008).

The average speed comparison of the roadway before and after the installation of the variable speed limits indicates that the system did improve safety by reducing speeds and telling drivers what the safe speed on the roadway should be given the roadway surface condition (Lind, 2007). The system appeared to have a very limited effect when road conditions were good to moderately slippery (Lindkvist \& Landerfors, 2008). Motorists responded best to the recommended speeds when conditions are the most severe. A comparison of the number of persons injured and killed in crashes in the 2.5 years before and after the study suggests a $40 \%$ reduction in severe crashes (Lindkvist \& Landerfors, 2008).

Quantitative analysis of the effectiveness of the variable speed limit system was limited to a comparison of the collected vehicles speeds at one location before and after the installation of the VSL signs. Given the length and normal non-uniformity of weather conditions over a distance, speed reductions at one location may not be able to be extrapolated over $55 \mathrm{~km}$.

\subsubsection{Summary of Past VSL Deployment}

Table 1 and Table 2 summarize the description, findings, and limitations from all reviewed weather variable speed limits systems. Very little analysis has been performed on visibility controlled variable speed limit systems. Of the weather-controlled variable speed limit systems researched, five systems were designed to respond to low visibility: the A16 Motorway in the Netherlands, the I-10 Jubilee Parkway Bridge in Alabama, I-80 in northern Nevada, I-75 in southeastern Tennessee, and I-215 near Salt Lake City, Utah. The A16, I-10, and I-75 systems were all built to improve safety in response to a multivehicle crash event. For the I-10 and I-75 systems, improved safety has been observed but quantifiable success of the system has never been analyzed. Only the A16 and I-215 systems have been studied to measure their effectiveness; however, neither study looked at crashes or speed compliance, only the mean speed at a function of visibility. It was concluded from the study on the A16 system that the presence of the VSL system caused the mean speed to decrease by 8 to $10 \mathrm{~km} / \mathrm{h}$ in visibility greater than $35 \mathrm{~m}$; however, in visibility less than $35 \mathrm{~m}$, the mean speed was higher with the VSL than when the system was not present (Hogema \& van der Horst, 1994). Furthermore, the vehicle speeds decrease as visibility decreased at approximately the same rate with and without the VSL system present. A study of the I-215 VSL system concluded that mean speed along the 
corridor increased by $15 \%$ and standard deviation of speed decreased due to the VSL system (Perrin et al., 2003).

All the visibility controlled variable speed limit systems except the I-80 system in Nevada used a step-function with threshold limits based on the available visibility distance to determine the displayed speed limit. These systems were all only partially automated or not automated at all and had to be manually activated. The I- 80 system was designed to be fully automated and the displayed speed limit would be calculated as a function of visibility, $85^{\text {th }}$ percentile speed, and road surface condition; however the success of this algorithm is unknown as the system was never evaluated and complications prevented full automation. Far more studies have been conducted on variable speed limit systems that are controlled by snow, rain, and ice. 
Table 1: Summary of Visibility Controlled VSL Systems

\begin{tabular}{|c|c|c|c|}
\hline $\begin{array}{l}\text { Location of VSL } \\
\text { Implementation }\end{array}$ & Description of System & Major Findings & Limitations \\
\hline $\begin{array}{l}\text { Alabama - I-10 } \\
\text { (Goodwin, 2003a) }\end{array}$ & $\begin{array}{l}\text { - Manually activated fog system on a } 7.5 \text { mile bridge } \\
\text { - Step-function visibility thresholds for speed limits } \\
\text { - } 660-900 \mathrm{ft}-65 \mathrm{MPH} \\
\text { - } 450-660 \mathrm{ft}-55 \mathrm{MPH} \\
\text { - } 280-450 \mathrm{ft}-45 \mathrm{MPH} \\
\text { - } 175-280 \mathrm{ft}-35 \mathrm{MPH} \\
\text { - }<175 \mathrm{ft}-\text { Road Closure }\end{array}$ & $\begin{array}{l}\text { - Control operators observed decreased } \\
\text { speeds and Alabama DOT reported } \\
\text { improved safety }\end{array}$ & $\begin{array}{l}\text { - No quantitative analysis } \\
\text { available }\end{array}$ \\
\hline $\begin{array}{l}\text { Nevada - I-80 } \\
\text { (Robinson, 2002) }\end{array}$ & $\begin{array}{l}\text { - Two variable speed limit signs in each direction } \\
\text { approaching fog problem area } \\
\text { - Algorithm to determine speed using } 85^{\text {th }} \text { percentile speed, } \\
\text { visibility, and roadway surface condition } \\
\text { - Fully automated with a regulatory speed limit }\end{array}$ & $\begin{array}{l}\text { - Study could not be conducted because } \\
\text { of visibility sensors issues }\end{array}$ & $\begin{array}{l}\text { - No reported system } \\
\text { evaluation }\end{array}$ \\
\hline $\begin{array}{l}\text { Oregon - I-5 and US-97 } \\
\text { (Kimley-Horn, 2014) }\end{array}$ & $\begin{array}{l}\text { - Fog, Congestions, Surface Condition } \\
\text { - Fully automated advisory VSL signs spaced } 1.5 \text { miles } \\
\text { - Combination of visibility \& grip factor } \\
\text { - Reduced visibility is }<500 \mathrm{ft} \text {, no further visibility bins }\end{array}$ & - No report of the effects & - No report of the effects \\
\hline $\begin{array}{l}\text { Tennessee - I-75 } \\
\text { (Goodwin, 2003a; Jensen, } \\
\text { 1995) }\end{array}$ & $\begin{array}{l}\text { - } 10 \text { VSL signs, manually activated for fog } \\
\text { - Step-function visibility thresholds for speed limits } \\
\text { - } 480-1320 \mathrm{ft}-50 \mathrm{MPH} \\
\text { - } 340-480 \mathrm{ft}-35 \mathrm{MPH} \\
\text { - }<240 \mathrm{ft}-\text { Road Closure }\end{array}$ & - Reduction of fog related crashes & $\begin{array}{l}\text { - No quantitative analysis } \\
\text { - No speed data or any } \\
\text { baseline comparison }\end{array}$ \\
\hline $\begin{array}{l}\text { Utah - I-215 } \\
\text { (Perrin et al., 2003) }\end{array}$ & $\begin{array}{l}\text { - Fog system with advisory VSLs } \\
\text { - } 2 \text { mile corridor with VSL signs on each end of the corridor } \\
\text { - Step-function visibility thresholds for speed limits } \\
\text { - } 492-656 \mathrm{ft}-50 \mathrm{MPH} \\
\text { - } 328-492 \mathrm{ft}-40 \mathrm{MPH} \\
\text { - } 197-328 \mathrm{ft}-30 \mathrm{MPH} \\
\text { - }<197 \mathrm{ft}-25 \mathrm{MPH}\end{array}$ & $\begin{array}{l}\text { - Decrease in the spread of vehicle } \\
\text { speeds when VSL system is used } \\
\text { - Mean speed increased by } 15 \% \\
\text { - Cautious drivers sped up rather than } \\
\text { aggressive drivers slowing down to } \\
\text { meet recommended speed }\end{array}$ & $\begin{array}{l}\text { - No crash analysis } \\
\text { - No analysis of } \\
\text { compliance }\end{array}$ \\
\hline $\begin{array}{l}\text { Netherlands - A16 } \\
\text { (Hogema \& van der } \\
\text { Horst, 1994) }\end{array}$ & $\begin{array}{l}\text { - Fog } \\
\text { - } 12 \mathrm{~km} \text { corridor } \\
\text { - Step-function visibility thresholds for speed limits } \\
\text { - }>140 \mathrm{~m}-100 \mathrm{~km} / \mathrm{h} \\
\text { - } 70 \mathrm{~m}-140 \mathrm{~m}-80 \mathrm{~km} / \mathrm{h} \\
\text { - }<70 \mathrm{~m}-60 \mathrm{~km} / \mathrm{h}\end{array}$ & $\begin{array}{l}\text { - Mean speed } 8 \text { to } 10 \mathrm{~km} / \mathrm{h} \text { less with the } \\
\text { system than without it in visibility }>35 \\
\mathrm{~m} \\
\text { - In visibility }<35 \text {, mean speeds greater } \\
\text { with the system than without it }\end{array}$ & $\begin{array}{l}\text { - Control road used for } \\
\text { comparison } \\
\text { - No crash analysis } \\
\text { - Lowest speed limit was } \\
60 \mathrm{~km} / \mathrm{h} \\
\text { - No before and after data }\end{array}$ \\
\hline
\end{tabular}


Table 2: Summary of Snow, Rain , \& Ice Controlled VSL Systems

\begin{tabular}{|c|c|c|c|}
\hline $\begin{array}{l}\text { Location of VSL } \\
\text { Implementation }\end{array}$ & Description of System & Major Findings & Limitations \\
\hline $\begin{array}{l}\text { Maine - I-95 } \\
\text { (Belz \& Garder, 2010) }\end{array}$ & $\begin{array}{l}\text { - Snow/Rain } \\
\text { - VSL signs that can be set at any speed } \\
\text { - Only a } 45 \text { MPH speed was used during the study } \\
\text { period } \\
\text { - Manually activated, only Maine State Police has } \\
\text { the authority to turn on system }\end{array}$ & $\begin{array}{l}\text { - Variable speed limit had little no } \\
\text { effect on driver speeds }\end{array}$ & $\begin{array}{l}\text { - Only } 45 \mathrm{MPH} \text { speed limit was tested } \\
\text { - Only thirteen days used for analysis } \\
\text { - Sometimes the } 45 \mathrm{MPH} \text { speed limit } \\
\text { - was displayed during clear conditions } \\
\text { - No control scenario } \\
\text { - System not automated }\end{array}$ \\
\hline $\begin{array}{l}\text { New Jersey -Turnpike } \\
\text { (Goodwin, 2003a; } \\
\text { Robinson, 2002) }\end{array}$ & $\begin{array}{l}\text { - Snow/Rain system for } 150 \text { mi corridor } \\
\text { - Variable speed limit system in place since 1960's } \\
\text { - } 120 \text { VSL signs } \\
\text { - Regulatory speed limit } \\
\text { - Manually activated by TOC operators who decided } \\
\text { appropriate speed limit }\end{array}$ & $\begin{array}{l}\text { - New Jersey Turnpike Authority } \\
\text { feels that the system improves } \\
\text { daily operations and safety }\end{array}$ & $\begin{array}{l}\text { - No formal test of the system } \\
\text { - It would be difficult to do } \\
\text { comparison analysis with before data } \\
\text { or a control road }\end{array}$ \\
\hline $\begin{array}{l}\text { Washington - I-90 } \\
\text { (Goodwin, 2003a; } \\
\text { Ulfarsson et al., 2002) }\end{array}$ & $\begin{array}{l}\text { - Snow/Rain/Ice system for a } 40 \text { mile corridor } \\
\text { - } 13 \text { dynamic message signs with VSL's } \\
\text { - Manually activated } \\
\text { - Automated speed limit calculation by computer }\end{array}$ & $\begin{array}{l}\text { - Decrease in mean speed } \\
\text { - Increase in speed variance }\end{array}$ & $\begin{array}{l}\text { - No breakdown of weather type or } \\
\text { severity } \\
\text { - Only } 1 \text { experimental site very close } \\
\text { to the end of the corridor } \\
\text { - No speed compliance analysis }\end{array}$ \\
\hline $\begin{array}{l}\text { Wyoming - I-80 } \\
\text { (Buddemeyer et al., } \\
\text { 2011) }\end{array}$ & $\begin{array}{l}\text { - Snow/Rain/Ice } \\
\text { - } 52 \text { mile corridor } \\
\text { - Manually activated } \\
\text { - Speed limit determined by Wyoming Highway } \\
\text { Patrol }\end{array}$ & $\begin{array}{l}\text { - Driver speeds lowered } 0.47 \text { to } \\
0.75 \mathrm{mph} \text { for every } 1 \mathrm{mph} \text { of } \\
\text { speed limit reduction } \\
\text { - Significant factors on drivers } \\
\text { speed are surface condition, wind } \\
\text { speed, dew point, and visibility }\end{array}$ & $\begin{array}{l}\text { - Sensors and VSL signs spread out, } \\
\text { not representative of the entire } \\
\text { corridor } \\
\text { - No good before data of weather and } \\
\text { speed for comparison }\end{array}$ \\
\hline $\begin{array}{l}\text { Finland - E18 } \\
\text { (Rämä, 1999) }\end{array}$ & $\begin{array}{l}\text { - Snow/Rain } \\
\text { - } 14 \mathrm{~km} \text { corridor } \\
\text { - } 36 \mathrm{VSL} \text { signs } \\
\text { - Weather collection stations and speed sensors }\end{array}$ & $\begin{array}{l}\text { - Decrease in mean speed and } \\
\text { standard deviation of speed } \\
\text { - Percentage of headways less than } \\
1 \text { second decreased } \\
\text { - Most effective with undetectable } \\
\text { adverse weather }\end{array}$ & $\begin{array}{l}\text { - Control road used for comparison, } \\
100 \mathrm{~km} \text { away, no before data } \\
\text { - Low volume roadway } \\
\text { - Data was matched using weather } \\
\text { conditions } \\
\text { - No fog related weather events }\end{array}$ \\
\hline $\begin{array}{l}\text { Sweden - E6 } \\
\text { (Lind, 2007; Lindkvist \& } \\
\text { Landerfors, 2008) }\end{array}$ & $\begin{array}{l}\text { - Snow/Rain/Ice } \\
\text { - } 55 \mathrm{~km} \text { corridor } \\
\text { - Conditions classified by coefficient of friction with } \\
\text { corresponding reduced speed limit }\end{array}$ & $\begin{array}{l}\text { - } 12 \text { to } 20 \mathrm{~km} / \mathrm{h} \text { decrease in mean } \\
\text { speeds during ice/very slippery } \\
\text { road surface conditions } \\
\text { - No significant speed difference in } \\
\text { less severe weather }\end{array}$ & $\begin{array}{l}\text { - System is not automated } \\
\text { - Speed analysis at only one lactation } \\
\text { - Limited crash and compliance } \\
\text { analysis }\end{array}$ \\
\hline
\end{tabular}




\subsection{GAPS IN PAST RESEARCH}

From this literature review it is clear that there are several gaps in past research. There have been very few field evaluations of crashes and driver behavior in varying degrees of low visibility with and without the presence of variable speed limit systems. Data availability is the primary barrier due to the amount of visibility, speed, and crash data needed for this type of analysis.

While there have been a few studies that look at crashes in low visibility, relatively limited research has been performed regarding the causes and characteristics of crashes during fog. Several studies examined raw numbers of crashes by type and severity, but there is a gap in research regarding crash characteristics as a function of visibility condition. This is likely due to a lack in the availability of detailed visibility data at the crash locations.

In looking at driver behavior, a majority of the research was performed using driving simulators as opposed to collecting data in the field. Given the rarity and unpredictability of fog it's not surprising that many more driving simulator studies have been performed. The availability of visibility data required for meaningful field research is a major barrier. The I-84 study in Idaho discussed previously looked at only two days of low visibility with driver speeds.

This research aims to fill some of these gaps. Speed and visibility data were available across multiple locations on I-77 in Fancy Gap, Virginia and I-64 in Afton, Virginia during low visibility and clear conditions. This availability of data allows for more in-depth modeling than is seen in previous research and a better understanding of safety as a function of the severity of the visibility conditions. 


\section{CHAPTER 3: SITE CHARACTERISTICS}

\subsection{INTRODUCTION}

Two locations in Virginia were the focus of this research: I-77 in Fancy Gap and I-64 in Afton. Both locations have significant grades and experience dense reoccurring fog. I-77 has a history of severe crashes in fog and was identified by VDOT as a critical location with respect to safety. As a result, an Active Traffic and Safety Management System was installed to improve operations and safety in low visibility conditions. The chapter expands on the characteristics of each site and the ATSMS.

\subsection{I-77 IN FANCY GAP, VIRGINIA}

\subsubsection{Site Description}

I-77 in Fancy Gap is a four lane divided freeway with a posted speed limit of $65 \mathrm{mph}$. The section studied had a 2014 Annual Average Daily Traffic (AADT) of approximately 18,000 vehicles per day in each direction with trucks representing $27 \%$ of this traffic. The site is rural, and VDOT indicated that this site has a relatively large proportion of through drivers unfamiliar with the corridor. They noted large volumes of through traffic traveling from Ohio to North and South Carolina as being particularly prevalent. The grade is approximately $4 \%$ with the peak of the mountain near mile post 8. Figure 1: I-77 Study AreaFigure 1 shows a map of the study area on I-77.

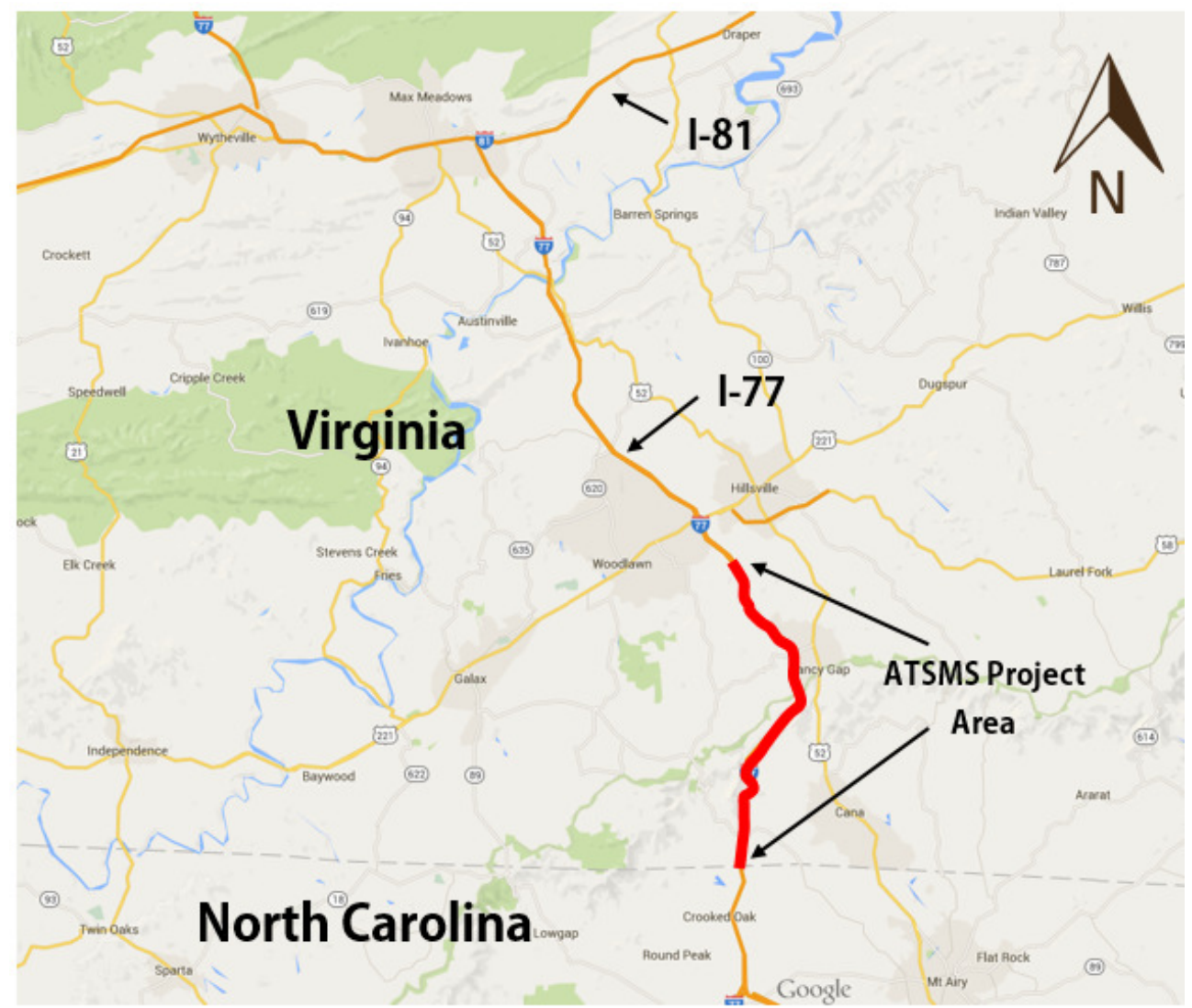


Figure 1: I-77 Study Area

\subsubsection{ATSMS Overview}

In February 2014, VDOT awarded a $\$ 7.5$ million contract to G4S Technologies to construct the I-77 ATSMS. The system was originally expected to be operational in the summer of 2015. Due to construction delays, the system has not yet become operational as of April 2016, although the infrastructure has largely been installed. As a result, no data following system activation was available for review for this thesis.

A primary component of the I-77 ATSMS is the variable speed limit system. Various sign types will be installed to alert motorist when the variable speed limit system is in use. New weather sensors were installed to supplement the existing sensors to provide denser coverage in the project area. A list of the system components is shown in Table 3 ("Active Traffic \& Safety Management System for Interstate 77 in Virginia,” 2015).

Table 3: I-77 ATSMS Components

\begin{tabular}{|l|l|c|}
\hline \multicolumn{1}{|c|}{ Component } & \multicolumn{1}{c|}{ Description } & Quantity \\
\hline Type 1 DMS & Full Size Walk-in DMS & 6 \\
\hline Type 2 DMS & Arterial DMS & 3 \\
\hline Type 3 DMS & Corridor Entry DMS & 4 \\
\hline Type 4 DMS & Full Color Matrix DMS VSL Display & 36 \\
\hline VSL Signs & Static Speed Limit Sign with VSL Cutout & 8 \\
\hline Traffic Sensors & Wavetronix & 22 \\
\hline CCTV Cameras & Pelco PTZ Dome & 25 \\
\hline RWIS & Vaisala (PWD10/12) & 14 \\
\hline Flashers & Static Signs with Flashers & 12 \\
\hline Power & Redundant Power System (AEP) & 12 miles \\
\hline Communications & Fiber Optic Network with Leased Backup & 14 miles \\
\hline UPS & 6 hour battery backup at each device & - \\
\hline
\end{tabular}

\subsubsection{Road Weather Information System Stations}

Weather information is collected throughout the corridor via fourteen Road Weather Information Systems (RWIS) stations. The RWIS stations continuously collect pavement temperature and condition, air temperature, humidity, pressure, precipitation type and intensity, wind speed and direction, and visibility. The visibility sensors are mounted twenty feet in the air and use the forward scatter measurement principle to measure the meteorological optical range ("Vaisala Visibility Sensors PWD10, PWD20 and PWD20W," 2015). Visibility is measured over a few inches and extrapolated to estimate a visibility distance in feet. Figure 2 shows the locations of the RWIS stations ("DMS Site Activation Status Diagram," 2015). In the northbound direction, RWIS stations are located at MP's 1.3, 3.1, 5.6, 6.5, 7.2, 9.0, and 9.5. In the southbound direction, RWIS stations are located at MP's 4.4, 5.4, and 11.4. RWIS stations 
are located in the median at MP 1.9, 2.7, 3.5, and 8.1 to collect weather information for both directions of traffic.

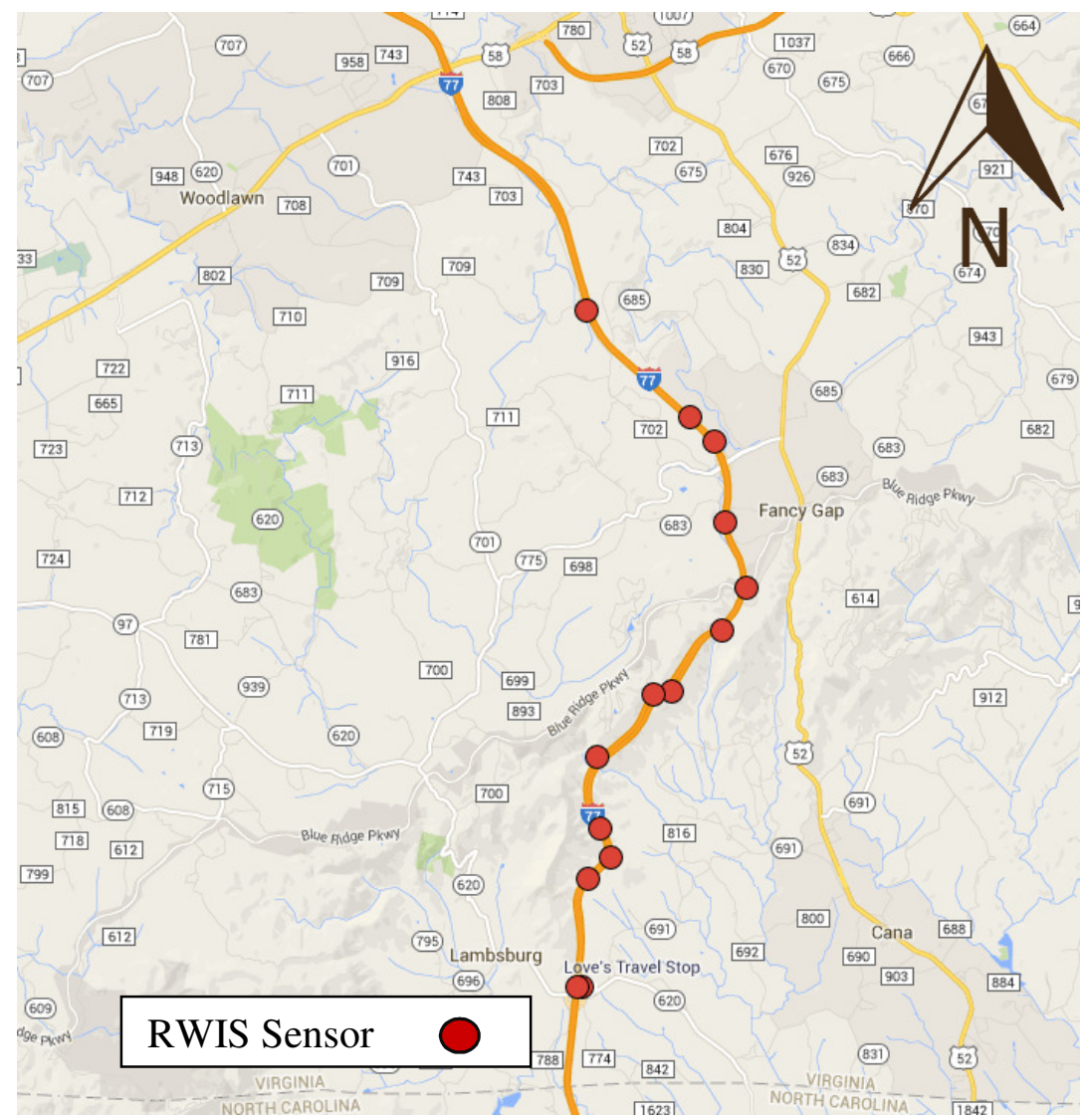

Figure 2: Map of RWIS Visibility Stations

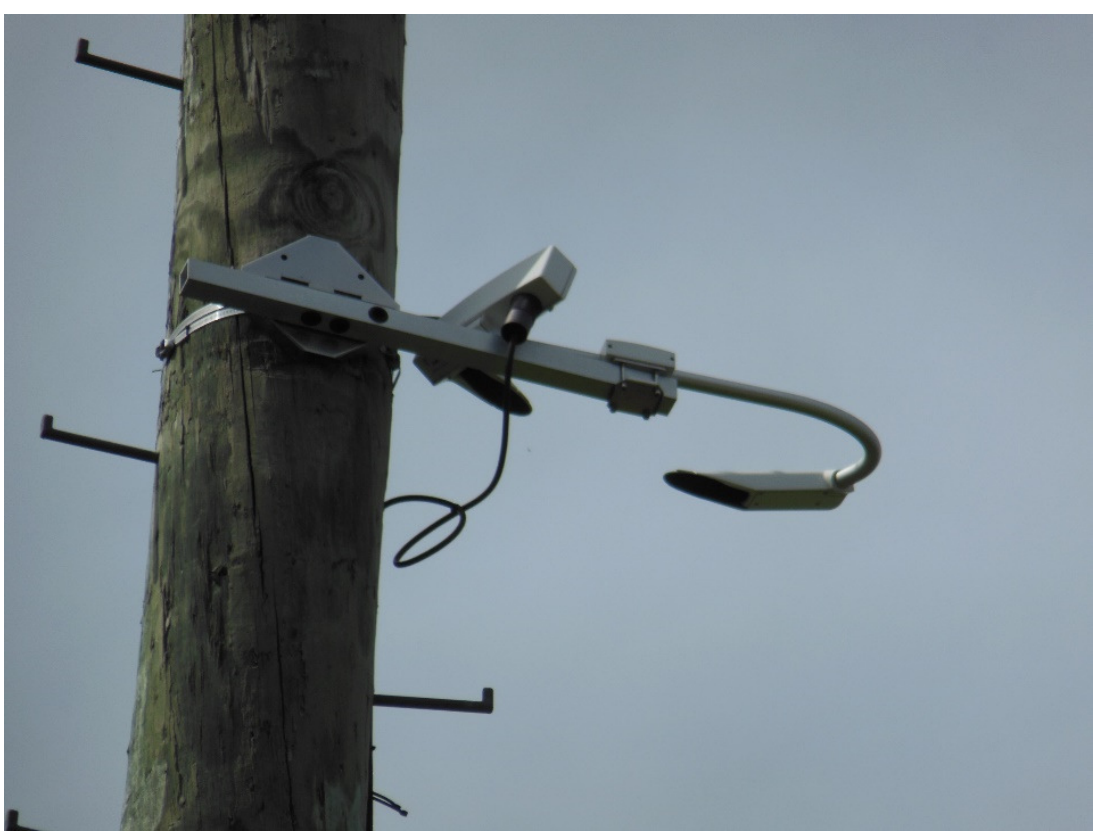

Figure 3: Vaisala Forward Scatter Visibility Sensor 


\subsubsection{Variable Speed Limit Signs}

Safe speeds are displayed on full color dynamic message signs (DMS) and variable speed limit cutout signs along the corridor. All speed limit signs are dual mounted in each direction. There are eight variable speed limit cutout signs dual mounted at MP 1.3 and MP 11.6 northbound and MP 10.2 and MP 1.8 southbound. A map of the planned VSL signs is shown in Figure 4 ("DMS Site Activation Status Diagram," 2015). In the northbound direction full color DMS are dual mounted at MP's 1.3, 2.4, 3.5, 4.6, 5.6, 6.5, 7.6, 8.1, 9.2, and 10.2 and in the southbound direction full color DMS are dual mounted at MP's 3.4, 4.5, 5.6, 6.5, 7.2, 8.1, 9.5, and 11.6. Figure 5 shows examples of what the VSL cutout sign and the full matrix sign will look like.

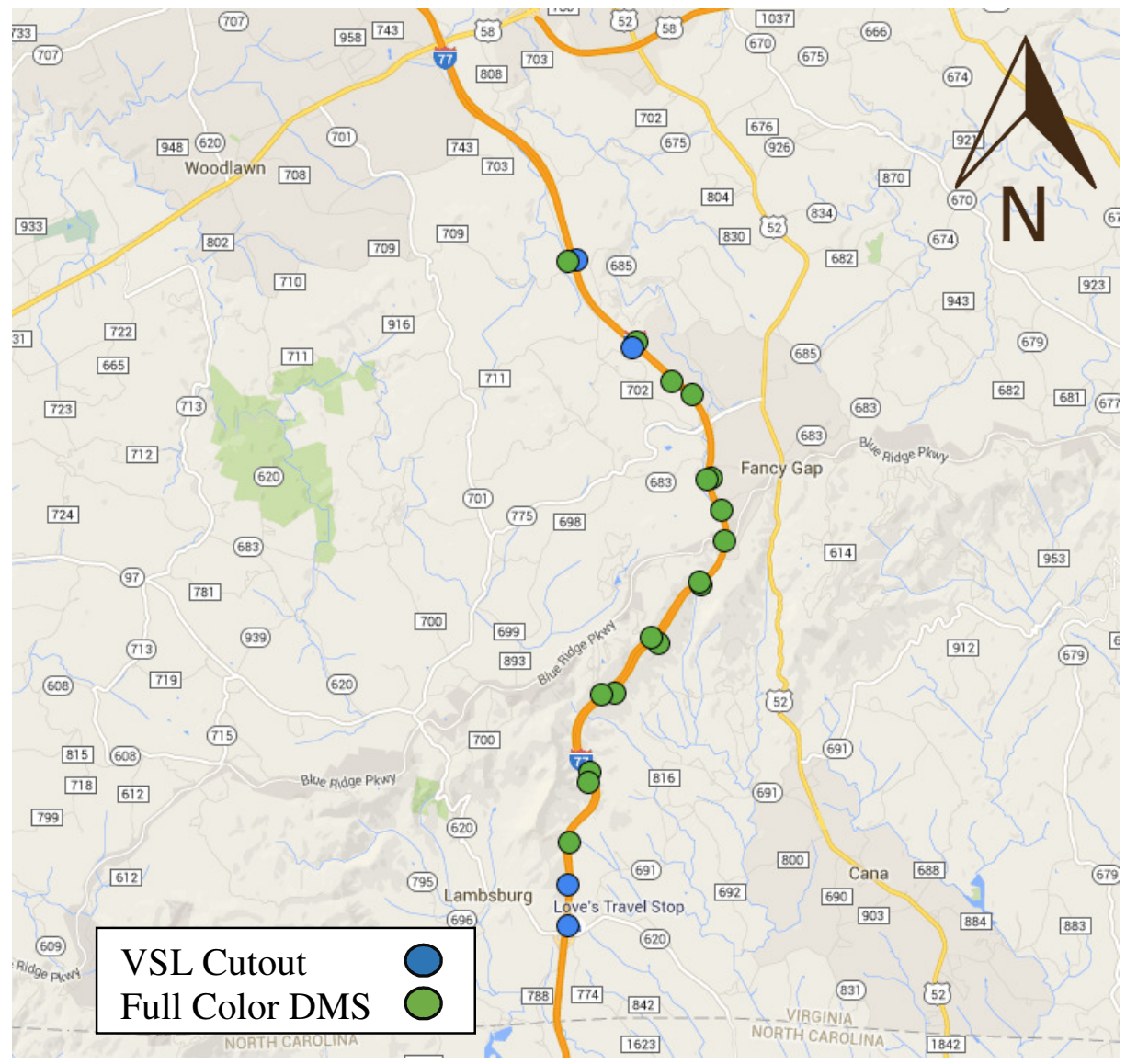

Figure 4: Planned VSL Sign Locations 


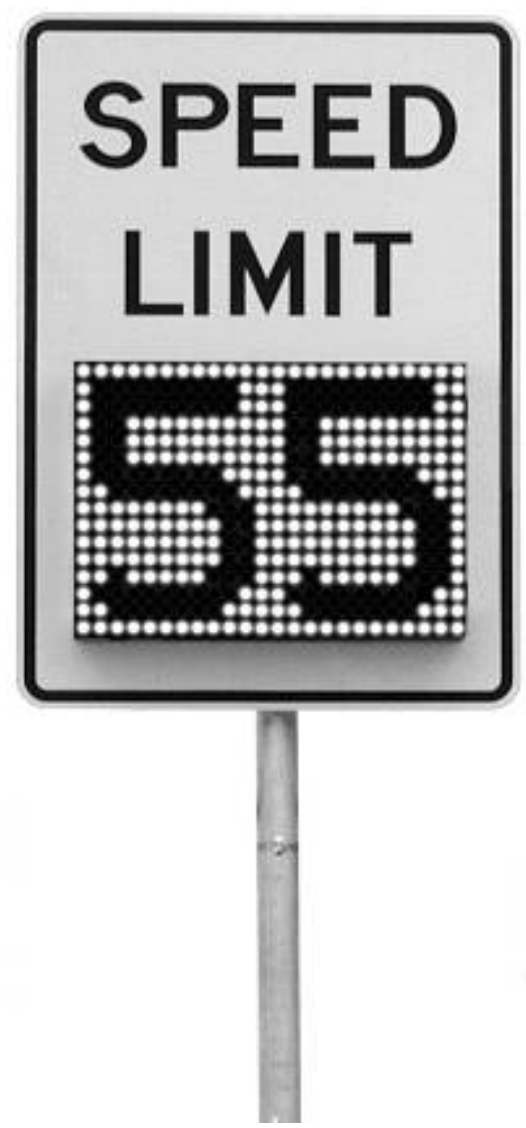

(a)

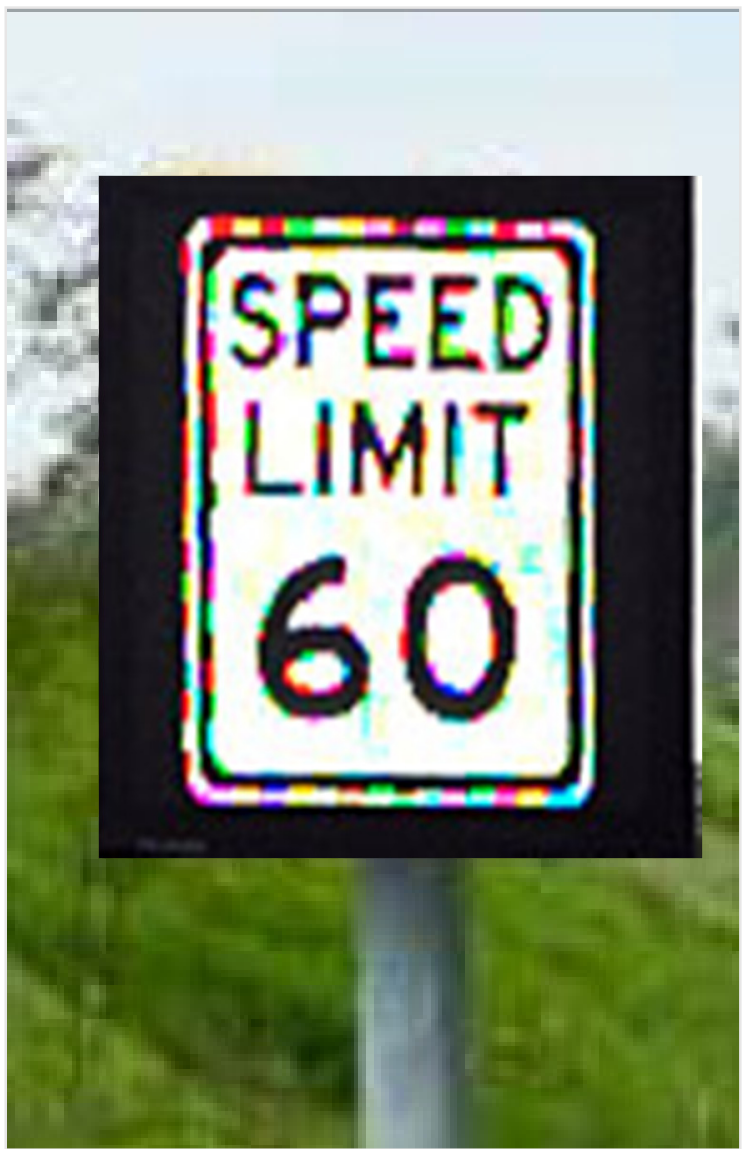

(b)

Figure 5: (a) Variable Speed Limit Cutout Sign, (b) Full Color Dynamic Message Sign

\subsubsection{Algorithm Development}

While the contractor G4S was responsible for installing the physical infrastructure of the ATSMS, the algorithm to control the VSL was undefined. VDOT formed a technical advisory committee composed of Southwest Region Operations, Traffic Engineering Division, Operations Division, Kimley-Horn and Associates, and the Virginia Transportation Research Council to develop a control algorithm. The final algorithm used to develop speed limits in low visibility conditions was developed as part of a collaborative effort by a technical committee. The initial VSL algorithm that has been developed relied heavily on results from this research and is discussed in Chapter 5.

\subsection{I-64 IN AFTON, VIRGINIA}

\subsubsection{Site Description}

I-64 in Afton, VA is a four lane divided freeway with a posted speed limit of $65 \mathrm{mph}$. The 2014 AADT was approximately 17,000 vehicles per day in each direction with trucks representing $9 \%$ of this traffic. In contrast to I-77, the Afton site is located at the top of a mountain pass, with the peak occurring around MP 100. Two data collection sites were present 
in each direction of travel, and these sites were located near the midpoint of most fog events. The grade in the eastbound direction approaching the peak is approximately $+2.9 \%$ and the grade in the westbound direction approaching the peak is approximately $+4.2 \%$. This site has a high volume of regular commuter traffic according to VDOT. Figure 6 shows the study area on I-64.

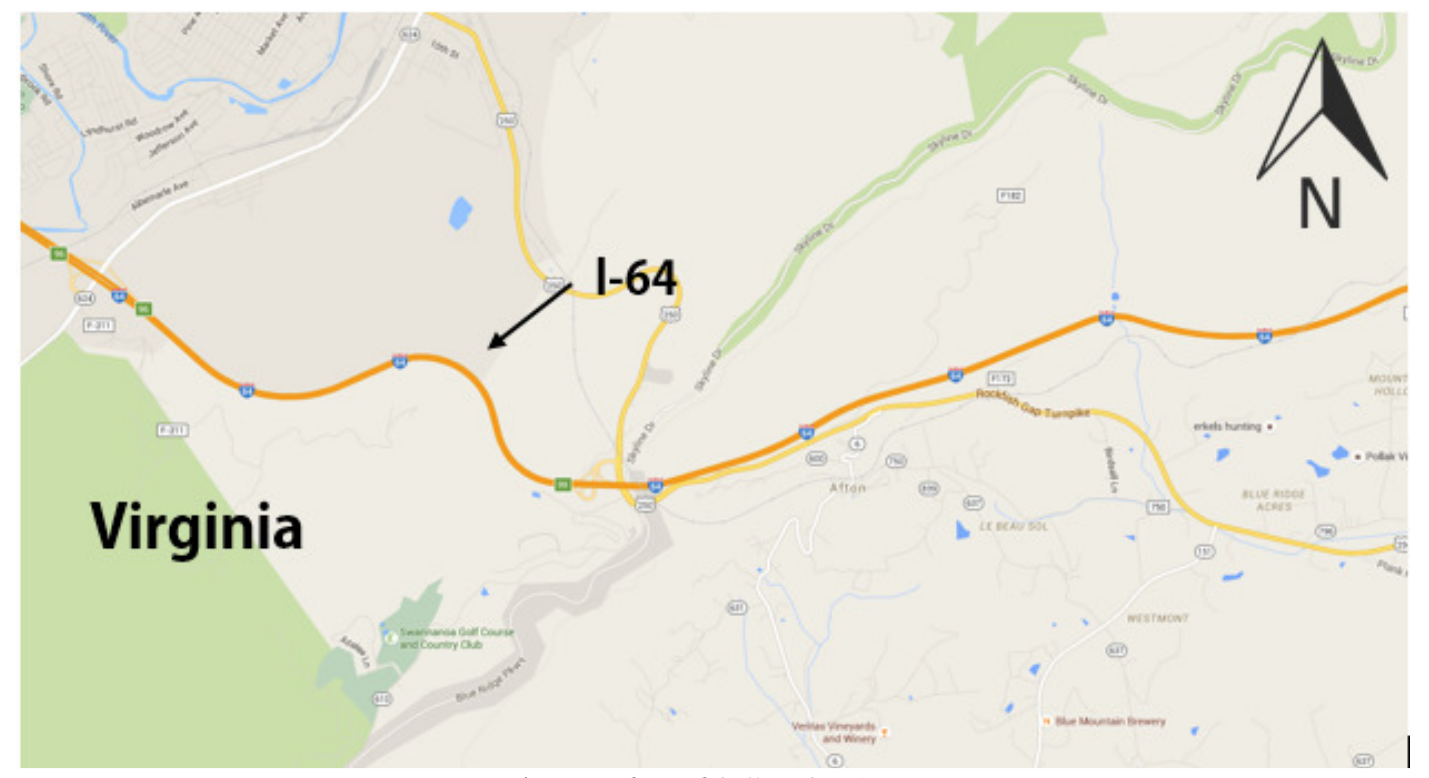

Figure 6: I-64 Study Area

A unique feature of the I-64 site is that in-pavement amber warning lights have been installed along the left and right edge lines of the roadway between mile posts 98 and 104 . Figure 7 shows an example of the lights. These warning lights are activated by the traffic operations center when the visibility drops below 1400 feet and are intended to improve delineation during fog.

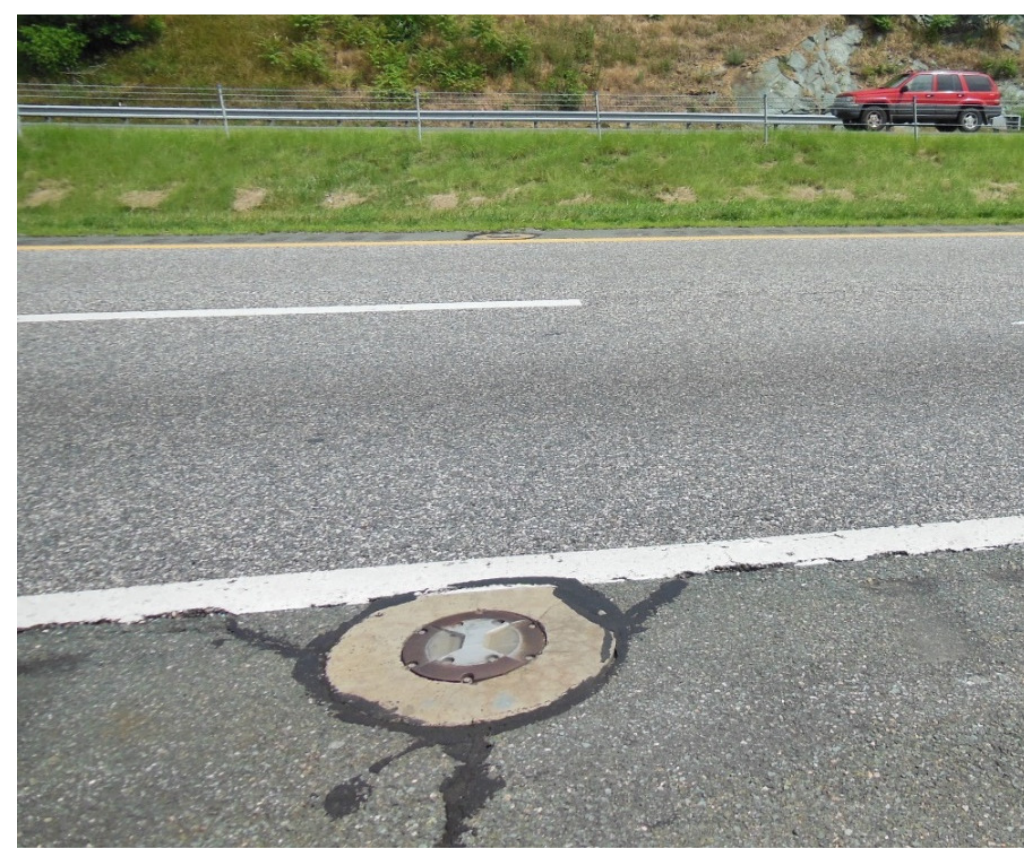

Figure 7: Fog Lights on Afton Mountain 
G4S Technologies was also awarded a $\$ 4.8$ million contract to install additional infrastructure on Afton Mountain, with a current estimated completion date of Spring 2016. In contrast to I-77, the Afton contract is focused on upgrading current infrastructure by installation addition dynamic message signs, weather sensors, and closed circuit television cameras. The communication backbone is also being upgraded to fiber optics. While no VSL signs are part of this contract, the intent was to install the infrastructure required to support a future VSL system, should the I-77 VSL system prove successful. 


\section{CHAPTER 4: METHODOLOGY}

\subsection{DATA COLLECTION AND PROCESSING}

Traffic and weather data were collected on the ATSMS Corridor on I-77 in Fancy Gap, Virginia and on I-64 in Afton, Virginia (Figure 8). This section describes the data that was available, as well as the methods used to clean and process the data prior to analysis.

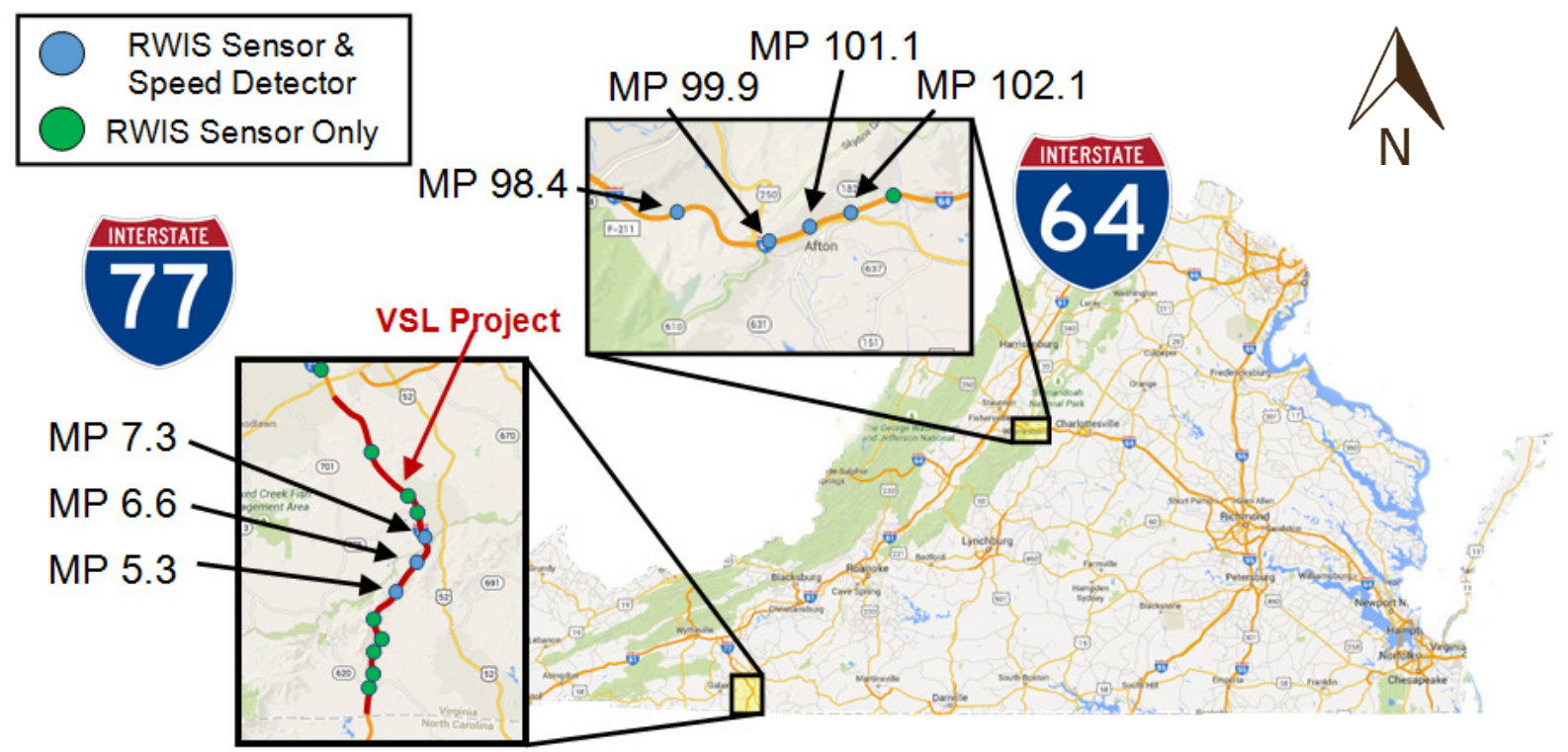

Figure 8: Map with Data Collection Locations

\subsubsection{Visibility Data}

\subsubsection{I-77 in Fancy Gap, Virginia}

The site has road weather information system (RWIS) stations at twelve locations over approximately 16 miles, which provided a dense network of visibility readings along the corridor. Vaisala RWIS weather stations with visibility sensors were located at mile points (MP) $1.2,1.8,2.7,3.0,4.4,5.3,6.6,7.3,9.0,9.6,11.3$, and 16.9. The visibility sensors used the forward scatter measurement principle to measure the meteorological optical range ("Vaisala Visibility Sensors PWD10, PWD20 and PWD20W,” 2015). Visibility measurements were provided in units of feet, and information on precipitation type and road surface condition was also collected. Visibility data were collected every ten minutes, and sensors were located 20 feet above the surface of the road. The data from these sensors was archived by Vaisala on an external website which could be queried by the researchers (Figure 9). 


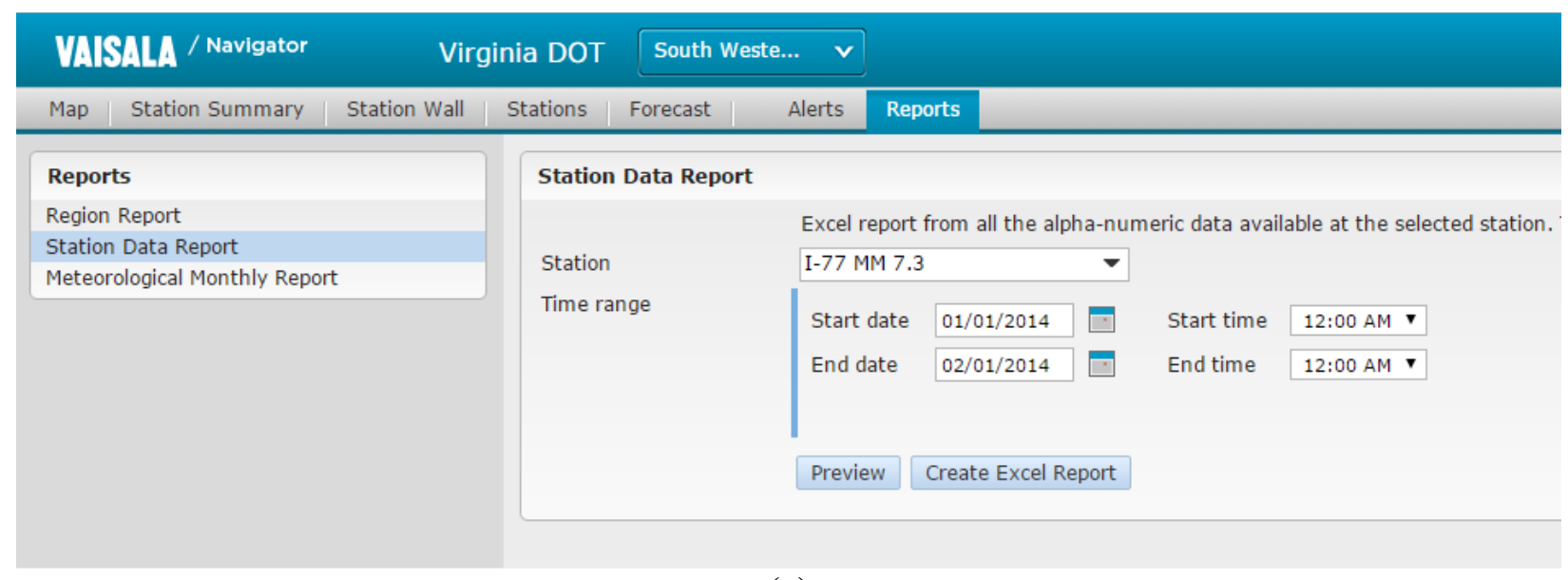

(a)

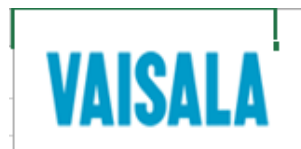

Observations for I-77 MM 7.3

01.01.2014 12:00 AM $\rightarrow$ 02.01.2014 12:00 AM

\begin{tabular}{|c|c|c|c|c|c|c|c|c|}
\hline Timestamp & $\begin{array}{l}\left.\text { Air T ( }{ }^{\circ} \mathrm{F}\right) \\
\text { Atmospheric } \\
\text { site }\end{array}$ & \begin{tabular}{|l} 
Dew $\left({ }^{\circ} \mathrm{F}\right)$ \\
Atmospheric \\
site
\end{tabular} & \begin{tabular}{|l} 
Relative \\
Humidity (\%) \\
Atmospheric \\
site \\
\end{tabular} & \begin{tabular}{|l} 
Precip St \\
Atmospheric \\
site
\end{tabular} & \begin{tabular}{|l} 
Rain Intensity \\
(in/h) \\
Atmospheric \\
site
\end{tabular} & $\begin{array}{l}\text { Wind Sp (mph) } \\
\text { Atmospheric } \\
\text { site }\end{array}$ & $\begin{array}{l}\text { Wind Dir } \\
\text { Atmospheric } \\
\text { site }\end{array}$ & $\begin{array}{l}\text { Vis (ft) } \\
\text { Atmospheric } \\
\text { site }\end{array}$ \\
\hline 01.01.2014 12:00 AM & 30 & 20.8 & 68 & none & 0 & & $\mathrm{~N}$ & 6562 \\
\hline $01.01 .201412: 10 \mathrm{AM}$ & 29.1 & 21.9 & 74 & none & 0 & 0 & $\mathrm{~N}$ & 6562 \\
\hline $01.01 .201412: 20 \mathrm{AM}$ & 29.3 & 21 & 71 & none & 0 & 0 & $\mathrm{~N}$ & 6562 \\
\hline $01.01 .201412: 30 \mathrm{AM}$ & 28.9 & 21.9 & 75 & none & 0 & 0 & NNE & 6562 \\
\hline $01.01 .201412: 40 \mathrm{AM}$ & 28.9 & 21.2 & 73 & none & 0 & 0 & $\mathrm{~N}$ & 6562 \\
\hline $01.01 .201412: 50 \mathrm{AM}$ & 28.4 & 21.9 & 76 & none & 0 & 0 & $N$ & 6562 \\
\hline 01.01.2014 01:00 AM & 28 & 22.3 & 79 & none & 0 & 0 & $\mathrm{~N}$ & 6562 \\
\hline 01.01.2014 01:10 AM & 27.7 & 22.3 & 80 & none & 0 & & $\mathrm{~N}$ & 6562 \\
\hline
\end{tabular}

(b)

Figure 9: (a) Viasala Navigator Interface and (b) Sample Data Exported to Excel

\subsubsection{I-64 in Afton, Virginia}

On I-64, Vaisala RWIS stations were also present, but they were configured slightly differently than at I-77. Visibility data were collected from the fog light visibility sensors every minute at MP's 98.4, 101.1, 102.1, and 103.1 and every five minutes at MP 99.9. The sensors located on I-64 are the same as the sensors used on I-77. The data was stored locally at the Staunton Traffic Operations Center, and only a limited data archive was available for analysis in this research. Visibility data were collected continuously from July 1, 2014 to December 31, 2014 with approximately 420 hours of low visibility data collected during this period. To be consistent with the analysis on I-77, only the visibility data collected every fifth minute was saved and matched with the five minutes speed data.

\subsubsection{Crash Data}

All police crash reports were compiled from VDOT's Roadway Network System (RNS) using the date ranges for when visibility data was available from the RWIS sensors. The 
weather conditions field on the police report was used to identify crashes that occurred in fog and verified using the visibility data from RWIS sensors. The crash data were used to examine whether the frequency, rate, or characteristics of crashes along the corridor varied by visibility condition. For I-77 crashes were collected from January 1, 2010 to December 31, 2015 between mile posts 0 and 15. For I-64 crashes were collected from July 1, 2014 to December 31, 2014 between mile posts 97 and 103 .

\subsubsection{Speed and Volume Data}

\subsubsection{I-77 in Fancy Gap, Virginia}

Speed data were collected by temporary Wavetronix side-fire radar installations at MP 5.3, MP 6.6, and MP 7.3 adjacent to the RWIS stations. At each location, traffic data were recorded in five minute bins for vehicles traveling in the southbound lanes of I-77. The data collected by the detectors included volume by vehicle class, mean speed, and $85^{\text {th }}$ percentile speed. Speed and weather data were matched by timestamps. Because the weather data were reported every ten minutes and speed data were reported every five minutes, visibility was linearly interpolated between ten minutes readings to get estimated visibility data in five minutes intervals. The Wavetronix readers were initially installed in September 2014. When low visibility periods were observed from the RWIS stations, corresponding speed data was collected from the speed stations. Speed and visibility data were available for ten low visibility events between September 2014 and March 2015, representing approximately 180 hours of data. Speeds were also collected for two 3 day periods in November and December 2014 to represent behavior in clear conditions.

\subsubsection{I-64 in Afton, Virginia}

Speed data were collected in 1-minute bins using permanent Wavetronix devices mounted on the same poles as the visibility sensors at MP's 98.4, 99.9, 101.1, and 102.1. Volume weighted speeds were calculated for 5 minute periods and matched with the visibility data by timestamp. The MP 101.1 eastbound, MP 102.1 eastbound, and the MP 98.4 westbound sites are on a downhill grade and the MP 102.1 westbound, MP 101.1 westbound, MP 99.9 eastbound, and MP 98.4 eastbound sites are on an uphill grade. The MP 99.9 westbound site is located on a downhill grade just downstream of the peak of Afton Mountain, so vehicles have not begun to pick up downhill momentum with respect to mean speed. Speed data was collected continuously for six months from July 1, 2014 to December 31, 2014. The maximum recorded visibility value was 2000 feet, which was dictated by the sensor hardware. For the analysis, speed recorded during visibility periods recorded as 2000 feet represents behavior in clear conditions. Speed recorded during visibility periods between 645 feet and 2000 feet were not used in the analysis so clear condition data is not influenced by periods of medium visibility surrounding low visibility events. 


\subsubsection{Categorization of Data by Stopping Sight Distance Safe Speed}

A safe speed based on stopping sight distance was determined for different visibility categories. This allows actual operating speeds to be contrasted to a theoretical safe speed for various densities of fog. For this analysis, any visibility measurement below 645 feet was considered "low visibility". This threshold corresponds with a safe speed of $65 \mathrm{mph}$ calculated from safe SSD, assuming a flat grade and a 2.5 second perception-reaction time. I-77 and I-64 have a $65 \mathrm{mph}$ posted speed limit, so there should theoretically be no need to reduce speed when visibilities exceed 645 feet. A flat grade was assumed in this analysis so that visibility categories would remain constant for uphill and downhill sections, although obviously downhill sections would require longer stopping sight distances in reality. A safe speed was determined using the stopping sight distance equation shown below, substituting visibility measurements for SSD and solving for $\mathrm{V}$.

$$
S S D=1.47 \times V \times 2.5+\frac{1.075 \times V^{2}}{11.2 f t / s^{2}}
$$

Where:

SSD = Stopping sight distance (feet)

$\mathrm{V}=$ Speed $(\mathrm{mph})$

Observation of the speed data suggests driver speeds do not vary with visibility above this 645 feet threshold. The visibility was further divided into bins according to the safe SSD speed, as shown in Table 4. These bins were used to analyze driver behavior by severity of low visibility. It is worth noting that the I-64 fog lights were activated for visibilities below 1400 feet, which would correspond with a safe speed of over $100 \mathrm{mph}$.

Table 4: Safe Speeds by Visibility Bin

\begin{tabular}{|l|l|l|}
\hline \multicolumn{1}{|c|}{ Bin Range } & \multicolumn{2}{c|}{ Safe Speed } \\
\hline$>645$ feet & $65 \mathrm{mph}$ & Clear Conditions \\
\hline $495-645$ feet & $55 \mathrm{mph}$ & \\
\hline $360-495$ feet & $45 \mathrm{mph}$ & \multirow{2}{*}{ Low Visibility } \\
\hline $250-360$ feet & $35 \mathrm{mph}$ & \\
\hline $155-250$ feet & $25 \mathrm{mph}$ & \\
\hline$<155$ feet & $<25 \mathrm{mph}$ & \\
\hline
\end{tabular}

\subsection{DATA ANALYSIS}

\subsubsection{Visibility Profiles}

To represent the visibility conditions on the corridor spatially, visibility data was compiled from the RWIS stations in order to determine the frequency and magnitude of fog events. For I-77, yearly visibility was averaged for the years 2010 to 2015 . For I-64 visibility was compiled from July 1, 2014 to December 31.2014. Visibility was assigned into the safe stopping sight distance analysis bins based on available visibility, and for I-77 the average hours of low visibility each year was calculated for each RWIS station. Hours of low visibility were summed for I-64 for the six month period. 


\subsubsection{Crash Analysis}

\subsubsection{Crash Frequency and Characteristics}

Crashes were matched with visibility data so that crash characteristics in varying degrees of low visibility could be compared to crashes in clear conditions. Crash severity, collision type, and number of vehicles involved in the crash were all tabulated for easy comparison of the proportions of crashes by visibility bin. This was done to examine how density of fog impacted crash occurrence and type, which had not been previously examined. Full analysis was performed for 5 years of crashes on I-77. Due to the limited availability of visibility data on I64 , crash analysis is discussed qualitatively for a six month period when visibility data is available. Crashes where police indicated fog was present was examined for the full 5 year period on I-64, but there was no visibility data archived that could be used to validate the officer assessment.

\subsubsection{Crash Rate Analysis}

Crash rates on the corridor were calculated for I-77 using visibility and crash data from five years prior to the activation of the ATSMS (2010 to 2015). Since real-time volume data were not available throughout the corridor, hourly volume profiles were determined using available short-term counts which were assumed to represent the temporal distribution of travel on I-77 for all days. The yearly AADT was multiplied by this hourly distribution to get an estimated hourly AADT for a given day in each analysis year. Visibility data was used to calculate the hourly breakdown of visibility in each of the visibility bins. The vehicles miles traveled (VMT) was then calculated by multiplying hourly AADT by the hours of visibility throughout the year recorded in that bin in that hour of the day. Finally, each of the 24 hourly VMTs were summed to get the VMT for each of the analysis years. The crashes were each assigned a visibility and placed in the appropriate bin. Since this site is in a rural area and does not experience significant variability in traffic, this approach is expected to provide a reasonable estimate of VMT, but it does not account for changes in travel that may be occurring due to poor weather conditions. Because only six months of visibility data was available for I-64, crash rates were not calculated for that study area.

\subsubsection{Driver Speed Choice Behavior}

\subsubsection{Speed Analysis}

Crashes are an obvious indicator of safety, but because they are random events it may be difficult to get a large enough sample to draw meaningful conclusions, particularly when the analysis is focused on fog events. Alternatively, mean speed and standard deviation of speed can be used as a surrogate indicator to evaluate safety. Mean speed was calculated for each visibility bin at all collection sites. Hypothesis testing was done to determine whether there was a statistically significant difference between mean speed in each low visibility bin and the mean speed during clear conditions. The null hypothesis, $\mathrm{H}_{0}$, was that the mean speed in each low visibility bin is equal to the mean speed in clear conditions. An alpha value of 0.05 correlates to 
a $\mathrm{Z}_{\text {critical }}$ value of 1.96. The $\mathrm{Z}_{\text {test }}$ statistic was then calculated and compared to the $\mathrm{Z}_{\text {critical }}$. The same hypothesis test was applied to the right and left lane speed differentials. Further hypothesis testing using an F-test was performed to the speed variance in each low visibility bin to the speed variance in clear conditions. The null hypothesis, $\mathrm{H}_{0}$, was that the speed variance in each low visibility bin was equal to the speed variance in clear conditions. An alpha value of 0.05 was used to determine the $\mathrm{F}_{\text {critical }}$ value.

At MP 6.6 on I-77, and MP's 89.4 and 102.1 on I-64, vehicles speeds were collected in 5 mph bins. For data from these sensors, standard deviation of speed, coefficient of variation, and pace speed was calculated for each visibility bin. For each five minute observation, the number of vehicles exceeding the safe speed based on stopping sight distance was used to measure compliance with safe speed by visibility condition. The pace speed and the percentage of vehicles traveling in the pace were also examined to assess the amount of consistency in travel speeds. Finally, mean speed by lane for each visibility bin was calculated to look at trends in driver behavior that may be masked by the combined lanes means. At other data collection sites, only aggregate mean and standard deviation values were available, and no information on the distribution of speeds was collected. As a result, these analyses could not be performed at other locations.

\subsubsection{Modeling of Mean Speed as a Function of Visibility}

The data was analyzed to determine if a relationship between observed mean speed and visibility could be established. The mean speed per 5-minutes was identified as the dependent variable for the data analysis. Independent variables considered included visibility (in feet), total vehicular volume per 5 minutes, truck volume per 5 minutes, day or night, and site location. Site location and day/night were modeled using binary indicator variables. Transformations of these variables were also investigated. Precipitation rate, precipitation type, temperature, and interaction combinations of these variables were also considered as independent variables, however, none proved to be statistically significant predictors of speed.

Step-wise linear regression was performed using these independent variables. Step-wise regression is an iterative process that adds and removes independent variables one at a time into the model. Independent variables are removed from the model if they have a significance value greater than 0.05 . For each site the adjusted $\mathrm{R}^{2}$ model fit values, the average absolute error and bias, and visual inspection of the model fit and the residuals were used to evaluate individual models. Different candidate models were created by summarizing the data based on direction of travel, individual sensor site, and whether the site was traveling uphill or downhill. Ultimately, while some individual models performed better than others, the models combining all data for each site provided the best representation of the datasets.

The I-64 dataset was further analyzed with a generalized linear model. This allowed for hypothesis testing to easily compare the effects of visibility and site on mean speed. This analysis was performed on the I-64 dataset only due to the apparent insensitivity of speed to visibility and high variation in the I-64 linear regression model. 


\section{CHAPTER 5: RESULTS}

\subsection{INTRODUCTION}

This chapter discusses the results of the analysis. Crash and speed analysis and speedvisibility modeling is discussed first for I-77, followed by I-64. The driver behavior in low visibility at the two sites is compared and possible explanations for differences is discussed. Finally, applications of the speed-visibility modeling to the I-77 VSL algorithm is reviewed.

\subsection{I-77 IN FANCY GAP, VIRGINIA}

\subsubsection{Visibility Profiles}

Figure 10 shows the visibility profile for the I-77 study section using all data from 2010 to 2015. The purple line shows the percentage of time that the RWIS sensor was reporting reduced visibility, once invalid readings were removed from the analysis. Figure 10 shows that the distribution of fog varied spatially along the corridor. The worst visibility occurs between mile post 4.4 and 7.3, with MP 6.6 observing reduced visibility for more than 5\% of the year on average. The proportion of very severe fog events was also highest at MP 6.6. At MP 6.6, visibility was less than 360 feet during $60 \%$ of fog events. This percentage goes to $50 \%$ at MP 5.3 and $47 \%$ at MP 4.4 and 3.0. Thus, even within this relatively short corridor, the characteristics of fog varied substantially. This may indicate that treating fog as a homogeneous condition may not be appropriate.

Every station experienced problems with missing data. The RWIS station at MP 3.0 was offline for all of 2013 and the RWIS station at MP 2.7 did not collect any visibility data in 2015. Averaging the amount of missing data each year revealed that several sites experienced more problems than others. The RWIS station at MP 4.4 had the most missing data with an average of 23\% missing per year. The stations at MP's 1.8, 6.6, 9.0, 9.6, and 11.3 performed the best with less than $10 \%$ missing data a year on average.

There was some variability in the amount of fog from year to year, but the spatial distribution of fog was relatively consistent over the 5-year study period. Examination of the low visibility at each site from year to year reveals that MP 6.6 experiences the most low visibility conditions every year. The missing data time is removed and the low visibility time calculated as a percentage of the collected visibility data. This shows some variation in the low visibility year to year. Low visibility at MP 6.6 ranges from $4.01 \%$ in 2010 to $7.13 \%$ in 2013 . This variability is typical of the other sites as well. Across all sites, 2010 had a combined 920 hours of low visibility while 2013 had 2,355 hours of low visibility. The other sites experienced 1646, 1614, 1180, and 998 hours of low visibility in 2011, 2012, 2014, and 2015 respectively. The relationships between the amounts of low visibility recorded at each site is consistent year to year so variability between years is likely a function of a given year being foggier or less foggy than another. 


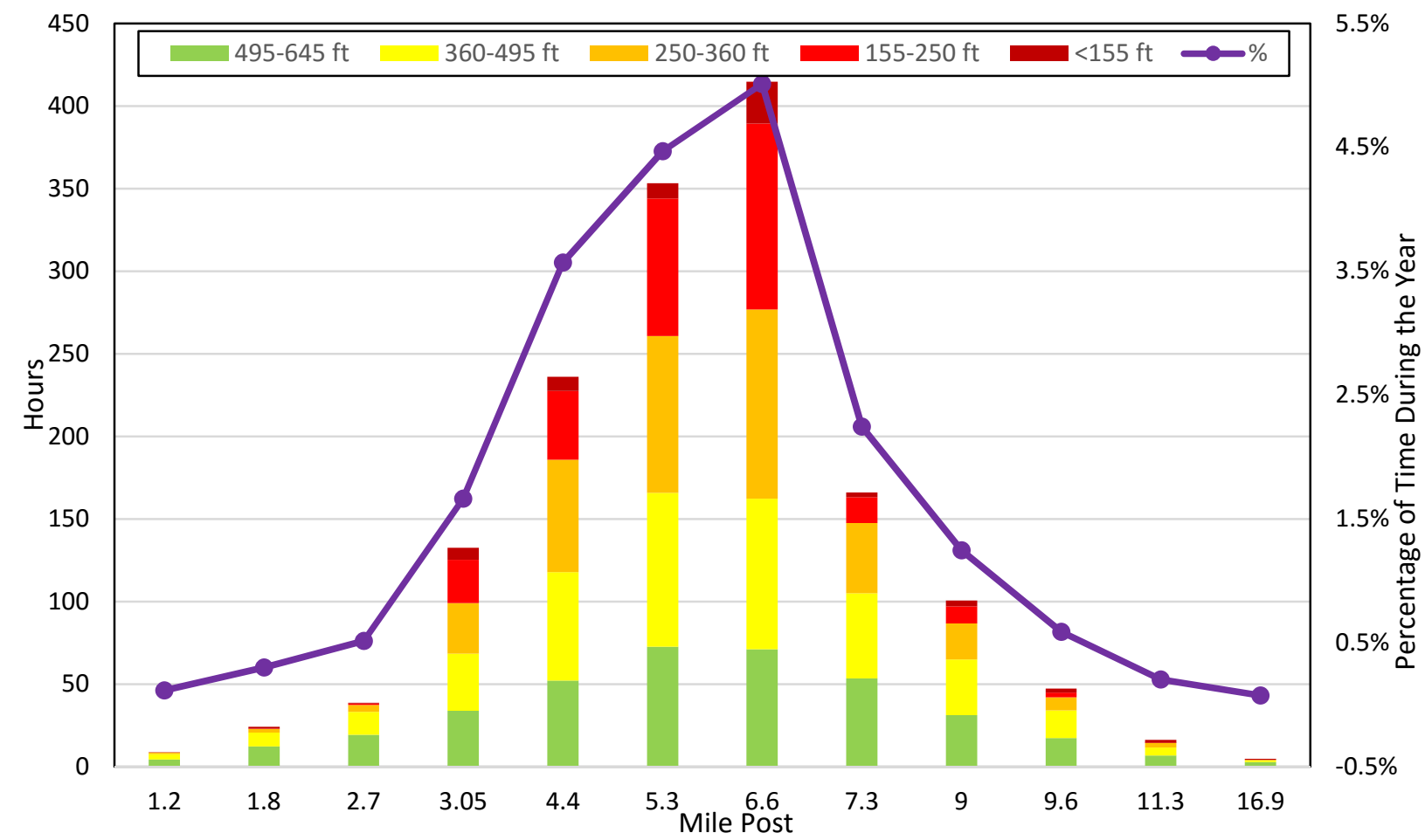

Figure 10: I-77 Average Annual Visibility Profile

\subsubsection{Crash Analysis}

\subsubsection{Crash Frequency and Characteristics}

To represent the crash distribution before the installation of the ATSMS, police crash reports were used to analyze crashes from 2010 to 2014 on I-77 between MP 0 and mile point 15. The five year crash history revealed 524 total crashes with 77 "fog" crashes coded on the police crash report. Each crash was assigned a visibility reading by matching data from the RWIS stations using the timestamp and mile point listed on the crash report. Linear interpolation between stations and 10 minute readings was used to estimate the visibility associated with each crash.

After performing the matching, 58 crashes could be associated with visibility measurements less than 645 feet, representing $11 \%$ of the total crashes during this time period. This indicates that crash likelihood is higher than would be expected based purely on the amount of time when fog was present in the corridor, as shown in Figure 10. It also means that 19 of the 77 crashes where police recorded fog on the crash report actually occurred during periods when there was no visibility reduction that should have significantly adversely impacted safety. This indicates an inconsistent definition and interpretation of fog by reporting officers versus what is observed at RWIS stations.

The 58 crashes occurred on only 10 different days all between September and May. Of these crashes, 49 occurred in the southbound direction and 9 occurred northbound. Rear end collisions were the most common crash type, consisting of 37 crashes (63.8\%). There were five 
fatal crashes and 23 injury crashes. Ten crashes occurred in visibility between 495 and 645 feet, five crash each in the 360-495 feet and 250-360 feet bins, and 1 crash in visibility less than 155 feet. The remaining 37 crashes all occurred in visibility between 155 and 250 feet. The high proportion of crashes in the 155-250 feet bin can be explained by looking at the crash dates: 26 crashes occurred on March 23, 2013 and 5 crashes occurred on September 21, 2013 accounting for 31 of the 37 crashes in this visibility bin. A review of the low visibility crashes found that 42 of the 58 crash descriptions used the phrase slow" or stopped traffic ahead. Several of these descriptions mentioned traffic stopped for an accident ahead. Thus, it appears that many of these crashes were secondary collisions created by reduced visibility coupled with traffic that was unexpectedly stopped due to prior crashes.

Table 5 shows the breakdown by crash severity on I-77 for crashes during clear conditions and fog. The table shows that fatal and injury crashes make up a greater proportion of crashes during fog versus clear conditions, which is supported on a larger scale in the AAA Foundation report (Hamilton et al., 2014). During reduced visibility, fatal and injury crashes are almost twice as common as they are during clear conditions (48\% vs. 25\%). The proportion of injury and fatal crashes shows no clear trend across the visibility categories, so there is no indication of increasing likelihood of fatal or injury crashes as fog gets more severe. No statistical testing of proportions was done given the small sample size. 
Table 5: Crash Severity by Visibility Bin, 2010-2014

\begin{tabular}{|c|c|c|c|c|c|c|c|c|c|}
\hline \multirow{2}{*}{$\begin{array}{l}\text { Visibility Bin } \\
>645 \mathrm{ft}, 65 \mathrm{mph}\end{array}$} & \multicolumn{2}{|c|}{ Fatal } & \multicolumn{2}{|c|}{ Injury } & \multicolumn{2}{|c|}{ Fatal + Injury } & \multicolumn{2}{|c|}{$\begin{array}{l}\text { Property Damage } \\
\text { Only }\end{array}$} & \multirow{2}{*}{$\frac{\text { Total }}{462}$} \\
\hline & 9 & $2 \%$ & 105 & $23 \%$ & 114 & $25 \%$ & 348 & $75 \%$ & \\
\hline All Low Visibility & 5 & $9 \%$ & 23 & $40 \%$ & 28 & $48 \%$ & 30 & $52 \%$ & 58 \\
\hline $495-645 \mathrm{ft}, 55 \mathrm{mph}$ & 2 & $20 \%$ & 4 & $40 \%$ & 6 & $60 \%$ & 4 & $40 \%$ & 10 \\
\hline $360-495 \mathrm{ft}, 45 \mathrm{mph}$ & 0 & $0 \%$ & 2 & $40 \%$ & 2 & $40 \%$ & 3 & $60 \%$ & 5 \\
\hline $250-360 \mathrm{ft}, 35 \mathrm{mph}$ & 1 & $20 \%$ & 2 & $40 \%$ & 3 & $60 \%$ & 2 & $40 \%$ & 5 \\
\hline $155-250,25 \mathrm{mph}$ & 2 & $5 \%$ & 15 & $41 \%$ & 17 & $46 \%$ & 20 & $54 \%$ & 37 \\
\hline$<155 \mathrm{ft},<25 \mathrm{mph}$ & 0 & $0 \%$ & 0 & $0 \%$ & 0 & $0 \%$ & 1 & $100 \%$ & 1 \\
\hline $\begin{array}{l}\text { Error, no visibility } \\
\text { information }\end{array}$ & 0 & $0 \%$ & 2 & $50 \%$ & 2 & $50 \%$ & 2 & $50 \%$ & 4 \\
\hline All Conditions & 14 & $3 \%$ & 130 & $25 \%$ & 144 & $27 \%$ & 380 & $73 \%$ & 524 \\
\hline
\end{tabular}


The AAA Foundation report also found that a high proportion of fatal crashes in fog involved multiple vehicles (Hamilton et al., 2014). The data from I-77 suggests a similar trend. Table 6 shows the proportions of crashes that had a given number of vehicles involved in the crash. Table 6 indicates that in clear conditions, only $47 \%$ of crashes on the corridor involved multiple vehicles. During fog, this number increases to an average of $91 \%$. The percentage of crashes involving 3 or more vehicles was more than 4 times greater during foggy versus clear conditions (45\% vs. 10\%). The proportion of multiple vehicle crashes appeared to increase as visibility degraded. Between 360 and 645 feet of visibility, approximately 80 percent of crashes involved more than 1 vehicle. This increased to 97 percent when visibility was between 155 and 360 feet. Only one crash was observed in visibility lower than 155 feet and it involved only 1 vehicle.

Table 6: Number of Vehicles Involved in Crashes by Visibility Bin, 2010-2014

\begin{tabular}{|c|c|c|c|c|c|c|c|}
\hline \multirow{3}{*}{$\frac{\text { Visibility Bin }}{>645 \mathrm{ft}, 65 \mathrm{mph}}$} & \multicolumn{6}{|c|}{ Number of Vehicles Involved in Crash } & \multirow{3}{*}{$\frac{\text { Total }}{462}$} \\
\hline & \multicolumn{2}{|c|}{1} & \multicolumn{2}{|c|}{2} & \multicolumn{2}{|c|}{$3+$} & \\
\hline & 246 & $53 \%$ & 172 & $37 \%$ & 44 & $10 \%$ & \\
\hline All Low Visibility & 5 & $9 \%$ & 27 & $47 \%$ & 26 & $45 \%$ & 58 \\
\hline $495-645 \mathrm{ft}, 55 \mathrm{mph}$ & 2 & $20 \%$ & 5 & $50 \%$ & 3 & $30 \%$ & 10 \\
\hline $360-495 \mathrm{ft}, 45 \mathrm{mph}$ & 1 & $20 \%$ & 3 & $60 \%$ & 1 & $20 \%$ & 5 \\
\hline $250-360 \mathrm{ft}, 35 \mathrm{mph}$ & 0 & $0 \%$ & 0 & $0 \%$ & 5 & $100 \%$ & 5 \\
\hline $155-25025 \mathrm{mph}$ & 1 & $3 \%$ & 19 & $51 \%$ & 17 & $46 \%$ & 37 \\
\hline$<155 \mathrm{ft},<25 \mathrm{mph}$ & 1 & $100 \%$ & 0 & $0 \%$ & 0 & $0 \%$ & 1 \\
\hline $\begin{array}{l}\text { Error, no visibility } \\
\text { information }\end{array}$ & 2 & $50 \%$ & 2 & $50 \%$ & 0 & $0 \%$ & 4 \\
\hline All Conditions & 253 & $48 \%$ & 201 & $38 \%$ & 70 & $13 \%$ & 524 \\
\hline
\end{tabular}

Table 7 shows the breakdown by crash type for fog crashes and crashes during clear conditions. Rear-end crashes represent $64 \%$ of fog crashes compared to $25 \%$ of crashes during clear conditions. This trend coincides with the finding of increased multiple vehicle crashes shown in Table 6. Not surprisingly, the proportion of rear end crashes appears to be greater as the visibility conditions decline. While the likelihood of rear end crashes is higher overall during fog, it appears that the risk of rear end crashes is particularly high as the safe speed drops below $45 \mathrm{mph}$. This suggests that drivers are more prone to traveling too fast for conditions as visibilities are significantly reduced. 
Table 7: Crash Type by Visibility Bin, 2010-2014

\begin{tabular}{|c|c|c|c|c|c|c|c|c|c|c|c|}
\hline \multirow{2}{*}{$\begin{array}{r}\text { Visibility Bin } \\
>645 \mathrm{ft}, 65 \mathrm{mph} \\
\end{array}$} & \multicolumn{2}{|c|}{ Rear End } & \multicolumn{2}{|c|}{$\begin{array}{c}\text { Fixed Object - } \\
\text { Off Road }\end{array}$} & \multicolumn{2}{|c|}{ Angle } & \multicolumn{2}{|c|}{$\begin{array}{c}\text { Sideswipe - } \\
\text { Same } \\
\text { Direction } \\
\end{array}$} & \multicolumn{2}{|c|}{ Other } & \multirow{2}{*}{$\begin{array}{r}\text { Total } \\
462 \\
\end{array}$} \\
\hline & 116 & $25 \%$ & 178 & $39 \%$ & 23 & $5 \%$ & 45 & $10 \%$ & 100 & $22 \%$ & \\
\hline All Low Visibility & 37 & $64 \%$ & 3 & $5 \%$ & 10 & $17 \%$ & 6 & $10 \%$ & 2 & $3 \%$ & 58 \\
\hline $495-645 \mathrm{ft}, 55 \mathrm{mph}$ & 4 & $40 \%$ & 1 & $10 \%$ & 4 & $40 \%$ & 0 & $0 \%$ & 1 & $10 \%$ & 10 \\
\hline $360-495 \mathrm{ft}, 45 \mathrm{mph}$ & 2 & $40 \%$ & 0 & $0 \%$ & 1 & $20 \%$ & 1 & $20 \%$ & 1 & $20 \%$ & 5 \\
\hline $250-360 \mathrm{ft}, 35 \mathrm{mph}$ & 5 & $100 \%$ & 0 & $0 \%$ & 0 & $0 \%$ & 0 & $0 \%$ & 0 & $0 \%$ & 5 \\
\hline $155-25025 \mathrm{mph}$ & 26 & $70 \%$ & 1 & $3 \%$ & 5 & $14 \%$ & 5 & $14 \%$ & 0 & $0 \%$ & 37 \\
\hline$<155 \mathrm{ft},<25 \mathrm{mph}$ & 0 & $0 \%$ & 1 & $100 \%$ & 0 & $0 \%$ & 0 & $0 \%$ & 0 & $0 \%$ & 1 \\
\hline $\begin{array}{l}\text { Error, no visibility } \\
\text { information }\end{array}$ & 1 & $25 \%$ & 3 & $75 \%$ & 0 & $0 \%$ & 0 & $0 \%$ & 0 & $0 \%$ & 4 \\
\hline All Conditions & 154 & $29 \%$ & 184 & $35 \%$ & 33 & $6 \%$ & 51 & $10 \%$ & 102 & $19 \%$ & 524 \\
\hline
\end{tabular}




\subsubsection{Crash Rate}

While the crash frequency analysis provides some insight into crashes in fog, it does not control for exposure in any way. Some fog events occurred during low volume, overnight hours while others occurred during the day. In order to address this, crash rates were calculated per 100 million vehicle miles traveled and are shown in Table 8. This analysis shows that in worsening visibility conditions, the crash rates increases. Crash rates when safe speeds are less than $65 \mathrm{mph}$ are more than 8.5 times the crash rates experienced during clear conditions. The crash rates are greater in the southbound direction than the northbound direction, which was expected given the downhill grades in the southbound direction and high truck percentages at the location with the worst visibility. While the general trend towards greater crash rates in low visibility compared to clear conditions is likely reliable, the magnitude of some of the calculated rates is driven by the relatively small sample size of crashes. In particular, the crash rates in the $25 \mathrm{mph}$ safe speed bin were a function of a large number of crashes occurring during a few, very severe fog events.

While this analysis does show that fog is correlated with higher crash rates, the analysis has several limitations. Crash times and locations are taken from the police reports that are recorded at the scene following a crash. The accuracy of the time and location has a large effect on the visibility value assigned to the crash and subsequently which visibility bin it is placed in for the crash rate calculation. This analysis makes the assumption that there is a linear relationship in visibility between weather sensors and between ten minute sensor readings.

Another limitation is that real-time volumes are not available continuously throughout the corridor. Average hourly volume profiles were used to create estimates of AADT by hour, which may deviate from what was experienced at the site. This was expected to be a minor concern, however, since fog events would be expected to reduce volume, if anything. If volumes dropped during fog, then the crash rates would be even higher than what is shown in Table 8 .

Table 8: Crash Rate by Visibility Condition, 2010-2014

\begin{tabular}{|l|c|c|c|c|c|c|}
\hline \multirow{2}{*}{ Visibility Bin } & \multicolumn{3}{|c|}{ Number of Crashes } & \multicolumn{3}{c|}{ Crash Rates } \\
& \multicolumn{2}{|c|}{ (Crashes per 100 Million VMT) } \\
\cline { 2 - 7 } & North & South & Both & North & South & Both \\
\hline$>645 \mathrm{ft}, 65 \mathrm{mph}$ & 231 & 231 & 462 & 66.8 & 69.1 & 67.9 \\
\hline All Low Visibility & 9 & 49 & 58 & 175.3 & 1000.5 & 578.1 \\
\hline $495-645 \mathrm{ft}, 55 \mathrm{mph}$ & 0 & 10 & 10 & 0.0 & 879.3 & 429.3 \\
\hline $360-495 \mathrm{ft}, 45 \mathrm{mph}$ & 1 & 4 & 5 & 73.3 & 307.0 & 187.4 \\
\hline $250-360 \mathrm{ft}, 35 \mathrm{mph}$ & 1 & 4 & 5 & 74.5 & 311.3 & 190.4 \\
\hline $155-25025 \mathrm{mph}$ & 6 & 31 & 37 & 591.5 & 3213.3 & 1869.6 \\
\hline$<155 \mathrm{ft},<25 \mathrm{mph}$ & 1 & 0 & 1 & 448.7 & 0.0 & 232.4 \\
\hline No Visibility Information & 2 & 2 & 4 & 6.0 & 4.8 & 5.3 \\
\hline All Conditions & 242 & 282 & 524 & 63.0 & 74.0 & 68.5 \\
\hline
\end{tabular}




\subsubsection{Driver Behavior}

\subsubsection{Speed Analysis}

The mean speeds at each station by visibility bin are shown in Table 9. The $\mathrm{N}$ column in Table 9 represents the number of 5-minute speed observations included in each bin. Table 9 shows an overall trend that speeds decrease as visibility decreases, but that speeds are often far greater than the SSD speed, particularly in the lowest visibility bins. Hypothesis testing at a confidence $\alpha=0.05$ revealed that the mean speed in each low visibility bin is statistically significantly different than the mean speed during clear conditions for all cases, even though it exceeds the SSD speed. This points to a relationship between mean speed and visibility that will be evaluated further.

Table 9: I-77 Mean Speed by Visibility Bin

\begin{tabular}{|l|c|c|c|c|c|c|}
\hline \multirow{2}{*}{ Visibility Bin } & \multicolumn{7}{|c|}{ I-77 Southbound } \\
\cline { 2 - 8 } & \multicolumn{2}{|c|}{ MP 5.3 } & \multicolumn{2}{c|}{ MP 6.6 } & \multicolumn{2}{c|}{ MP 7.3 } \\
\cline { 2 - 7 } & N & $\begin{array}{c}\text { Speed } \\
(\mathbf{m p h})\end{array}$ & N & $\begin{array}{c}\text { Speed } \\
(\mathbf{m p h})\end{array}$ & N & $\begin{array}{c}\text { Speed } \\
(\mathbf{m p h})\end{array}$ \\
\hline$>645$ feet $(65 \mathrm{mph})$ & 445 & 68.6 & 1322 & 66.7 & 849 & 65.7 \\
\hline 495-645 feet $(55 \mathrm{mph})$ & 398 & 58.2 & 273 & 62.0 & 104 & 56.0 \\
\hline 360-495 feet $(45 \mathrm{mph})$ & 480 & 55.8 & 448 & 61.0 & 98 & 51.6 \\
\hline 250-360 feet $(35 \mathrm{mph})$ & 189 & 49.6 & 729 & 57.6 & 22 & 49.9 \\
\hline $155-250$ feet $(25 \mathrm{mph})$ & 15 & 47.2 & 738 & 51.2 & 0 & - \\
\hline$<155$ feet $(<25 \mathrm{mph})$ & 0 & - & 9 & 44.3 & 0 & - \\
\hline
\end{tabular}

For each 5-minute speed observation, the speed differential between lanes was calculated by subtracting the right lanes speed from the left lane speed. The differentials are aggregated in the same manner as the mean speeds and shown in Table 10. Sample sizes differ from Table 9, because periods that did not have traffic in both lanes were discarded.

Table 10: I-77 Speed Differential between Lanes by Visibility Bin

\begin{tabular}{|l|c|c|c|c|c|c|}
\hline \multirow{2}{*}{ Visibility Bin } & \multicolumn{7}{|c|}{ MP 5.3 } & \multicolumn{2}{c|}{ MP 6.6 } & \multicolumn{2}{c|}{ MP 7.3 } \\
\cline { 2 - 8 } & $\mathbf{N}$ & $\begin{array}{c}\text { Mean } \\
\text { Speed } \\
\text { Differential } \\
\text { (mph) }\end{array}$ & N & $\begin{array}{c}\text { Mean } \\
\text { Speed } \\
\text { Differential } \\
\text { (mph) }\end{array}$ & N & $\begin{array}{c}\text { Mean } \\
\text { Speed } \\
\text { Differential } \\
\text { (mph) }\end{array}$ \\
\hline$>645$ feet $(65 \mathrm{mph})$ & 443 & 3.15 & 1318 & 5.16 & 849 & 3.84 \\
\hline $495-645$ feet $(55 \mathrm{mph})$ & 397 & 3.21 & 270 & 7.39 & 104 & 4.92 \\
\hline 360-495 feet $(45 \mathrm{mph})$ & 480 & 3.59 & 442 & 7.70 & 98 & 3.87 \\
\hline 250-360 feet $(35 \mathrm{mph})$ & 187 & 3.36 & 715 & 7.22 & 22 & 3.14 \\
\hline 155-250 feet $(25 \mathrm{mph})$ & 14 & 6.61 & 701 & 6.54 & 0 & - \\
\hline$<155$ feet $(<25 \mathrm{mph})$ & 0 & - & 2 & -1.10 & 0 & - \\
\hline
\end{tabular}


Increased speed differentials during reduced visibility could indicate safety concerns due to potential conflicts between vehicles in adjacent lanes. Hypothesis testing at a confidence $\alpha=0.05$ revealed that the mean speed differential in the 495-645 feet and 250-360 feet bins were not statistically different than the mean speed differential in clear conditions at MP 5.3. The mean speed differential in the 360-495 feet and 155-250 feet bins were found to be statistically different than the mean speed differentials in clear conditions at MP 5.3. All low visibility bins were found to be statistically different from clear conditions at MP 6.6. This suggests that in low visibility drivers in the right lane are slowing down while drivers in the left lane are maintaining speed. Increased speed differential between lanes points to a potential safety concern. At MP 7.3, visibility bins less than 495 feet were found not to be statistically different from clear conditions. These results imply inconsistent effects by site, although there are pronounced increases in differentials at the location that is prone to the worst fog events. Full hypothesis testing results is found in Appendix B: Additional Tables.

More detailed speed analysis was performed using the $5 \mathrm{mph}$ binned speed data available at MP 6.6 and shown in Table 11. Standard deviation of speed is sometimes used as a surrogate measure of safety since it represents the variability of speeds on a road. It appears that standard deviation remains relatively consistent with visibility condition. Hypothesis testing at a confidence $\alpha=0.05$ revealed that the standard deviation speed in every low visibility bin was not significantly different than the standard deviation of speed in clear conditions. At approximately $9 \mathrm{mph}$, the standard deviation is higher than expected for an interstate highway but may be a result of the steep grade and heavy truck traffic in the southbound direction. Thus, there is no evidence that variability in speeds increased as visibility declined.

Since mean speeds are declining as visibility drops, the coefficient of variation may be a better measure of the dispersion of speed data since it accounts for the amount of variation relative to the mean speed. The coefficient of variation appears constant in visibility 250 feet to 645 feet, and then continues to increases in the visibility less than 250 feet. This potentially indicates a higher likelihood of severe interactions between vehicles at these severely reduced visibilities.

Compliance with the SSD may also provide an indicator of safety across visibility levels. In all reduced visibility bins, at least $74 \%$ of drivers are exceeding the stopping sight distance safe speed. In the lowest visibility bin nearly every vehicle is exceeding the stopping sight distance safe speed. The same trend is apparent with the percent of vehicles driving within 10 mph of the stopping sight distance safe speed. In fact, for safe speeds of $45 \mathrm{mph}$ or less, over $90 \%$ of vehicles are exceeding the SSD and over $71 \%$ are traveling more than $10 \mathrm{mph}$ above the SSD. 
Table 11: I-77 Speed Profile Characteristics

\begin{tabular}{|l|c|c|c|c|c|c|c|c|c|}
\hline Visibility Bin & SSD & $\mathbf{n}$ & $\begin{array}{c}\text { Mean Speed } \\
(\mathbf{m p h})\end{array}$ & $\begin{array}{c}\text { Standard } \\
\text { Deviation } \\
(\mathbf{m p h})\end{array}$ & $\begin{array}{c}\text { Coefficient } \\
\text { of Variation }\end{array}$ & $\begin{array}{c}\text { Pace } \\
\text { Speed }\end{array}$ & $\begin{array}{c}\text { \% of Vehicles } \\
\text { Traveling in } \\
\text { Pace }\end{array}$ & \multicolumn{2}{|c|}{ Percent Vehicles } \\
\cline { 5 - 10 } & & & SSD & > SSD + 10 mph \\
\hline$>645$ feet & $65 \mathrm{mph}$ & 1322 & 66.7 & 8.70 & 0.13 & $65-75 \mathrm{mph}$ & $49 \%$ & $\mathrm{n} / \mathrm{a}$ & $\mathrm{n} / \mathrm{a}$ \\
\hline $495-645 \mathrm{feet}$ & $55 \mathrm{mph}$ & 250 & 61.7 & 9.37 & 0.16 & $60-70 \mathrm{mph}$ & $44 \%$ & $74 \%$ & $33 \%$ \\
\hline $360-495 \mathrm{feet}$ & $45 \mathrm{mph}$ & 404 & 60.7 & 9.11 & 0.15 & $60-70 \mathrm{mph}$ & $43 \%$ & $92 \%$ & $71 \%$ \\
\hline $250-360 \mathrm{feet}$ & $35 \mathrm{mph}$ & 683 & 57.5 & 8.99 & 0.16 & $55-65 \mathrm{mph}$ & $44 \%$ & $98 \%$ & $87 \%$ \\
\hline $155-250 \mathrm{feet}$ & $25 \mathrm{mph}$ & 737 & 51.2 & 9.09 & 0.18 & $50-60 \mathrm{mph}$ & $38 \%$ & $98 \%$ & $92 \%$ \\
\hline$<155 \mathrm{feet}$ & $<25 \mathrm{mph}$ & 9 & 44.3 & 9.39 & 0.22 & $45-55 \mathrm{mph}$ & $38 \%$ & $99 \%$ & $91 \%$ \\
\hline
\end{tabular}


Figure 11 shows the aggregate distribution of vehicle speeds for each visibility category using data from all fog events since September 2014 at MP 6.6. The distribution appears relatively consistent for visibilities between 360 and 645 feet. For visibilities less than 360 feet, the profile for each subsequent lower visibility bin shifts to the left. For each of these bins, the peak also appears increasingly spread out. This is reflected by the percentage of vehicles traveling the pace speed as shown in Table 11. During clear conditions, nearly 50 percent of vehicles are traveling in the $10 \mathrm{mph}$ pace. Under the worst visibility category, about 38 percent of vehicles are traveling in the $10 \mathrm{mph}$ pace. This spreading of the peak will likely increase interactions between vehicles traveling at different speeds, which could create negative safety effects.

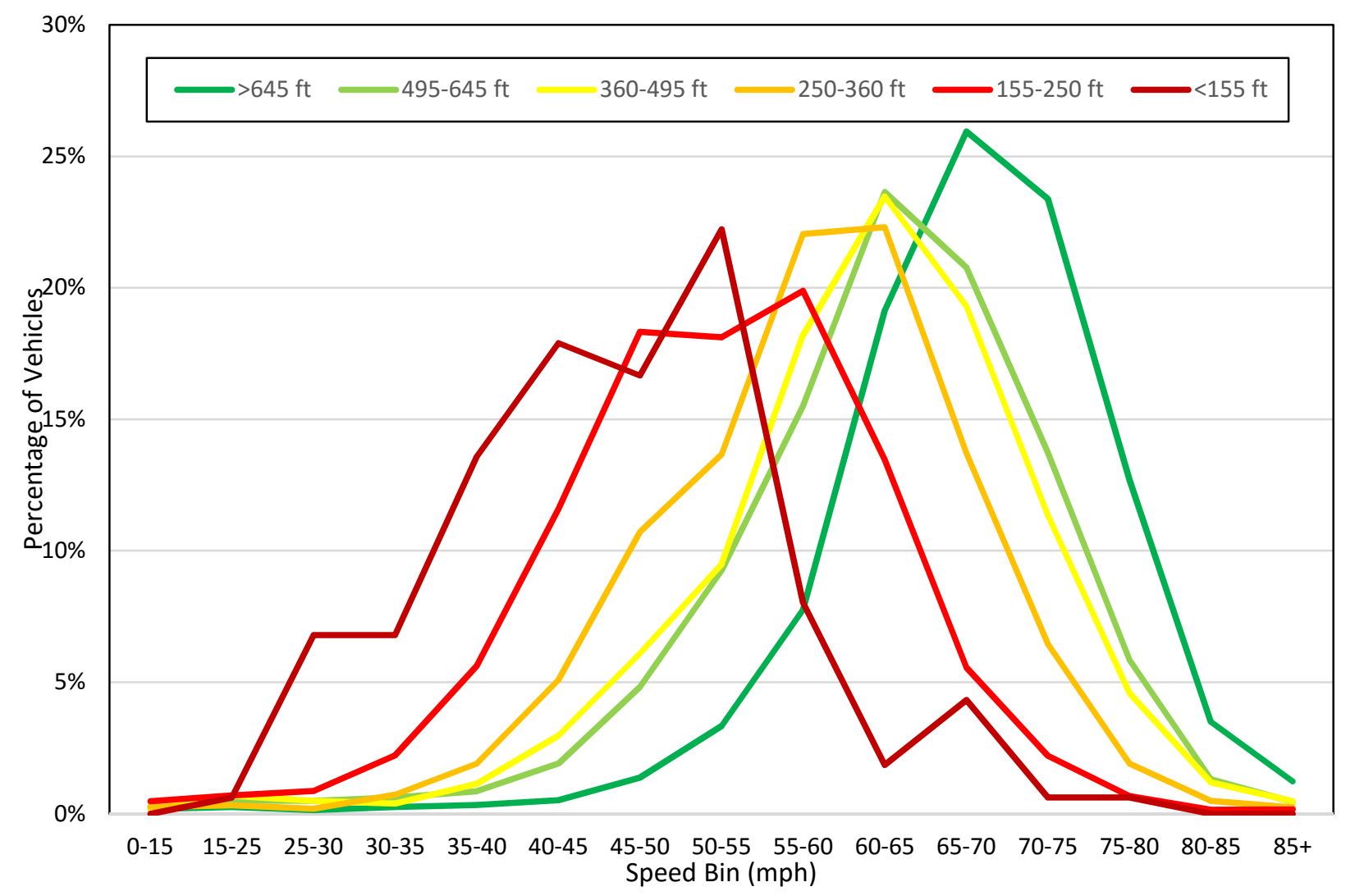

Figure 11: I-77 Speed Profiles

The speed analysis findings reinforce the crash analysis findings presented earlier. As fog becomes more severe, the differences between the safe speed and the observed travel speeds increase. Since drivers are over-driving the available visibility, this may lead to increased conflicts between vehicles and more rear end and multi-vehicle crashes. The speed data also supports the findings that safety concerns become increasingly severe when visibility drops below a 35 to $45 \mathrm{mph}$ safe speed. Additional attention to driver performance and behavior in those very severe conditions appears to be warranted. 


\subsubsection{Speed/Visibility Models}

Speed models were developed to relate the mean speed per 5 minutes to site characteristics. This was intended to provide an explanatory model that could be used to help explain how drivers reacted to lower visibilities before implementation of the VSL system on I-77, and was not intended to be transferable across sites. During the modeling process, several trends emerged:

1. Mean speed was correlated with the inverse of visibility distance.

2. Volumes at the sites were typically far below capacity during fog events, and no significant relationships between speed and traffic volumes were detected.

3. The day/night indicator variable typically showed slight reductions in mean speed during overnight hours.

4. Site indicator variables were often significant, which captured specific geometric conditions at the location.

The final model for I-77 is discussed in the following sections. All variables selected were significant at $\alpha=0.05$ and all other regression assumptions were met for the models. Since this model was intended simply to describe observed characteristics at the sites, $100 \%$ of the data were used for model development. Given the influence of site specific variables, this model cannot be directly transferred to another location. That being said, the model does provide some important information about the relative sensitivity of driver speed choice to available visibility on I-77.

The final model for I-77 is shown by the following equation:

$$
S=64.6-\frac{4204}{\text { Vis }}+(1.13 \times \text { DayNight })+(6.07 \times S B 6)-(2.67 \times S B 7)
$$

Where:

$\mathrm{S}=$ Mean speed per 5 minutes $(\mathrm{mph})$

Vis = Visibility distance (feet)

DayNight $=$ Day or night dummy variable, with 1 indicating day and 0 indicating night

SB6 = Dummy variable, with 1 indicating site Southbound MP 6.6

SB7 = Dummy variable, with 1 indicating site Southbound MP 7.3

Table 12 shows the model statistics. The p-values are less than 0.05 for all of the coefficients, indicating that they are significantly different than 0 . As mentioned in the Methodology, precipitation type, precipitation intensity, temperature and factor interactions were also tested, but were not found to be significant. It is also important to consider the practical significance of each coefficient to determine if the model makes physical sense. The coefficient on the inverse of visibility variable is -4204 . This sign and magnitude makes sense because as the visibility decreases, driver speed will also decrease. The inverse transformation of this variable affects the rate at which the speed increases or decreases with a change in visibility. The coefficient value of 1.13 on the day/night variable indicates that driver speeds are approximately $1 \mathrm{mph}$ greater during the day than at night, which is intuitive. The coefficient value of 6.07 on the MP 6.6 site variable indicates that drivers are traveling approximately $6 \mathrm{mph}$ 
faster at MP 6.6 than at MP 5.3 under the same visibility condition. The coefficient value of 2.67 on the MP 7.3 site variable indicates that drivers are traveling approximately $2.7 \mathrm{mph}$ slower at MP 7.3 than at MP 5.3 under the same visibility condition. Examination of the standardized coefficients helps show the relative importance of the different factors in generating the mean speed prediction. The standardized coefficient shows that the transformed visibility variable has the largest influence on the driver speed, as expected.

Table 12: I-77 Model Parameters

\begin{tabular}{|l|l|l|l|l|}
\hline \multirow{2}{*}{ Model Elements } & Coefficients & \multirow{2}{*}{ t-statistic } & \multirow{2}{*}{ p-value } \\
\cline { 2 - 5 } & Unstandardized & Standardized & & 0.000 \\
\hline Constant & 64.6 & n/a & 259.46 & 0.000 \\
\hline Inverse Visibility & -4204 & -0.752 & -52.02 & 0.000 \\
\hline Day Night & 1.13 & 0.089 & 7.07 & 0.000 \\
\hline SB6 & 6.07 & 0.462 & 30.61 & 0.000 \\
\hline SB7 & -2.67 & -0.103 & -7.70 & \\
\hline
\end{tabular}

Figure 12 shows the raw data and the model estimates, broken up by site. The adjusted $\mathrm{R}^{2}$ value for this model is 0.451 . While a better fit would be more ideal, this $\mathrm{R}^{2}$ value indicates that the model explains about 45 percent of the variation in the data. In this case, the wide dispersion in the model data adversely affected the model fit, although a clear relationship between visibility and speed is evident. The difference between SSD safe speed and observed speeds are evident in the figures. 


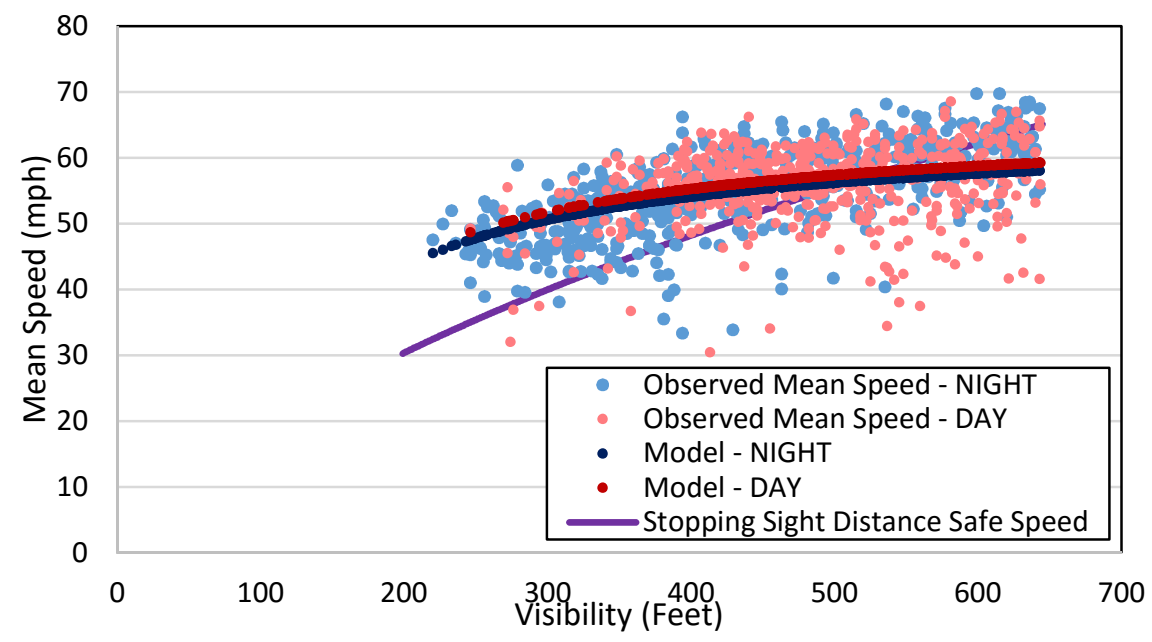

(a)

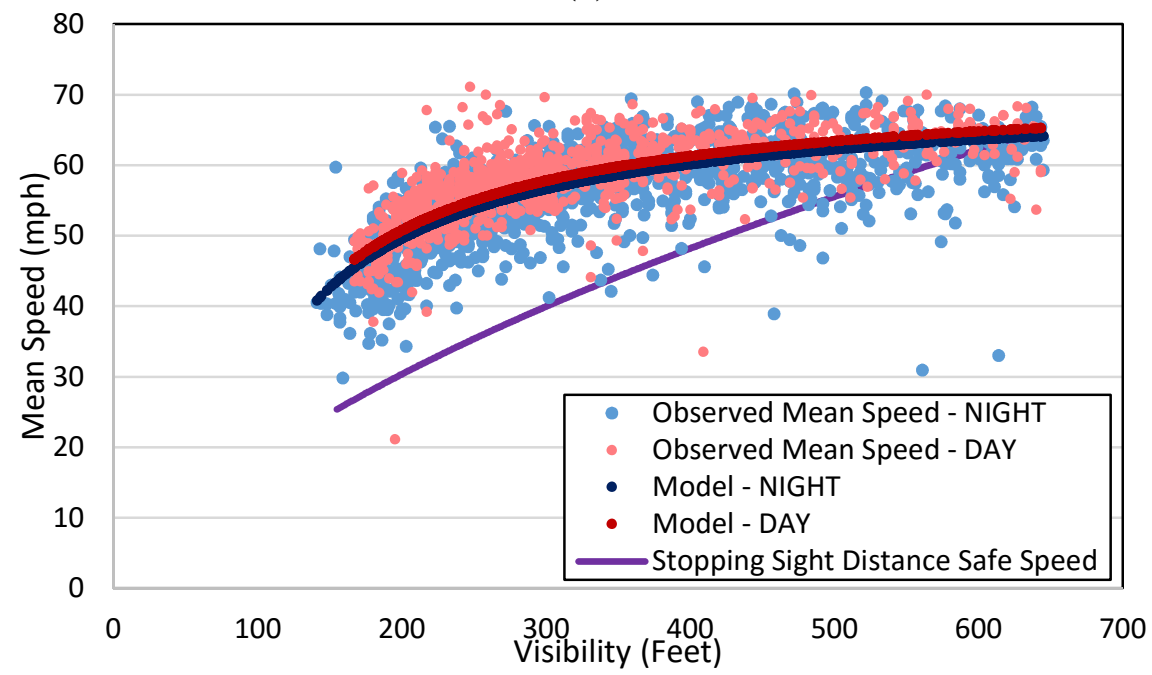

(b)

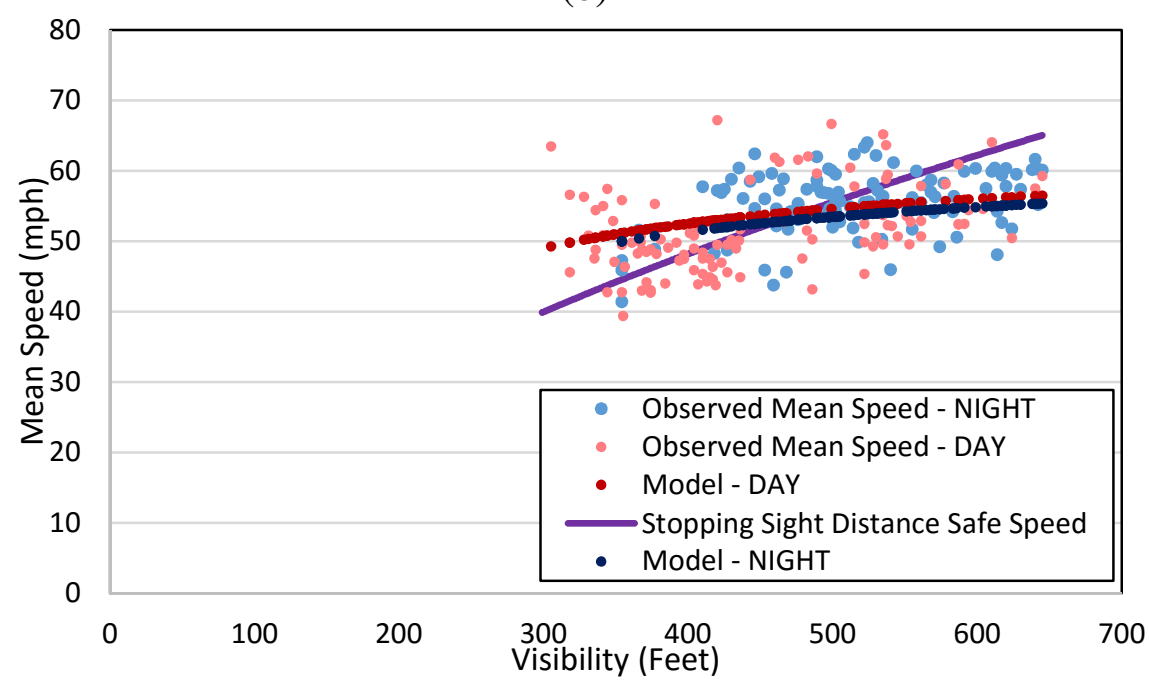

(c)

Figure 12: I-77 Models for (a) MP 5.3, (b) MP 6.6, and (c) MP 7.7 
A particularly interesting finding from the I-77 model was related to the coefficients of the site dummy variables. The coefficients suggest that compared to speeds at MP 5.3, speeds were about $6 \mathrm{mph}$ faster at MP 6.6 and $2.5 \mathrm{mph}$ slower at MP 7.3 when visibility is held constant. This is interesting because all three sites are on downhill grades and separated by short distances. To better understand this relationship, individual low visibility events were plotted in time to see how speeds change by site, as shown in Figure 13. Visual analysis of the individual events showed that driver's speeds were fairly consistent from site to site, both on clear days and on foggy days, but that the visibility varied from site to site, with the worst visibility typically occurring at MP 6.6. Therefore, the compliance with safe speed appears better at MP 5.3 and MP 7.3 simply because the visibility is better relative to MP 6.6. This accounts for the difference in magnitude of the coefficient on the site indicator variables. Because there are not additional speed detectors upstream of MP 7.3 it is not known what the visibility is when the drivers are choosing the speed that they maintain throughout this corridor. Thus, the data appears to indicate that drivers do not necessarily alter their speed much as visibility changes as they proceed through the corridor. This implies that the MP 6.6 model represents the critical case for driver behavior on the corridor.

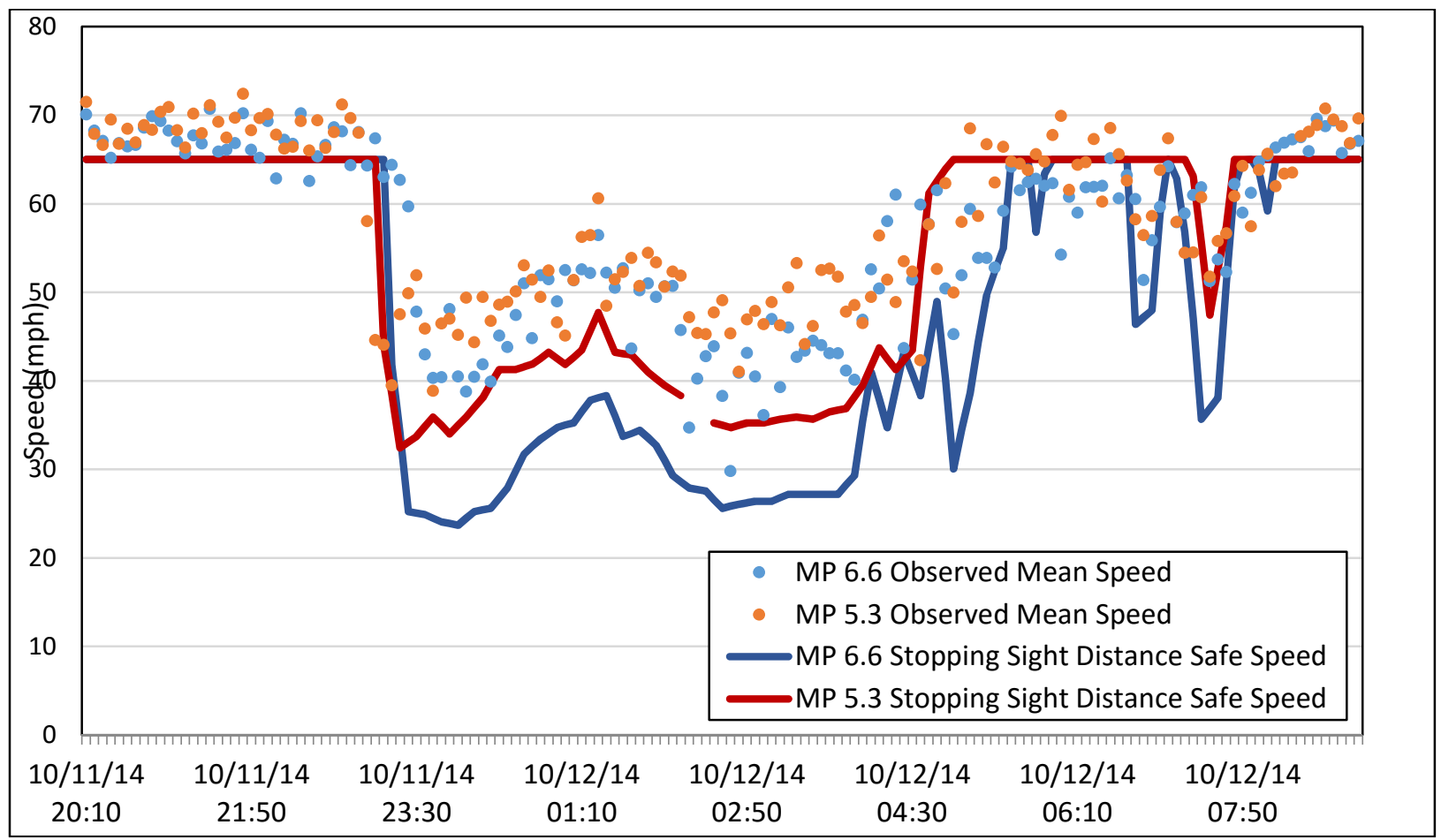

Figure 13: I-77 Low Visibility Event

\subsection{I-64 IN AFTON, VIRGINIA}

\subsubsection{Visibility Profiles}

Low visibility was observed on 77 days between July 1, 2014 and December 31, 2014. Figure 14 shows the visibility profile for the I-64 study section using all data from this period. The purple line shows the percentage of time that the RWIS sensor was reporting reduced 
visibility, once invalid readings were removed from the analysis. Figure 14 shows that the distribution of fog varied spatially along the corridor. The worst visibility occurs at MP 99.9 observing reduced visibility for more than $10 \%$ of the collection period. Since data were only available for 6 months in 2014, the frequency distribution data cannot be directly compared to I77 .

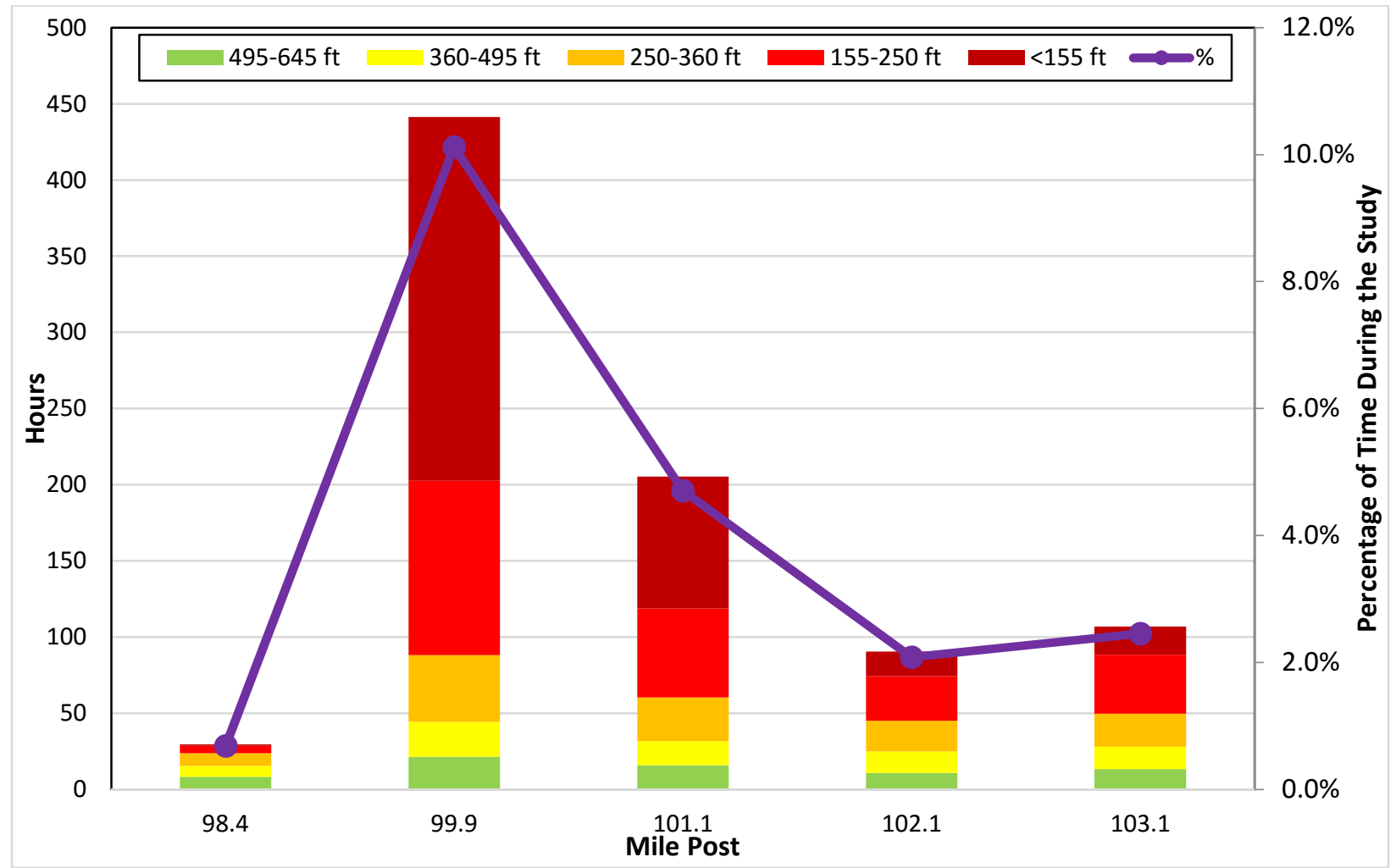

Figure 14: I-64 Visibility Profile, July to December 2014

\subsubsection{Crash Analysis}

\subsubsection{Crash Frequency}

Police crash reports were used to analyze crashes from July 1, 2014 to December 31, 2014 in conjunction with the visibility measurements. A review of these reports revealed 27 total crashes between MP 97 and MP 103 with one crash being coded as having occurred in fog. The remaining crash dates were cross referenced with a list of dates during the collection period that experienced fog to determine if any other crashes occurred in low visibility. The process revealed that ten crashes occurred during periods that the corridor experienced foggy conditions, again indicating inconsistency between visibility measurements and police judgements of weather conditions. The ten crashes occurred on seven different days spread evenly throughout the six month period. Nine of the crashes occurred between MP 97 and MP 99 and are nearest to the RWIS station at MP 98.4.

A closer examination of the visibility on the corridor when each of the crashes occurred found that the visibility at the MP 98.4 was clear while the sensors at adjacent station MP 99.9 
recorded severe low visibility. Five of these crashes occurred in the westbound direction so while the visibility at the crash site may have been clear, the vehicle had recently traveled through a foggy area. The crash at MP 102 was coded as a fog crash on the police report; however, the data reveals that the visibility at the time of the crash was 1500 feet, well above the safe stopping sight distance of 645 feet. It's possible that there was a coding error by the policeman; the visibility at the station five minutes later was 463 feet. Eight of the ten crashes were fixed object-off road collisions. The remaining two crashes occurred when a driver struck a bear in the roadway and a second vehicle struck the bear carcass. This crash type break down does not align with the findings of the AAA Foundation study as none of these crashes were rear-end, none involved multiple vehicles, and none resulted in any injuries (Hamilton et al., 2014). This is likely due to the small sample size.

Although visibility data was not available, police reports were examined for all crashes for 2010 to 2014. Between MP 97 and MP 103 there were 148 crashes. Six crashes were coded as occurring during fog by the responding officer. A review of the crash descriptions written by the officer found one additional crash that was coded as occurring in rain but was described as occurring in foggy/rainy conditions. Icy road conditions played a role in five of the seven crashes. Four crashes were fix object-off road collisions, one was an angle crash, one was a sideswipe-same direction, and one was a rear-end collision. Approximately $4.7 \%$ of the crashes occurred during fog based on the police coding and descriptions. This percentage is lower than the proportion of fog crashes on I-77 (approximately 11\%). This could be a function of missing crashes in low visibility due to the inability to get visibility readings for the crashes. Or, if this is a representative crash sample, then this points to safer driving behavior on I-64 compared to I77. Possible explanations for this will be discussed later in the thesis.

\subsubsection{Driver Behavior}

\subsubsection{Speed Analysis}

The mean speeds at each station by visibility bin are shown in Table 13 . The N column in Table 13 represents the number of 5-minute speed observations included in each bin. Table 13 shows an overall trend that speeds decrease as visibility decreases, but that speeds are often far greater than the SSD speed, particularly in the lowest visibility bins. Hypothesis testing at a confidence $\alpha=0.05$ revealed that the mean speed in each low visibility bin is statistically significantly different than the mean speed during clear conditions for all cases.

For each 5-minute speed observation the lane speed differential is calculated by subtracting the right lane speed from the left lane speed. The differentials are aggregated in the same manner as the mean speeds and shown in Table 14. Hypothesis testing at a confidence $\alpha=0.05$ revealed that the mean speed differential in each low visibility bin was not statistically different than the mean speed differential in clear conditions at MP's 98.4 eastbound, 98.4 westbound, and 99.9 eastbound. This suggests that at these locations the potential for conflict between vehicles in adjacent lanes does not increase as visibility decreases. All low visibility bins were found to be statistically different from clear conditions at MP 101.1 eastbound and MP 102.1 westbound. At MP 99.9 westbound, visibility bins less than 495 feet were found to be different from clear conditions. At MP 101.1 westbound only the lowest visibility bin $(<155$ 
feet) was found to be different than clear conditions. At each of these locations, reduced visibility below a certain value increases the potential for conflict between vehicles in adjacent lanes compared to clear conditions. At MP 102.1 eastbound, three of the low visibility bins were found to be statistically different while two were not. Full hypothesis testing is found in Appendix B: Additional Tables. 
Table 13: I-64 Mean Speed by Visibility Bin

\begin{tabular}{|c|c|c|c|c|c|c|c|c|c|c|c|c|c|c|c|c|}
\hline \multirow{3}{*}{$\begin{array}{c}\text { Visibility } \\
\text { Bin }\end{array}$} & \multicolumn{8}{|c|}{ I-64 Eastbound } & \multicolumn{8}{|c|}{ I-64 Westbound } \\
\hline & \multicolumn{2}{|c|}{ MP 98.4} & \multicolumn{2}{|c|}{ MP 99.9} & \multicolumn{2}{|c|}{ MP 101.1 } & \multicolumn{2}{|c|}{ MP 102.1 } & \multicolumn{2}{|c|}{ MP 98.4} & \multicolumn{2}{|c|}{ MP 99.9} & \multicolumn{2}{|c|}{ MP 101.1 } & \multicolumn{2}{|c|}{ MP 102.1 } \\
\hline & $\mathbf{N}$ & $\begin{array}{l}\text { Speed } \\
(\mathbf{m p h}) \\
\end{array}$ & $\mathbf{N}$ & \begin{tabular}{|l} 
Speed \\
$(\mathrm{mph})$
\end{tabular} & $\mathbf{N}$ & $\begin{array}{l}\text { Speed } \\
(\mathrm{mph})\end{array}$ & $\mathbf{N}$ & $\begin{array}{l}\text { Speed } \\
(\mathbf{m p h}) \\
\end{array}$ & $\mathbf{N}$ & $\begin{array}{l}\text { Speed } \\
(\mathbf{m p h}) \\
\end{array}$ & $\mathbf{N}$ & $\begin{array}{l}\text { Speed } \\
(\mathbf{m p h}) \\
\end{array}$ & $\mathbf{N}$ & $\begin{array}{l}\text { Speed } \\
(\mathbf{m p h}) \\
\end{array}$ & $\mathbf{N}$ & $\begin{array}{l}\text { Speed } \\
(\mathrm{mph})\end{array}$ \\
\hline$>645$ feet & 48891 & 67.0 & 40753 & 66.5 & 41732 & 72.5 & 48678 & 70.5 & 48717 & 64.5 & 40658 & 63.5 & 44257 & 63.4 & 48031 & 69.4 \\
\hline $495-645$ feet & 100 & 60.1 & 250 & 61.4 & 155 & 67.8 & 119 & 67.9 & 100 & 60.2 & 251 & 59.6 & 178 & 60.8 & 129 & 66.4 \\
\hline $250-360$ feet & 100 & 61.1 & 516 & 61.8 & 295 & 67.7 & 230 & 64.7 & 99 & 60.6 & 517 & 59.4 & 307 & 60.8 & 242 & 64.9 \\
\hline $155-250$ feet & 59 & 57.4 & 1341 & 59.5 & 563 & 65.8 & 351 & 62.8 & 59 & 58.5 & 1340 & 57.4 & 616 & 59.8 & 351 & 64.0 \\
\hline$<155$ feet & 13 & 49.4 & 2730 & 54.0 & 705 & 60.4 & 196 & 59.7 & 13 & 51.0 & 2721 & 53.0 & 849 & 55.7 & 196 & 62.4 \\
\hline
\end{tabular}

Table 14: I-64 Lane Speed Differential by Visibility Bin

\begin{tabular}{|c|c|c|c|c|c|c|c|c|c|c|c|c|c|c|c|c|}
\hline \multirow{3}{*}{$\begin{array}{l}\text { Visibility } \\
\text { Bin }\end{array}$} & \multicolumn{8}{|c|}{ I-64 Eastbound } & \multicolumn{8}{|c|}{ I-64 Westbound } \\
\hline & \multicolumn{2}{|c|}{ MP 98.4} & \multicolumn{2}{|c|}{ MP 99.9} & \multicolumn{2}{|c|}{ MP 101.1 } & \multicolumn{2}{|c|}{ MP 102.1 } & \multicolumn{2}{|c|}{ MP 98.4} & \multicolumn{2}{|c|}{ MP 99.9} & \multicolumn{2}{|c|}{ MP 101.1 } & \multicolumn{2}{|c|}{ MP 102.1 } \\
\hline & $\mathbf{N}$ & $\begin{array}{l}\text { Speed } \\
(\mathrm{mph})\end{array}$ & $\mathbf{N}$ & $\begin{array}{l}\text { Speed } \\
(\mathbf{m p h})\end{array}$ & $\mathbf{N}$ & $\begin{array}{l}\text { Speed } \\
(\mathbf{m p h})\end{array}$ & $\mathbf{N}$ & $\begin{array}{l}\text { Speed } \\
(\mathbf{m p h})\end{array}$ & $\mathbf{N}$ & $\begin{array}{l}\text { Speed } \\
(\mathbf{m p h})\end{array}$ & $\mathbf{N}$ & $\begin{array}{l}\text { Speed } \\
(\mathbf{m p h})\end{array}$ & $\mathbf{N}$ & $\begin{array}{l}\text { Speed } \\
(\text { mph })\end{array}$ & $\mathbf{N}$ & $\begin{array}{l}\text { Speed } \\
(\mathrm{mph})\end{array}$ \\
\hline$>645$ feet & 48891 & 7.4 & 40753 & 5.1 & 41732 & -0.2 & 48678 & 5.9 & 48717 & 7.9 & 40658 & 7.8 & 44257 & 6.5 & 48031 & 4.8 \\
\hline 495-645 feet & 100 & 7.2 & 250 & 5.2 & 155 & 1.2 & 119 & 6.2 & 100 & 8.4 & 251 & 7.5 & 178 & 6.4 & 129 & 5.4 \\
\hline $360-495$ feet & 84 & 8.0 & 267 & 5.2 & 158 & 2.4 & 161 & 6.5 & 84 & 8.7 & 266 & 7.3 & 170 & 6.8 & 169 & 5.8 \\
\hline $250-360$ feet & 100 & 7.7 & 516 & 5.2 & 295 & 1.8 & 230 & 6.6 & 99 & 8.7 & 517 & 7.2 & 307 & 6.7 & 242 & 5.7 \\
\hline $155-250$ feet & 59 & 8.1 & 1341 & 5.2 & 563 & 1.3 & 351 & 6.4 & 59 & 8.8 & 1340 & 7.4 & 616 & 6.7 & 351 & 5.6 \\
\hline$<155$ feet & 13 & 7.9 & 2730 & 5.0 & 705 & 2.3 & 196 & 6.5 & 13 & 9.2 & 2721 & 7.2 & 849 & 6.2 & 196 & 5.9 \\
\hline
\end{tabular}


More detailed speed analysis was performed using the $5 \mathrm{mph}$ binned speed data at MP's 98.4 and 102.1 and shown in Table 15. This analysis could not be performed at MP's 99.9 and 101.1 because the speed was not collected in $5 \mathrm{mph}$ bins. It appears that standard deviation remains relatively consistent with visibility condition particularly at MP 98.4. This is further supported with hypothesis testing. Hypothesis testing at a confidence $\alpha=0.05$ revealed that the standard deviation speed in every low visibility bin was not significantly different than the standard deviation of speed in clear conditions at MP 98.4 eastbound and westbound. This means that it cannot be stated that there is a relationship between low visibility and speed variance at MP 98.4. At MP 102.1 eastbound, standard deviation of speed in visibility less than 360 feet is significantly different from standard deviation of speed in clear conditions. At MP 102.1 westbound, standard deviation of speed in visibility less than 495 feet is significantly different from standard deviation of speed in clear conditions. This indicates that there is a relationship between low visibility and speed variance at MP 102.1, particularly in visibility below 360 feet. This points to safety concerns at MP 102.1 as increased variance can contribute to crashes.

Like the I-77 dataset, the coefficient of variation may be a better measure of the dispersion of speed data since it accounts for the amount of variation relative to the mean speed. The coefficient of variation increases as visibility worsens particularly in visibility less than 250 feet.

Figure 15 shows the speed profiles for the sites at MP's 98.4 and 102.1. Visually, it is obvious that speed at the MP 102.1 sites, particularly in the westbound direction, are most insensitive to changes in visibility. The curves representing each visibility case are very similar shape. At MP 98.4 there is more variation in the curves. The curve for each worsening visibility bin is clearly shifted to the left. The curves for the lowest visibility bins are flatter than the curves representing clear conditions.

At both MP 98.4 sites, at least $78 \%$ of drivers are exceeding the stopping sight distance safe speed. In the lowest visibility bin $100.0 \%$ of the vehicles are exceeding the safe stopping sight distance safe speed. This is consistent with the speed profile on I-77 at M 6.6. At MP 102.1 a different trend emerges. At the MP 102.1 westbound site more than $99 \%$ of vehicles are traveling faster than the stopping sight distance safe speed in even the highest fog bin. At MP 102.1 eastbound, at least $96 \%$ of vehicles are exceeding stopping sight distance safe speed in all low visibility bins.

In all reduced visibility bins, at least $74 \%$ of drivers are exceeding the stopping sight distance safe speed. In the lowest visibility bin nearly every vehicle is exceeding the stopping sight distance safe speed. The same trend is apparent with the percent of vehicles driving within $10 \mathrm{mph}$ of the stopping sight distance safe speed. In fact, for safe speeds of $45 \mathrm{mph}$ or less, over $90 \%$ of vehicles are exceeding the SSD and over $71 \%$ are traveling more than $10 \mathrm{mph}$ above the SSD. 
Table 15: I-64 Speed Profile Characteristics

\begin{tabular}{|c|c|c|c|c|c|c|c|c|c|c|c|}
\hline \multirow{2}{*}{ Site } & \multirow{2}{*}{ Visibility Bin } & \multirow{2}{*}{ SSD } & \multirow{2}{*}{$\begin{array}{c}\mathrm{N} \\
\text { (number } \\
\text { of bins) }\end{array}$} & \multirow{2}{*}{$\begin{array}{c}\text { Volume } \\
\text { (number of } \\
\text { vehicles) }\end{array}$} & \multirow{2}{*}{$\begin{array}{l}\text { Mean } \\
\text { Speed } \\
(\text { mph })\end{array}$} & \multirow{2}{*}{$\begin{array}{c}\text { Standard } \\
\text { Deviation } \\
(\mathrm{mph})\end{array}$} & \multirow{2}{*}{$\begin{array}{c}\text { Coefficient } \\
\text { of Variation }\end{array}$} & \multirow{2}{*}{$\begin{array}{c}\text { Pace } \\
\text { Speed } \\
(\text { mph })\end{array}$} & \multicolumn{3}{|c|}{$\%$ Vehicles } \\
\hline & & & & & & & & & In Pace & $>$ SSD & $>\mathrm{SSD}+10$ \\
\hline \multirow{6}{*}{$\begin{array}{l}\text { MP } 98.4 \\
\text { Eastbound }\end{array}$} & $>645$ feet & 65 & 48,896 & $3,052,823$ & 67.0 & 7.7 & 0.11 & $65-75$ & $54.0 \%$ & $\mathrm{n} / \mathrm{a}$ & $\mathrm{n} / \mathrm{a}$ \\
\hline & 495-645 feet & 55 & 100 & 4,493 & 60.1 & 8.0 & 0.13 & $60-70$ & $42.8 \%$ & $78.5 \%$ & $40.2 \%$ \\
\hline & $360-495$ feet & 45 & 84 & 3,795 & 60.9 & 8.0 & 0.13 & $60-70$ & $43.9 \%$ & $94.1 \%$ & $81.1 \%$ \\
\hline & 250-360 feet & 35 & 100 & 4,608 & 61.1 & 8.2 & 0.13 & $60-70$ & $45.5 \%$ & $98.9 \%$ & $94.8 \%$ \\
\hline & $155-250$ feet & 25 & 59 & 1,938 & 57.4 & 8.6 & 0.15 & $55-65$ & $38.5 \%$ & $99.8 \%$ & $98.9 \%$ \\
\hline & $<155$ feet & $<25$ & 13 & 344 & 49.4 & 7.5 & 0.15 & $45-55$ & $35.8 \%$ & $100.0 \%$ & $100.0 \%$ \\
\hline \multirow{6}{*}{$\begin{array}{l}\text { MP } 98.4 \\
\text { Westbound }\end{array}$} & $>645$ feet & 65 & 48,773 & $2,878,396$ & 64.5 & 9.0 & 0.14 & $65-75$ & $50.9 \%$ & $\mathrm{n} / \mathrm{a}$ & $\mathrm{n} / \mathrm{a}$ \\
\hline & 495-645 feet & 55 & 100 & 4,529 & 60.2 & 9.1 & 0.15 & $60-70$ & $46.5 \%$ & $82.0 \%$ & $46.7 \%$ \\
\hline & $360-495$ feet & 45 & 84 & 3,606 & 61.3 & 9.2 & 0.15 & $60-70$ & $44.0 \%$ & $93.0 \%$ & $80.3 \%$ \\
\hline & $250-360$ feet & 35 & 100 & 3,846 & 60.6 & 9.2 & 0.15 & $60-70$ & $44.4 \%$ & $99.0 \%$ & $93.0 \%$ \\
\hline & $155-250$ feet & 25 & 59 & 1,340 & 58.5 & 9.2 & 0.16 & $60-70$ & $40.4 \%$ & $100.0 \%$ & $98.6 \%$ \\
\hline & $<155$ feet & $<25$ & 13 & 220 & 51.0 & 9.3 & 0.18 & $55-65$ & $36.8 \%$ & $100.0 \%$ & $100.0 \%$ \\
\hline \multirow{6}{*}{$\begin{array}{l}\text { MP } 102.1 \\
\text { Eastbound }\end{array}$} & $>645$ feet & 65 & 48,868 & $2,908,852$ & 70.5 & 6.5 & 0.09 & $65-75$ & $55.8 \%$ & $\mathrm{n} / \mathrm{a}$ & $\mathrm{n} / \mathrm{a}$ \\
\hline & $495-645$ feet & 55 & 119 & 8,696 & 67.9 & 7.2 & 0.11 & $65-75$ & $49.9 \%$ & $96.0 \%$ & $70.0 \%$ \\
\hline & $360-495$ feet & 45 & 161 & 9,374 & 66.7 & 7.1 & 0.11 & $65-75$ & $49.2 \%$ & $99.3 \%$ & $95.6 \%$ \\
\hline & $250-360$ feet & 35 & 230 & 12,086 & 64.7 & 7.5 & 0.12 & $60-70$ & $44.1 \%$ & $99.6 \%$ & $98.3 \%$ \\
\hline & $155-250$ feet & 25 & 351 & 20,138 & 62.8 & 7.6 & 0.12 & $60-70$ & $43.4 \%$ & $99.8 \%$ & $99.5 \%$ \\
\hline & $<155$ feet & $<25$ & 196 & 10,675 & 59.7 & 7.5 & 0.13 & $60-70$ & $39.2 \%$ & $99.9 \%$ & $99.9 \%$ \\
\hline \multirow{6}{*}{$\begin{array}{l}\text { MP } 102.1 \\
\text { Westbound }\end{array}$} & $>645$ feet & 65 & 48,070 & $2,981,776$ & 69.4 & 5.9 & 0.08 & $65-75$ & $59.6 \%$ & $\mathrm{n} / \mathrm{a}$ & $\mathrm{n} / \mathrm{a}$ \\
\hline & 495-645 feet & 55 & 129 & 9,308 & 66.4 & 6.4 & 0.10 & $65-75$ & $53.3 \%$ & $99.6 \%$ & $66.6 \%$ \\
\hline & $360-495$ feet & 45 & 169 & 10,307 & 65.1 & 6.6 & 0.10 & $60-70$ & $48.7 \%$ & $99.9 \%$ & $98.1 \%$ \\
\hline & $250-360$ feet & 35 & 242 & 14,028 & 64.9 & 6.5 & 0.10 & $60-70$ & $51.2 \%$ & $99.9 \%$ & $99.3 \%$ \\
\hline & $155-250$ feet & 25 & 351 & 23,114 & 64.0 & 6.8 & 0.11 & $60-70$ & $49.0 \%$ & $99.9 \%$ & $99.7 \%$ \\
\hline & $<155$ feet & $<25$ & 196 & 12,666 & 62.4 & 7.3 & 0.12 & $60-70$ & $48.6 \%$ & $99.9 \%$ & $99.8 \%$ \\
\hline
\end{tabular}



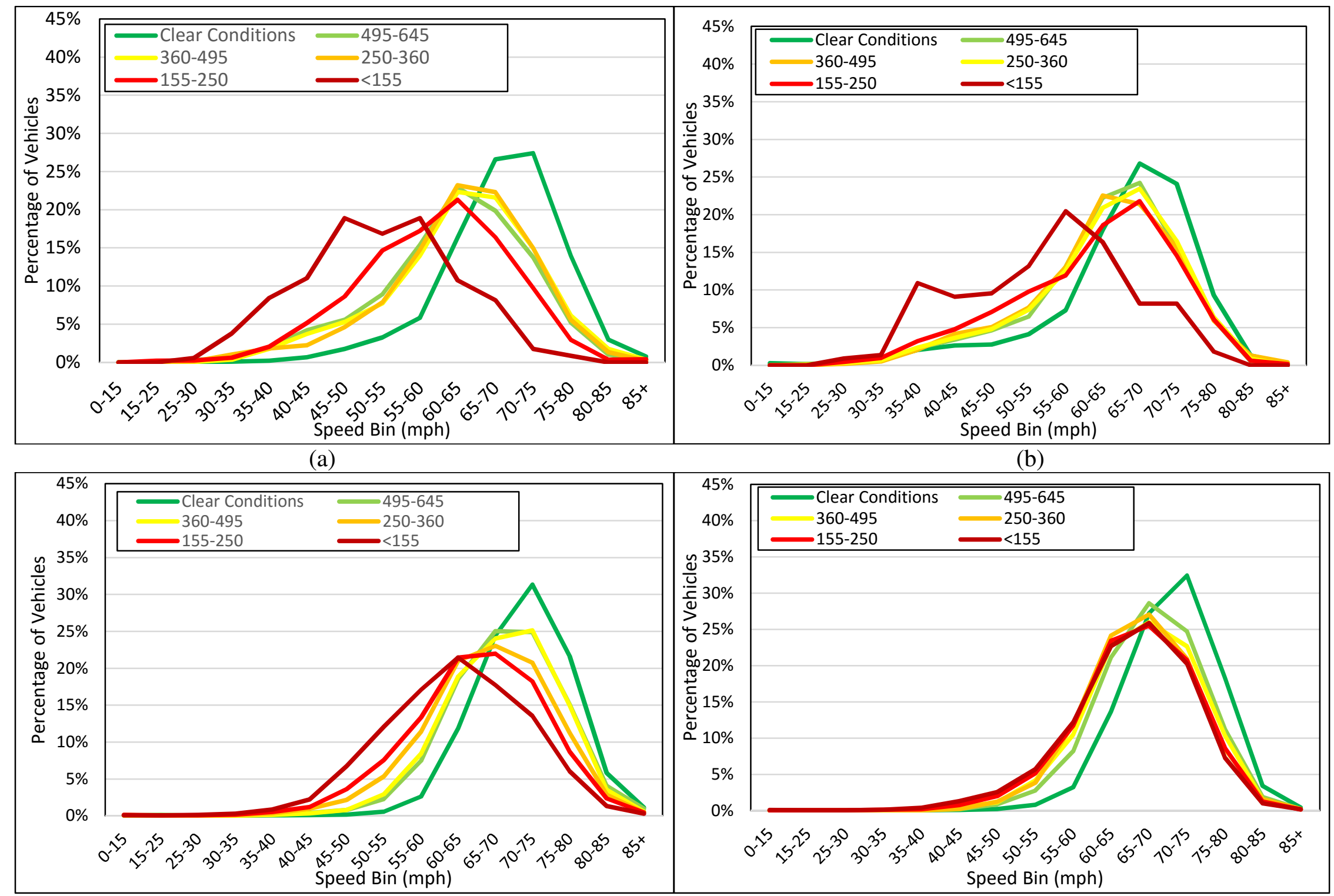

(c)

(d)

Figure 15: I-64 Speed Profiles (a) MP 98.4 EB, (b) MP 98.4 WB, (c) MP 102.1 EB, and (d) MP 102.1 WB 


\subsubsection{Modeling Speed}

The same trends from the I-77 model emerged during the modeling for I-64:

1. Mean speed was correlated with the inverse of visibility distance.

2. Volumes at the sites were typically far below capacity during fog events, and no significant relationships between speed and traffic volumes were detected.

3. The day/night indicator variable typically showed slight reductions in mean speed during overnight hours.

4. Site indicator variable were often significant, which captured specific geometric conditions at the location.

The final model for I-64 is discussed in the following sections. All variables selected were significant at $\alpha=0.05$ and all other regression assumptions were met for the models. Since this model was intended simply to describe observed characteristics at the sites, $100 \%$ of the data were used for model development. Given the influence of site specific variables, this model cannot be directly transferred to another location. That being said, the model does provide some important information about the relative sensitivity of driver speed choice to available visibility on I-64.

The final model for I-64 is shown by the following equation:

$$
S=62.2-\frac{1089}{V i s}+(5.25 \times \text { DayNight })-(1.52 \times W 99)+(5.84 \times E 101)+(4.13 \times E 102)+(4.65 \times W 102)
$$

Where:

$$
\mathrm{S}=\text { Mean speed per } 5 \text { minutes (mph) }
$$

Vis = Visibility distance (feet)

DayNight $=$ Day or night dummy variable, with 1 indicating day

WB99 = Dummy variable, with 1 indicating MP 99.9 Westbound

$\mathrm{EB} 101=$ Dummy variable, with 1 indicating MP 101.1 Eastbound

EB102 = Dummy variable, with 1 indicating MP 102.1 Eastbound

WB102 = Dummy variable, with 1 indicating MP 102.1 Westbound

Table 16 shows the model statistics. Again, the p-values are less than 0.05 for all the coefficient values, indicating that they are significantly different than 0 . The coefficient on the transformed visibility variable is -1089. Compared to the I-77 model, the sign is the same but the magnitude is less, indicating that changes in visibility have a smaller influence on speed on I64 than on I-77. The coefficient value of 5.25 on the day/night variable indicates that driver speeds are more than $5 \mathrm{mph}$ greater during the day than at night, which is much larger than was determined for I-77. The site specific variable for MP's 98.4 eastbound, 98.4 westbound, 99.4 eastbound, and 101 westbound do not show up in the model indicating that data for the speedvisibility relationship at sites are not significantly different from one another can be represented by the same curves. The coefficient value of -1.52 on the MP 99 westbound site variable indicates that drivers are traveling approximately $1.5 \mathrm{mph}$ slower at MP 99 westbound than at MP's 98 eastbound, 98 westbound, 99 eastbound, and 101 westbound, holding visibility constant. The coefficient value of 5.84 on the MP 101 eastbound variable indicates that drivers 
are traveling approximately 6 mph faster at MP 101 eastbound than at the four base sites, which shows the influence of traveling downhill vs. uphill. The coefficient values on the MP 102 eastbound and westbound sites are 4.13 and 4.65 respectively. Despite these site-specific coefficients, the standardized coefficients still reveal that the inverse of the visibility distance exerts the single strongest influence on the model.

Table 16: I-64 Model Parameters

\begin{tabular}{|l|l|l|l|l|}
\hline \multirow{2}{*}{ Model Elements } & Coefficients & \multirow{2}{*}{ t-statistic } & p-value \\
\cline { 2 - 5 } & Unstandardized & Standardized & & \\
\hline Constant & 62.18 & - & 538.176 & 0.000 \\
\hline Inverse Visibility & -1089 & -.432 & -77.152 & 0.000 \\
\hline Day Night & 5.25 & .341 & 62.787 & 0.000 \\
\hline E101 & 5.84 & .239 & 41.984 & 0.000 \\
\hline W102 & 4.65 & .149 & 26.326 & 0.000 \\
\hline E102 & 4.13 & .130 & 23.094 & 0.000 \\
\hline W99 & -1.52 & -.091 & -15.632 & 0.000 \\
\hline
\end{tabular}

Error! Reference source not found. to Figure 20 show the raw data with the model predictions, separated by site. The adjusted $\mathrm{R}^{2}$ value for this model is 0.500 , which is comparable to the I-77 model. Again, there was a large amount of dispersion in the observations, particularly at low visibility levels, which negatively impacts model fit. Examination of the figures shows that in this case the observed speeds were relatively insensitive to changes in visibility as compared to what was observed on I-77, perhaps due to the commuter driving population and the fog lights at these sites. Speed reductions are observed at lower visibility ranges, but the magnitude of the change is inconsistent. 


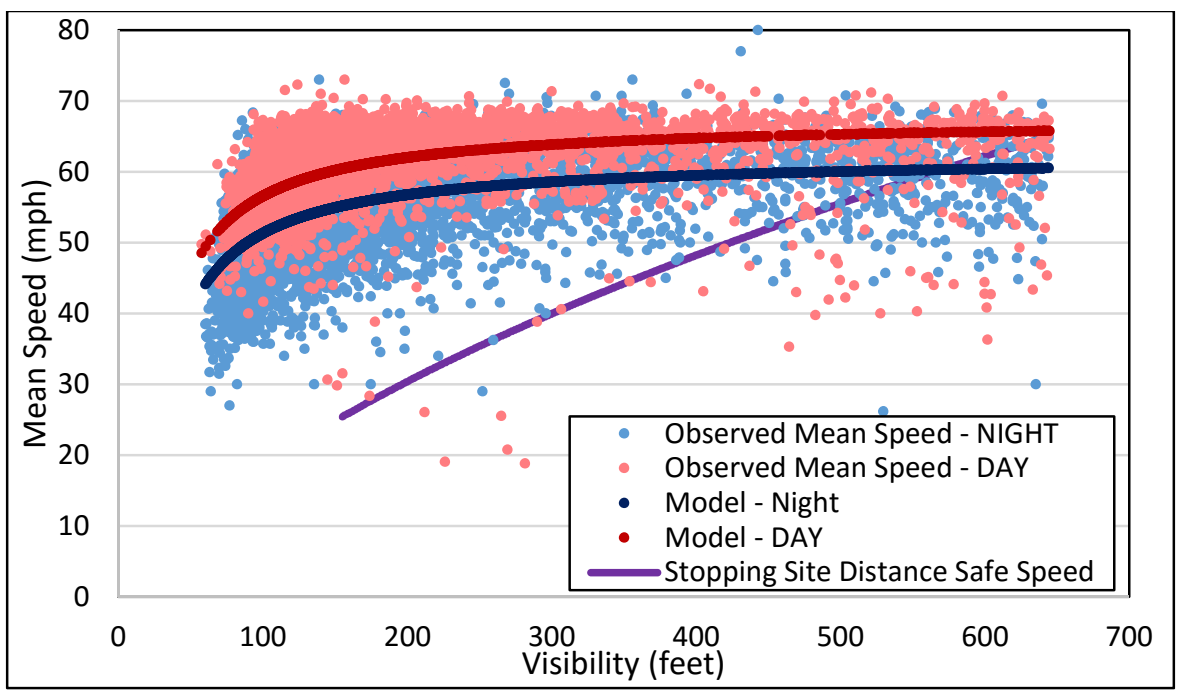

Figure 16: I-64 Models for MP's 98.4 EB, 98.4 WB, 99.9 WB, 101.1 EB

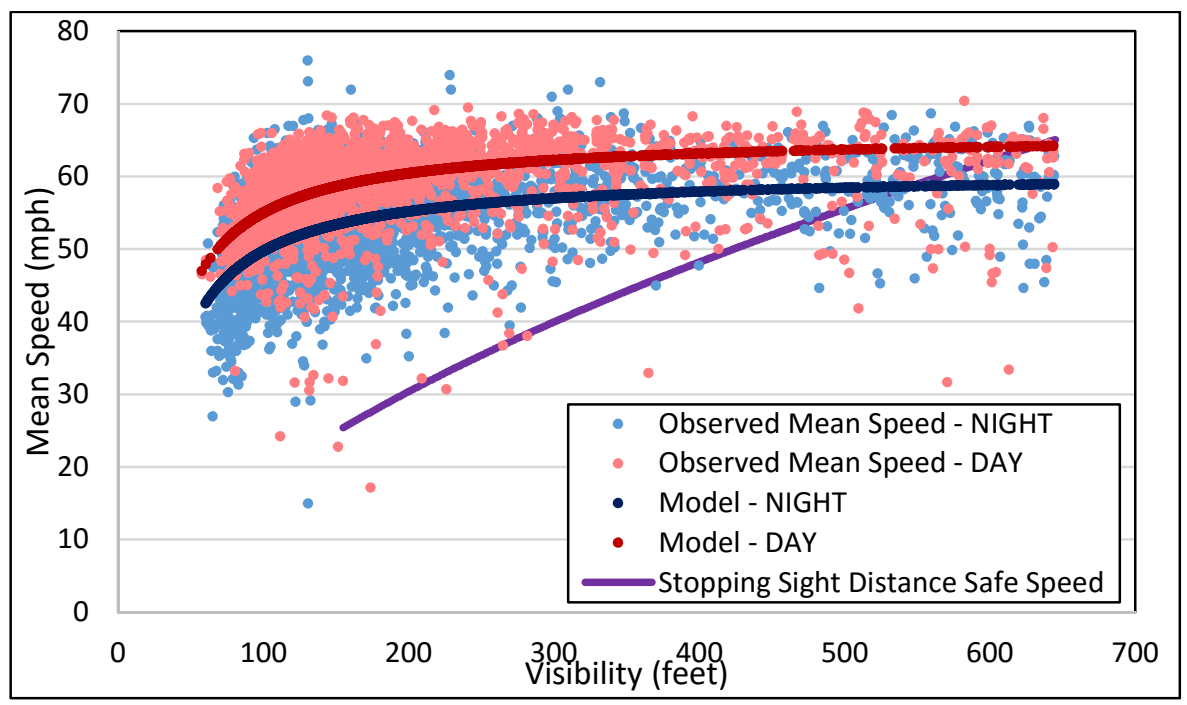

Figure 17: I-64 Model for $99.9 \mathrm{~EB}$

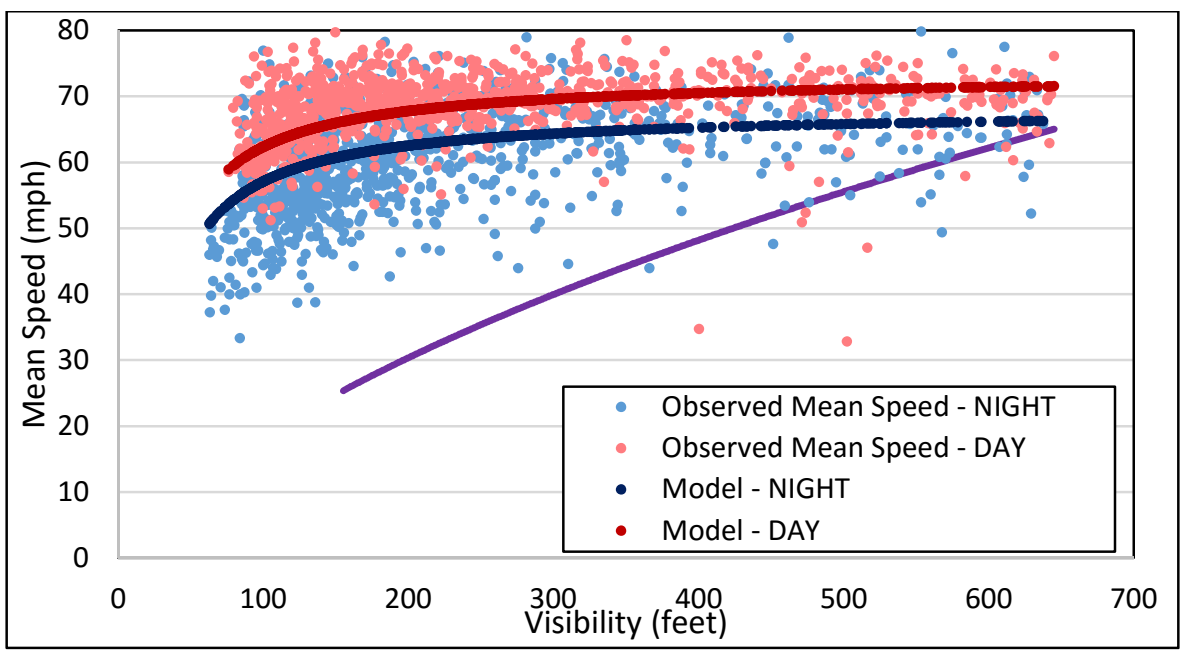

Figure 18: I-64 Model for MP 101.1 EB 


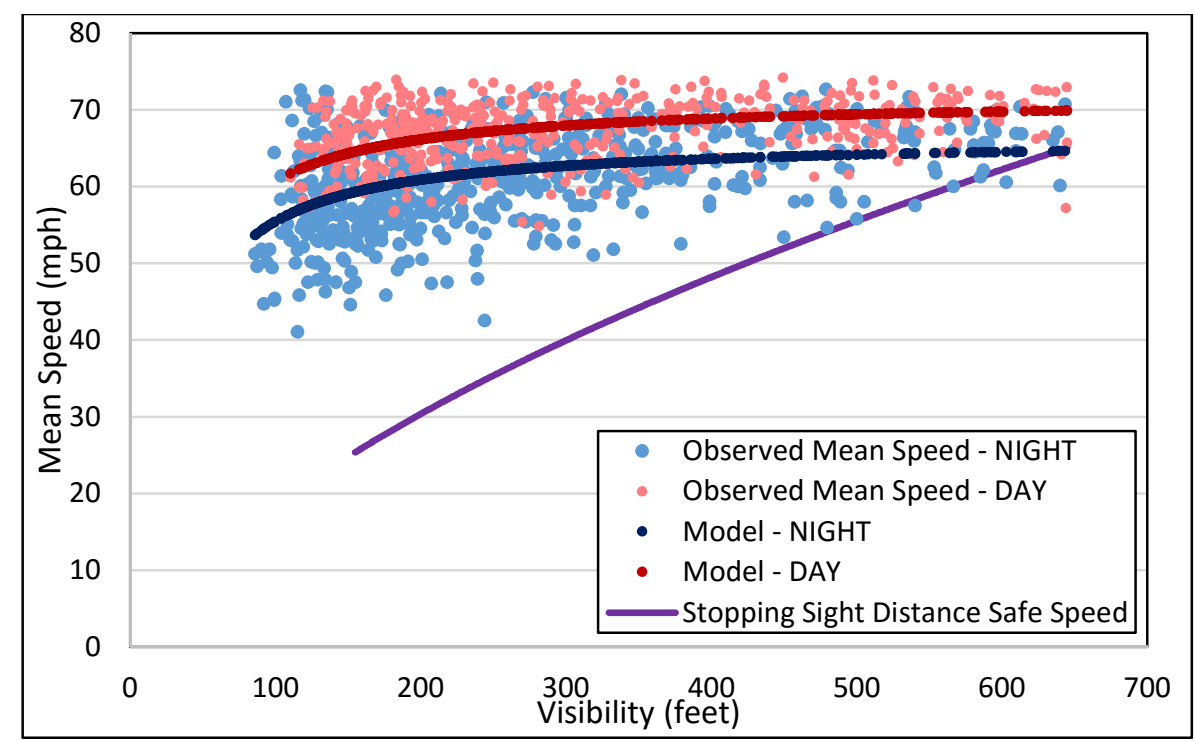

Figure 19: I-64 Model for MP 102.1 EB

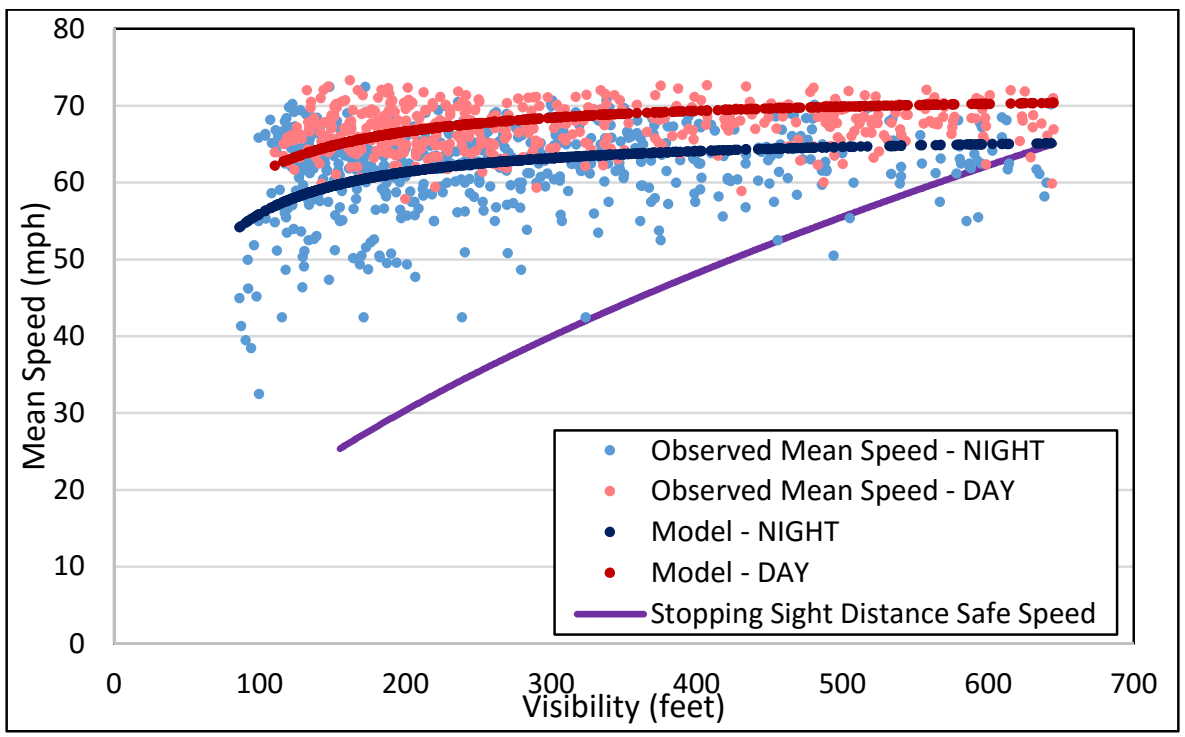

Figure 20: I-64 Model for 102.1 WB

The speed-visibility relationship in time at adjacent sites was analyzed in the same way as I-77. A review of multiple low visibility events did not reveal any speed relationship that was masked by the model coefficients like I-77 dataset. One observation from the time plots was the inconsistency in the RWIS visibility data. A sample plot of a low visibility event for I-64 westbound is shown in Error! Reference source not found.. As noted earlier, the grade impacts on I-64 exerted differential impacts depending on whether traffic was going uphill or downhill, so speeds along the route were influenced by geometric as well as visibility factors. Error! Reference source not found. shows that the visibility readings at MP 101 often fluctuated significantly, with no corresponding change in mean speed. It is unclear whether these fluctuations are a result of sensor data quality limitations or true changes in visibility. 


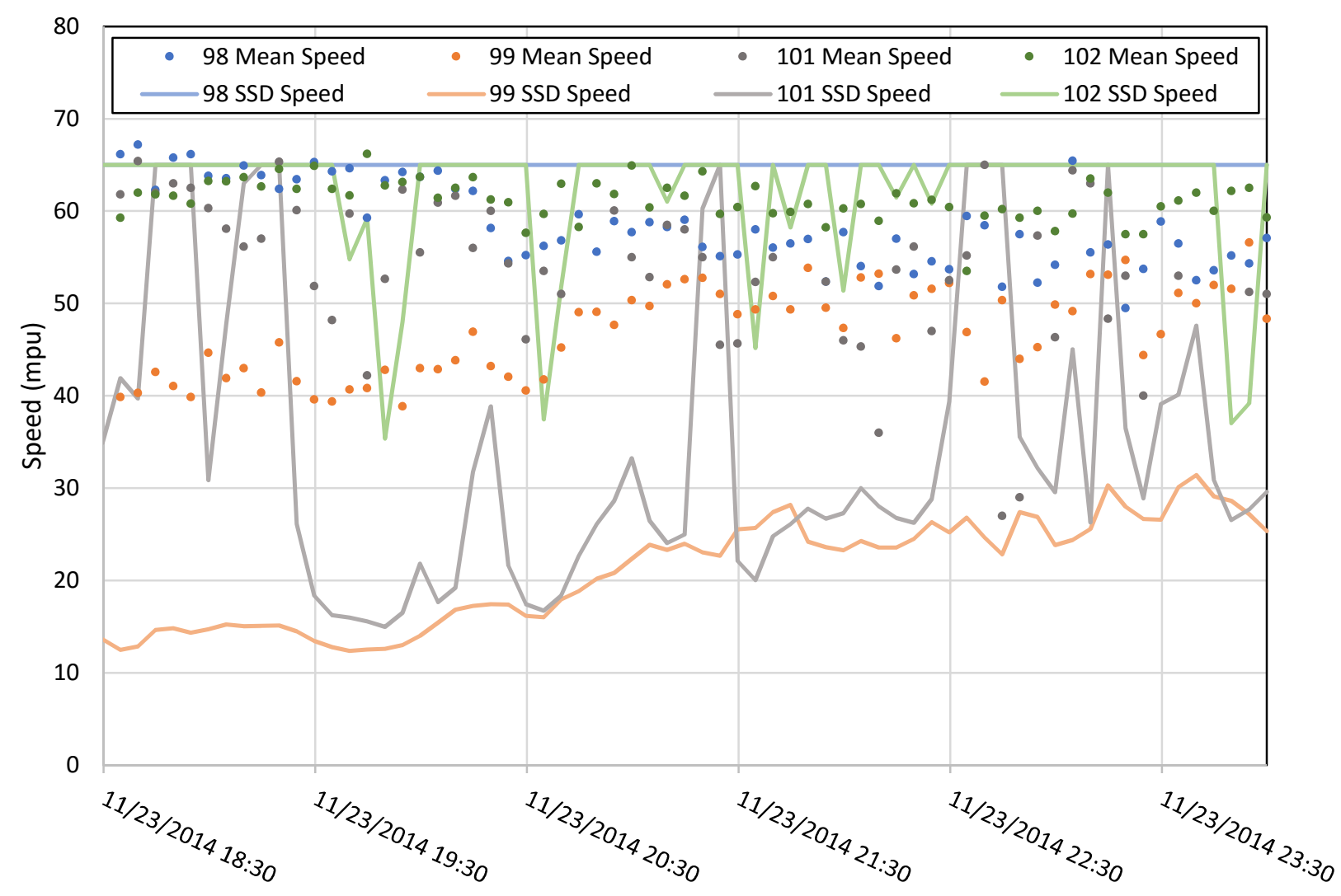

Figure 21: I-64 Westbound Low Visibility Event

\subsubsection{Generalized Linear Model}

Despite having a better model fit than I-77, the I-64 model showed a lack of sensitivity as a function of visibility. Visual inspection of the I-64 models shows that the mean speed curves are very flat, except in the very low visibility cases. To better understand the relationship between mean speed and visibility a generalized linear model was developed using the I-64 dataset. The ANOVA table revealed that all variables and all interaction variables are significant (Table 17). Pairwise comparisons using Tukey's LSD test by visibility bin and site were performed to determine the relative sensitivity of mean speeds. The results are shown in 
Table 18. The shaded boxes show which bins are significantly different from the other bins at that site. The analysis revealed than at all sites except MP 102 westbound, mean speeds in the lowest visibility bin were significantly different than means speeds in all other visibility bins. In general only visibility less than 155 to 250 feet shows a significant reduction in vehicles speeds versus clear conditions. As a result, it appears that drivers on Afton Mountain were less sensitive to changes in visibility than drivers on I-77.

Table 17: ANOVA Table for I-64 Generalized Linear Model

\begin{tabular}{|l|c|c|c|c|c|}
\hline \multicolumn{1}{|c|}{ Model Elements } & $\begin{array}{c}\text { Sum of } \\
\text { Squares }\end{array}$ & $\begin{array}{c}\text { Degrees of } \\
\text { Freedom }\end{array}$ & $\begin{array}{c}\text { Mean } \\
\text { Square }\end{array}$ & F & Sig. \\
\hline Corrected Model & 465201 & 77 & 6041.583 & 193.051 & 0.000 \\
\hline Intercept & 9068790.790 & 1 & 9068790.790 & 289781.095 & 0.000 \\
\hline Visibility Bin & 15583.088 & 4 & 3895.772 & 124.484 & 0.000 \\
\hline Site & 80655.654 & 7 & 11522.236 & 368.178 & 0.000 \\
\hline Day/Night & 16559.309 & 1 & 16559.309 & 529.131 & 0.000 \\
\hline Vis Bin * Site & 6672.511 & 28 & 238.304 & 7.615 & 0.000 \\
\hline Vis Bin * Day/Night & 3186.189 & 4 & 796.547 & 25.453 & 0.000 \\
\hline Site* Day/Night & 1807.503 & 7 & 258.215 & 8.251 & 0.000 \\
\hline Vis Bin * Site* Day/Night & 1215.994 & 26 & 46.769 & 1.494 & 0.051 \\
\hline Error & 531144.095 & 16972 & 31.295 & - & - \\
\hline Total & 59486486.57 & 17050 & - & - & - \\
\hline Corrected Total & 996345.985 & 17049 & - & - & - \\
\hline
\end{tabular}


Table 18: I-64 Generalized Linear Model Compare Means

\begin{tabular}{|c|c|c|c|c|c|c|}
\hline \multirow[b]{2}{*}{ Site } & \multirow[b]{2}{*}{$\begin{array}{l}\text { Visibility } \\
\text { Bin }\end{array}$} & \multirow[b]{2}{*}{ Mean } & \multirow{2}{*}{$\begin{array}{l}\text { Std. } \\
\text { Error }\end{array}$} & \multicolumn{2}{|c|}{ 95\% Confidence Interval } & \multirow[b]{2}{*}{$\begin{array}{l}\text { Significantly Different } \\
\text { From }\end{array}$} \\
\hline & & & & Lower Bound & Upper Bound & \\
\hline \multirow{5}{*}{$98 \mathrm{~EB}$} & $495-645$ & 60.493 & .610 & 59.296 & 61.689 & $<155$ \\
\hline & $360-495$ & 61.516 & .660 & 60.222 & 62.810 & $<155$ \\
\hline & $250-360$ & 61.905 & .630 & 60.670 & 63.140 & $<155$ \\
\hline & $155-250$ & 59.419 & 2.012 & 55.475 & 63.363 & $<155$ \\
\hline & $<155$ & 49.375 & 1.552 & 46.333 & 52.416 & All Others \\
\hline \multirow{5}{*}{$98 \mathrm{WB}$} & $495-645$ & 61.243 & .610 & 60.047 & 62.440 & $<155$ \\
\hline & $360-495$ & 61.888 & .660 & 60.594 & 63.182 & $<155$ \\
\hline & $250-360$ & 61.682 & .631 & 60.445 & 62.920 & $<155$ \\
\hline & $155-250$ & 63.563 & 2.012 & 59.619 & 67.507 & $<155$ \\
\hline & $<155$ & 50.986 & 1.552 & 47.944 & 54.027 & All Others \\
\hline \multirow{5}{*}{$99 \mathrm{~EB}$} & $495-645$ & 61.507 & .358 & 60.805 & 62.209 & $155-250,<155$ \\
\hline & $360-495$ & 62.521 & .342 & 61.850 & 63.192 & $155-250,<155$ \\
\hline & $250-360$ & 61.793 & .246 & 61.310 & 62.276 & $155-250,<155$ \\
\hline & $155-250$ & 59.701 & .153 & 59.401 & 60.002 & All Others \\
\hline & $<155$ & 54.570 & .109 & 54.356 & 54.784 & All Others \\
\hline \multirow{5}{*}{$99 \mathrm{WB}$} & $495-645$ & 59.742 & .357 & 59.041 & 60.442 & $155-250,<155$ \\
\hline & $360-495$ & 59.999 & .343 & 59.326 & 60.671 & $155-250,<155$ \\
\hline & $250-360$ & 59.391 & .246 & 58.909 & 59.873 & $155-250,<155$ \\
\hline & $155-250$ & 57.573 & .153 & 57.272 & 57.874 & All Others \\
\hline & $<155$ & 53.540 & .109 & 53.326 & 53.754 & All Others \\
\hline \multirow{5}{*}{$101 \mathrm{~EB}$} & $495-645$ & 67.362 & .460 & 66.461 & 68.264 & $155-250,<155$ \\
\hline & $360-495$ & 67.538 & .448 & 66.660 & 68.416 & $155-250,<155$ \\
\hline & $250-360$ & 67.591 & .326 & 66.952 & 68.229 & $155-250,<155$ \\
\hline & $155-250$ & 65.799 & .236 & 65.337 & 66.261 & All Others \\
\hline & $<155$ & 60.858 & .212 & 60.443 & 61.274 & All Others \\
\hline \multirow{5}{*}{$101 \mathrm{WB}$} & $495-645$ & 60.213 & .431 & 59.367 & 61.058 & $<155$ \\
\hline & $360-495$ & 60.619 & .433 & 59.770 & 61.467 & $<155$ \\
\hline & $250-360$ & 60.698 & .319 & 60.072 & 61.324 & $<155$ \\
\hline & $155-250$ & 59.821 & .225 & 59.379 & 60.262 & $<155$ \\
\hline & $<155$ & 55.890 & .192 & 55.513 & 56.267 & All Others \\
\hline \multirow{5}{*}{$102 \mathrm{~EB}$} & $495-645$ & 67.479 & .529 & 66.442 & 68.515 & $250-360,155-250,<155$ \\
\hline & $360-495$ & 66.929 & .445 & 66.057 & 67.801 & $250-360,155-250,<155$ \\
\hline & $250-360$ & 65.048 & .373 & 64.316 & 65.780 & All Others \\
\hline & $155-250$ & 62.913 & .299 & 62.328 & 63.499 & All Others \\
\hline & $<155$ & 61.364 & .442 & 60.497 & 62.231 & All Others \\
\hline \multirow{5}{*}{$102 \mathrm{WB}$} & $495-645$ & 65.850 & .509 & 64.852 & 66.849 & $155-250,<155$ \\
\hline & $360-495$ & 65.416 & .434 & 64.566 & 66.266 & $<155$ \\
\hline & $250-360$ & 65.257 & .366 & 64.541 & 65.974 & $<155$ \\
\hline & $155-250$ & 64.094 & .299 & 63.508 & 64.679 & $495-645$ \\
\hline & $<155$ & 63.653 & .442 & 62.786 & 64.520 & $\begin{array}{c}495-645,360-495,250- \\
360 \\
\end{array}$ \\
\hline
\end{tabular}




\subsection{SUMMARY OF RESULTS}

Crashes are the most obvious measure of traffic safety. A review of the crash history on I-77 supported the research performed by AAA Foundation that crashes in low visibility are more likely to be severe and involved multiple vehicles. Crashes in visibility less than 645 feet represent $11 \%$ of crashes between 2010 and 2014 on I-77. The crash rate calculations further support the findings that crashes are significant problem in low visibility on I-77 particularly in visibility less than 250 feet. Crash history on I-64 does not reveal the same trends: none of the crashes that occurred in low visibility were rear-end collisions and none involved multiple vehicles. Possible explanations for the different crash characteristics will be discussed further in Chapter 6.

Data from both the I-77 and I-64 sites showed that vehicle speed was inversely correlated with the available visibility distance, but the data also indicated that drivers also did not travel at a speed that was appropriate based on SSD values. In the worst visibility cases, drivers are driving as much as $35 \mathrm{mph}$ faster than the safe speed. Another interesting phenomenon observed on I-77 was that speed choice seemed to be relatively consistent between adjacent stations, even if visibility was changing. This may indicate that drivers do not react quickly to changes in visibility along the corridor.

The low adjusted $\mathrm{R}^{2}$ values for the model are likely due to the wide dispersion in the data, and show the large variability in driver speed choices during fog events, particularly during the worst visibility conditions. Despite being lower than desirable, the model fit does indicate that there is some value in the model and illustrates the relationship between speed choice and visibility. Additional data from other sites with varying characteristics could be used to develop models that isolate the effects of specific geometric or traffic characteristics, eliminating the need for the site indicator variables included here.

These findings show that addressing safety issues related to fog can be very challenging. The data from both sites indicates that drivers do not reduce speeds to an appropriate level based on visibility conditions. Furthermore, the I-64 data shows a less sensitive relationship between visibility distance and speed, possibly indicating that safety countermeasures to improve delineation (like fog lights) could create counterproductive speed impacts.

Design of a VSL system to mitigate fog crashes needs to take these findings into account. It is reasonable to assume that some drivers will comply with whatever is posted on the VSL signs, while others will continue to travel at speeds similar to what was observed without VSLs. If VSLs are set based on a strict SSD criterion, there is the potential to create several cohorts of traffic that are traveling at very different speeds. Large variances between speeds could have a negative safety impact so any VSL algorithm design must consider ways to encourage safer behavior without creating unduly large dispersion in traffic speeds. After the VSL system is installed on I-77, the distribution of speeds will need to be closely monitored to ensure that safety is not compromised. 


\subsection{APPLICATION OF SPEED MODELS TO I-77 VSL ALGORITHM DEVELOPMENT}

The results documented in this chapter served as a key input into the development of the algorithm that is being implemented on I-77. The existing driver behavior on the corridor in low visibility was reviewed by the VDOT VSL Technical Committee to aid the development process. A concern of the committee was that posting of a safe speed that is too low to be respected by drivers could create significant speed variation and more safety concerns. Therefore, it was determined that the algorithm should incorporate a model of pre-ATSMS driver behavior.

The initial algorithm takes the mean speed of traffic, visibility, and a day/night binary variable as inputs and used the MP 6.6 model as the baseline. The algorithm divides the visibility into three cases: stopping sight distance (SSD) safe speed between 50 and $65 \mathrm{mph}$ (Case 1), SSD safe speed between 40 and $50 \mathrm{mph}$ (Case 2), and SSD safe speed less than $40 \mathrm{mph}$ (Case 3). For case 1, the model speed is used if the mean speed of traffic is greater than the model speed. Otherwise, the algorithm outputs whichever is greater between the SSD speed and the mean speed of traffic. The same process is used for the other cases, however, Case 2 replaces the model speed with the model speed minus $5 \mathrm{mph}$ and Case 3 replaces the model speed with the model speed minus $10 \mathrm{mph}$. This help bridge the gap between SSD speed and model speed. A visual representation of this is shown in Figure 22. This algorithm uses the model for I-77 MP 6.6 as this is the best representation of the worst visibility conditions on the corridor. The day model or the night model is used depending on binary day/night variable input to the algorithm. As Figure 22 shows, the initial algorithm essentially splits the difference between observed pre-VSL drive behavior and desirable speeds based on SSD.

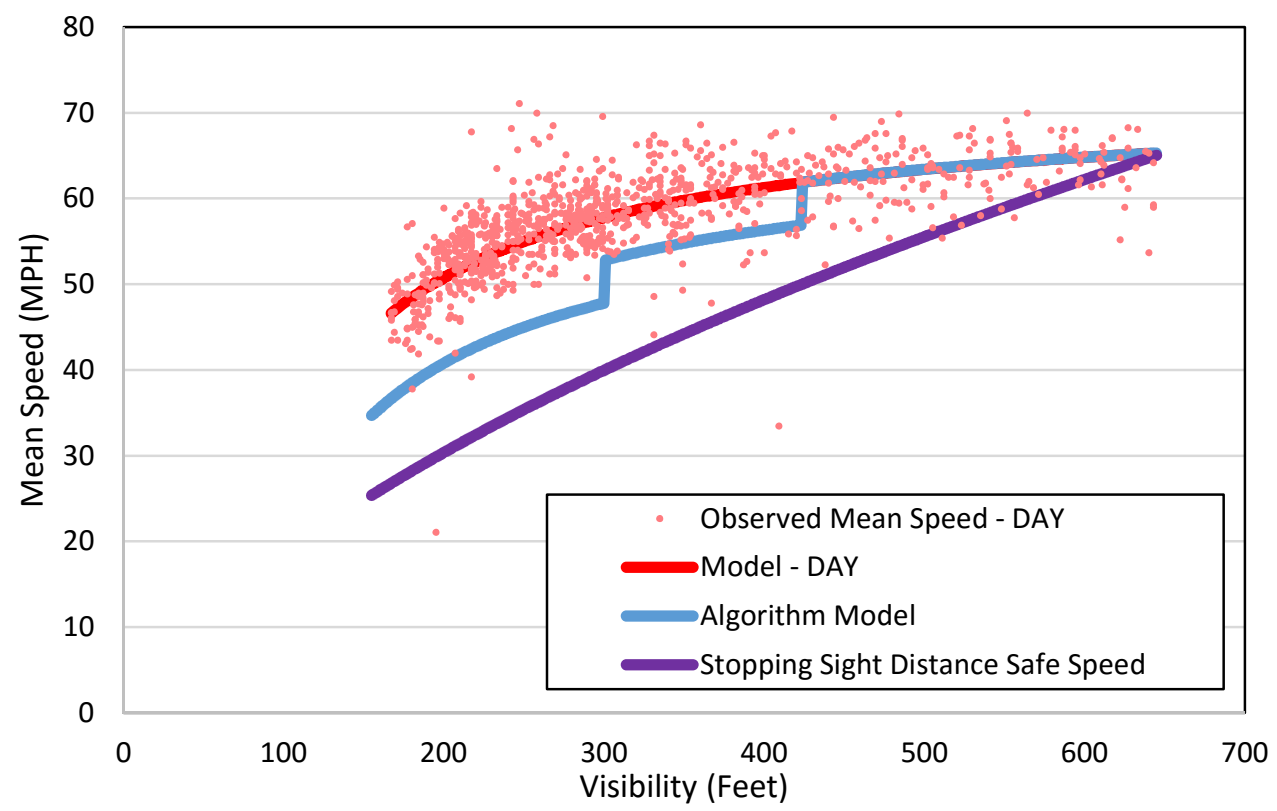

Figure 22: Algorithm Model

The process for determining the posted speed limit for any given sign is such that visibility will be read by the RWIS stations and this visibility value goes into the algorithm and a recommended speed is output for a given sign. Then a smoothing and trooping algorithm 
developed by the VSL vendor is applied to the corridor so that no the maximum step between adjacent signs is $15 \mathrm{MPH}$. For smoothing, the step down process is dictated by the sign recommending the lowest speed output from the algorithm. It was determined by the committee that there would not be a step up out of the low visibility; in clear conditions downstream of low visibility, the speed limit would be posted at $65 \mathrm{MPH}$. Future research will assess the effectiveness of the system and refine the algorithm depending on how drivers respond to the VSL. 


\section{CHAPTER 6: CONCLUSIONS AND RECOMMENDATIONS}

\subsection{CONCLUSIONS AND DISCUSSION}

\subsubsection{Crash Analysis}

The crash analysis on I-77 supported research performed by the AAA Foundation that crashes in low visibility are more likely to be severe and involve multiple vehicles (Hamilton et al., 2014). In general, the crash results on I-77 revealed that the presence of any fog that restricts visibility below SSD has an effect on safety, as there is a change in crash characteristics between clear conditions and the highest visibility bins. It then appears that crash characteristics change further when visibility dropped below 360 feet. The proportion of rear-end crashes and crashes involving multiple vehicles both increases, and crash rates were also extremely high in the 155 to 250 feet visibility range. Unfortunately, due to the limited visibility data on I-64 a detailed crash analysis was not performed. Qualitative analysis of the crashes during the six months of visibility available did not reveal the same crash trends as I-77. While it is difficult to draw many conclusions due to the small sample size on I-64, it is possible that the fog lights decrease the likelihood of rear-end and multiple vehicle crashes in low visibility thus improving safety. Similarly, the regular commuter traffic may play a role in the crash history as the regular commuters are used to driving in low visibility.

While the differential between safe speed and observed speed implies that driver behavior in low visibility is less safe on I-64, crash analysis suggests that this is not the case. Crash analysis on I-64 from July 1, 2014 to December 31, 2014 did not reveal the same crash trends found on I-77. The crash history on I-77 supported past research that crashes in low visibility are more likely to be severe and involved multiple vehicles. It's possible that the same hypotheses regarding the model difference can be applied to the crash analysis. This suggests that while the fog lights do not lead to decreases mean speeds, they do have an effect on crashes.

\subsubsection{Driver Speed Choice}

Mean speed and modeling at all sites reveals that there is a relationship between speed and visibility such that as visibility decreases, mean speed also decreases. The exact nature of this relationship is different for each site. At all sites, there is a differential between mean speed and safe speed, particularly in the lowest visibility bins.

Speed analysis on I-77 revealed that mean speeds exceeded safe speeds in all low visibility bins. Means speeds were in excess of $45 \mathrm{mph}$ when the safe speed was less than 25 mph. At MP 6.6 where the visibility was most severe more than $75 \%$ of vehicles exceeded the safe speed in all low visibility bins with $98 \%$ exceeding SSD speed in visibility below 360 feet. At MP 6.6 mean speed differential between lanes in all low visibility bins was found to be statistically different from differentials in clear conditions suggesting that there is a higher potential for conflict between vehicles in adjacent lanes. Hypothesis testing on the standard deviation of speeds in each visibility bin found that no standard deviation in reduced visibility was statistically different from that during clear conditions. This indicates that speed variance did not increase as visibility decreased. 
Speed analysis on I-64 also showed that means speeds exceeded safe speeds in all low visibility bins. Observed mean speeds on I-64 were less sensitive to changes in visibility than means speeds on I-77. At MP 101.1 EB speeds are greater than $60 \mathrm{mph}$ when the safe speed is less than $25 \mathrm{mph}$. Results from the lane differential analysis were mixed on I-64. At MP's 98.4 eastbound and westbound and MP 99.9 eastbound mean speed differential by lane in low visibility was not found to be statistically different than the differential in clear conditions while at the other sites at least one low visibility bin was statistically different from clear conditions. It's possible that differing grade could play a role in accounting for the difference between sites. In all reduced visibility bins, at least $74 \%$ of drivers are exceeding the stopping sight distance safe speed. In the lowest visibility bin nearly every vehicle is exceeding the stopping sight distance safe speed. Standard deviation in every low visibility bin was not found to be statistically different from standard deviation in clear conditions at MP 98.4 eastbound and westbound which is consistent with the findings on I-77 that speed variance does not increase as visibility decreases. Results differ at MP 102.1 where standard deviation is found to be different form clear condition in nearly every low visibility bin.

Speed choice behavior differed between the I-77 and I-64 sites, with larger deviations between observed and safe speed occurring on I-64. One theory to account for the difference in behavior is the presence of the fog lights installed on I-64 to delineate the edge of pavement during periods of low visibility. It is possible that these lights provide motorists with an improved feeling of safety which causes them to drive faster. A similar phenomenon occurs with application of permanent raised pavement makers (Behar et al., 2004). A human factors review of permanent raised pavement markers on two-lane roads and multilane freeways found that as the driving workload is decreased due to the improved delineation of the roadway, the drivers would compensate by increasing speed (Behar et al., 2004). It is possible that a similar compensation is happening on I-64 due to the fog lights. In this case, it is possible that the fog light safety countermeasure may actually be causing drivers to travel at higher speeds than they would if the lights were not present.

Another hypothesis is that difference in speed could be due to the differing driver populations on the two routes. According to VDOT Regional Operations staff, the I-64 site contained a higher proportion of regular commuters who are familiar with the recurring low visibility conditions on the corridor and may drive with a heightened sense of confidence compared to the motorists on I-77, who may be traveling the road for the first time. A simulator study found that in low-visibility conditions, driver behavior could be categorized into two groups, drivers who chose not to maintain visual contact with the vehicle ahead and drivers who maintain visual contact with a lead vehicle (Broughton et al., 2007). While the sample size for this study was small, analysis found that $75 \%$ of the vehicles chose to maintain visual contact with the lead vehicle, even if the speed and headway associated with this following behavior compromised safety (Broughton et al., 2007). It is possible that this behavior is more prevalent in regular commuting traffic, supporting the higher speeds at the I-64 model. The higher speeds during low visibility on I-64 indicate that implementing a VSL system may be more challenging at this site. Motorists on I-77 appear to be naturally reducing speed more than motorists on I-64, making this site an easier pilot site of the VSL system although there is still a significant disparity between current driver behavior and the SSD safe speed. 


\subsection{RECOMMENDATIONS}

Based on the results of this study, several recommendations can be made:

1. Future VSL deployments should incorporate current driver behavior to increase the likelihood of compliance. The results from this research show that posting the stopping sight distance safe speed as the speed limits would likely result in significant noncompliance. The models and mean speeds show that it is the natural tendency of drivers to slow in low visibility, although that they still drive much faster than the stopping sight distance safe speed. Therefore, many drivers will likely not respect a posted speed limit of the SSD safe speed. For the VSL system to improve safety, it is crucial the speed limit be respected elsewise speed variance could be an issue. Future visibility controlled variable speed limit systems should consider the lessons in driver behavior taken from this research and incorporate it into their own algorithms.

2. The proposed VSL algorithm should be monitored following activation to ensure that drivers are complying with the speed limit. The modeling showed significant differences between the SSD safe speed and the actual operating speeds on the roadway. The proposed VSL algorithm attempts to find an intermediate speed between the current operating speed in fog and the desired safe speed. Driver speed choice must be monitored following system activation to determine whether the system is positively impacting driver behavior. Lane differentials and standard deviation should also be monitored to determine the effects of the VSL system on speed variance.

3. If drivers comply with the VSLs following activation, the algorithm should be modified to move it closer to the SSD speed. The initial algorithm incorporates the model that represent driver behavior without any speed guidance. After the system is activated, new models should be developed to represent the driver behavior with guidance from VSL signs. With a regular commuter population the algorithm this could be an iterative process influencing driver behavior until it is near SSD speed. It may not be possible to influence behavior that much with non-regular traffic who are unfamiliar with driving in low visibility or VSL systems but speeds should be monitored and the algorithm adjusted when necessary.

4. If the I-77 system provides a benefit, VDOT should consider deploying VSLs on Afton Mountain. The I-77 ATSMS is serving as a pilot for weather controlled VSL systems in Virginia. This research shows that the fog on Afton Mountain is more severe speeds are less sensitive to changes in visibility than I-77 indicating that I-64 may benefit from a VSL system. Because of the speed insensitivity to visibility there is even more concern that motorists will not respect reduced speed limits. Algorithm development will be critical for the success of a system on Afton Mountain. Lessons learned from the I-77 VSL system algorithm should applied to any future weather controlled VSL system in Virginia. 
5. Safety in the worst visibility conditions should be carefully monitored. Results from this research shows that the most critical safety concerns occur when visibility is less than 250 feet. For this reason, crashes and speeds should be monitored when visibility is below this threshold to determine the effects of the VSL system on safety. Some of the visibility controlled VSL systems that were reviewed for this system shut the highway down when visibility fell below a certain threshold. If the VSL system does not improve safety when visibility is below a given threshold, then the operators for the I-77 should consider closing the interstate to traffic for safety reasons.

\subsection{FUTURE RESEARCH}

The next phase of this research would be to collect speed, volume, and crash data on I-77 after the ATSMS is activated and to evaluate the effectiveness of the variable speed system on driver behavior. The weather controlled VSL system on I-77 is serving as a pilot for Virginia. The results of a safety of effectiveness evaluation of this system would serve to determine whether I-64 would benefit from a similar system.

More detailed crash analysis for I-64 would be useful to evaluate the effects of the fog lights on crashes. Visibility and crashes from a longer period would allow for a more robust analysis like the analysis performed on I-77. The 6 months of crashes did not support the past research like was seen in the I-77 crash history; however, it's possible that with more data similar trends would emerge.

It has been hypothesized that differences in driver behavior between I-64 and I-77 can be accounted for by presence of fog lights and regular commuter traffic on I-64. The fog lights give drivers a sense of comfort and may cause them to drive faster than visibility conditions dictate. Regular commuters beome accustomed to driving in low visibility and feel more comfortable driving in fog causing them not to decrease speed as much as an unfamiliar driving population. Additional human factors studies of commuter vs. non-local drivers might help illuminate differences in driver responses. 


\section{REFERENCES}

Abdel-Aty, M., Ekram, A. A., Huang, H., \& Choi, K. (2011). A study on crashes related to visibility obstruction due to fog and smoke. Accident Analysis and Prevention, 43(5), 17301737. doi:10.1016/j.aap.2011.04.003

Active Traffic \& Safety Management System for Interstate 77 in Virginia. (2015). VDOT Southwest Regional Operations.

Behar, G., Mollett, C., Persaud, B., Lyon, C., Smiley, A., Smahel, T., \& McGee, H. (2004). Safety of Permanent Raised Pavement Markers. Transportation Research Record, NCHRP(518), 40-43.

Belz, N. P., \& Garder, P. E. (2010). Maine Statewide Deployment and Integration of Advanced Traveler Information Systems. Transportation Research Record, 2129, 16-23.

Brooks, J. O., Crisler, M. C., Klein, N., Goodenough, R., Beeco, R. W., Guirl, C., ... Beck, C. (2011). Speed choice and driving performance in simulated foggy conditions. Accident Analysis and Prevention, 43(3), 698-705.

Broughton, K. L. M., Switzer, F., \& Scott, D. (2007). Car following decisions under three visibility conditions and two speeds tested with a driving simulator. Accident Analysis and Prevention, 39(1), 106-116.

Buddemeyer, J., Young, R. K., \& Dorsey-Spitz, B. (2011). Rural Variable Speed Limit System for Southeast Wyoming. Transportation Research Record, 2189, 37-44.

DMS Site Activation Status Diagram. (2015). VDOT Southwest Regional Operations.

Goodwin, L. C. (2002). Analysis of Weather-Related Crashes on U . S . Highways.

Goodwin, L. C. (2003a). Best Practices for Road Weather Management Best Practices for Road Weather Management.

Goodwin, L. C. (2003b). Weather-Related Crashes on Slick Pavement Weather-Related Crashes in Adverse Weather.

Hamilton, B., Tefft, B., Arnold, L., \& Grabowski, J. (2014). Hidden Highways: Fog and Traffic Crashes on America's Roads. Washington, DC.

Hogema, J., \& van der Horst, R. (1994). Evaluation of A16 Motorway Fog-Signaling System with Respect to Driving Behavior. Transportation Research Record, 1573, 63-67.

Jarlebring, I. (2009). Road weather controlled variable speed limits, Sweden.

Jensen, G. A. (1995). Intelligent Transportation Systems: I-75 Fog Detection/Warning System.

Kang, J. J., Ni, R., \& Andersen, G. J. (2008). Effects of Reduced Visibility from Fog on CarFollowing Performance. Transportation Research Record, 2069, 9-15. doi:10.3141/206902

Kimley-Horn. (2014). Sythesis of Practice for Weather-Related Variable Speed Limit Systems in the United States.

Liang, W. L., Kyte, M., Kitchener, F., \& Shannon, P. (1998). Effect of Environmental Factors on Driver Speed: A Case Study. Transportation Research Record, (1635), 155-161.

Lind, G. (2007). Weather and Traffic Controlled Variable Speed Limits in Sweden. Stockholm, 
Sweden.

Lindkvist, A., \& Landerfors, L.-O. (2008). Variable Speed Limites - A Bright Idea. Stockholm, Sweden.

NY Daily News. (2013). Three Dead After 95-Car Pileup Near Va.-N.C. Border. Retrieved July 7, 2015, from http://www.nydailynews.com/news/national/dead-75-car-pileup-va-n-borderarticle-1.1303988

Perrin, J., Martin, P. T., \& Cottrell, W. (2003). Effects of Variable Speed Limit Signs on Driver Behavior During Inclement Weather. Salt Lake City, Utah.

Pisano, P. A., Goodwin, L. C., \& Rossetti, M. A. (2000). U.S. Highway Crashes in Adverse Road Weather Conditions.

Rämä, P. (1999). Effects of Weather-Controlled Variable Speed Limits and Warning Signs on. Transportation Research Record, 1689, 53-59.

Robinson, M. R. (2002). Safety Applications of ITS in Rural Areas. McLean, Virginia.

Snowden, R. J., Stimpson, N., \& Ruddle, R. A. (1998). Speed perception fogs up as visibility drops. Nature, 392(6675), 450. doi:10.1038/33049

Ulfarsson, G. F., Shankar, V. N., Vu, P., Mannering, F. L., Boyle, L. N., \& Morse, M. H. (2002). In-Vehicle Signing and Variable Speed Limit Evaluation. Seattle.

Vaisala Visibility Sensors PWD10, PWD20 and PWD20W. (2015). Retrieved January 1, 2015, from http://www.vaisala.com/en/products/visibilitysensors/Pages/PWD1020W.aspx 


\section{APPENDICES}

\section{APPENDIX A: PUBLICATIONS \& PRESENTATIONS}

\section{Journal Papers}

McCann, K. and Fontaine, M.D. Assessing Driver Speed Choice in Fog Using Visibility Data from Road Weather Information Systems. Submitted to Transportation Research Record: Journal of the

Transportation Research Board. (Accepted for publication, publication pending).

\section{Conference Proceedings}

McCann, K. and Fontaine, M.D. Examination of the Safety Impacts of Varying Fog Densities: A Case Study of I-77 in Virginia. In Transportation Research Board 95th Annual Meeting Compendium of Papers, Washington D.C., January 2016.

McCann, K., and Fontaine, M.D. Assessing Driver Behavior in Fog Using RWIS Visibility Data. ITSAmerica Annual Meeting Proceedings, Pittsburgh, PA, June 2015.

\section{Presentations}

"Evaluation of Driver Behavior in Low Visibility Conditions on I-77 in Southwest Virginia", VASITE Spring Meeting, Charlottesville VA, 2015.

"Assessing Driver Behavior in Fog Using RWIS Visibility Data", ITS America Conference, Pittsburgh PA, 2015.

"Examination of the Safety Impacts of Varying Fog Densities: A Case Study of I-77 in Virginia", Poster Personation. TRB Annual Meeting, Washington D.C., 2016

"Assessing Driver Speed Choice in Fog Using Visibility Data from Road Weather Information Systems”, Podium Presentation. TRB Annual Meeting, Washington D.C., 2016. 
APPENDIX B: ADDITIONAL TABLES

Table B1: Hypothesis Testing

\begin{tabular}{|c|c|c|c|c|c|c|c|c|c|c|c|c|c|c|c|c|c|}
\hline \multirow{2}{*}{ Site } & \multirow{2}{*}{ Visibility Bin } & \multicolumn{3}{|c|}{ Low Visibility } & \multicolumn{3}{|c|}{ Clear Conditions } & \multicolumn{3}{|c|}{$\begin{array}{c}\text { Hypothesis Test: } \mathrm{H}_{0}: \\
\text { mean }_{\text {low visibility }}=\text { mean }_{\text {clear conditions }}\end{array}$} & \multicolumn{2}{|c|}{$\begin{array}{c}\text { Low } \\
\text { Visibility }\end{array}$} & \multicolumn{2}{|c|}{$\begin{array}{c}\text { Clear } \\
\text { Conditions }\end{array}$} & \multicolumn{3}{|c|}{$\begin{array}{c}\text { Hypothesis Testing } \mathrm{H}_{0}: \\
\text { variance }_{\text {low vis }}=\text { variance clear }\end{array}$} \\
\hline & & Mean & SD & $\mathrm{N}$ & Mean & SD & $\mathrm{N}$ & $\begin{array}{c}\mathrm{Z} \\
\text { critical } \\
\end{array}$ & $\mathrm{Z}$ test & Results & SD & $\mathrm{N}$ & SD & $\mathrm{N}$ & $\begin{array}{c}\mathrm{F} \\
\text { critical }\end{array}$ & $\begin{array}{c}\mathrm{F} \\
\text { test }\end{array}$ & Results \\
\hline \multirow{5}{*}{$\begin{array}{l}1-77 \\
5.3 S\end{array}$} & 495 to $645 \mathrm{ft}$ & 3.2 & 2.7 & 397 & 3.2 & 2.0 & 443 & 1.96 & 0.34 & Fail to Reject & & & & & & & \\
\hline & 360 to $495 \mathrm{ft}$ & 3.6 & 2.7 & 480 & 3.2 & 2.0 & 443 & 1.96 & 2.80 & Reject & & & & & & & \\
\hline & 250 to $360 \mathrm{ft}$ & 3.4 & 4.2 & 187 & 3.2 & 2.0 & 443 & 1.96 & 0.63 & Fail to Reject & & & & & & & \\
\hline & 155 to $250 \mathrm{ft}$ & 6.6 & 4.7 & 14 & 3.2 & 2.0 & 443 & 1.96 & 2.74 & Reject & & & & & & & \\
\hline & $<155 \mathrm{ft}$ & & & & & & & & & & & & & & & & \\
\hline \multirow{5}{*}{$\begin{array}{l}1-77 \\
6.6 S\end{array}$} & 495 to $645 \mathrm{ft}$ & 7.4 & 6.6 & 270 & 5.2 & 5.9 & 1318 & 1.96 & 5.12 & Reject & 9.4 & 250 & 8.7 & 1322 & 1.17 & 1.16 & Fail to Reject \\
\hline & 360 to $495 \mathrm{ft}$ & 7.7 & 6.3 & 442 & 5.2 & 5.9 & 1318 & 1.96 & 7.43 & Reject & 9.1 & 404 & 8.7 & 1322 & 1.14 & 1.10 & Fail to Reject \\
\hline & 250 to $360 \mathrm{ft}$ & 7.2 & 6.6 & 715 & 5.2 & 5.9 & 1318 & 1.96 & 6.94 & Reject & 9.0 & 683 & 8.7 & 1322 & 1.11 & 1.07 & Fail to Reject \\
\hline & 155 to $250 \mathrm{ft}$ & 6.5 & 6.5 & 701 & 5.2 & 5.9 & 1318 & 1.96 & 4.70 & Reject & 9.1 & 737 & 8.7 & 1322 & 1.11 & 1.09 & Fail to Reject \\
\hline & $<155 \mathrm{ft}$ & -1.1 & 1.7 & 2 & 5.2 & 5.9 & 1318 & 1.96 & -5.17 & Reject & 9.4 & 9 & 8.7 & 1322 & 1.88 & 1.16 & Fail to Reject \\
\hline \multirow{4}{*}{$\begin{array}{l}1-77 \\
7.3 S\end{array}$} & 495 to $645 \mathrm{ft}$ & 4.9 & 3.9 & 104 & 3.8 & 3.2 & 849 & 1.96 & 2.71 & Reject & & & & & & & \\
\hline & 360 to $495 \mathrm{ft}$ & 3.9 & 2.8 & 98 & 3.8 & 3.2 & 849 & 1.96 & 0.09 & Fail to Reject & & & & & & & \\
\hline & 250 to $360 \mathrm{ft}$ & 3.1 & 1.8 & 22 & 3.8 & 3.2 & 849 & 1.96 & -1.75 & Fail to Reject & & & & & & & \\
\hline & $\begin{array}{c}155 \text { to } 250 \mathrm{ft} \\
<155 \mathrm{ft}\end{array}$ & & & & & & & & & & & & & & & & \\
\hline \multirow{5}{*}{$\begin{array}{l}\mathrm{I}-64 \\
98 \mathrm{E}\end{array}$} & 495 to $645 \mathrm{ft}$ & 8.0 & 4.4 & 88 & 7.4 & 3.7 & 46491 & 1.96 & 1.22 & Fail to Reject & 8.0 & 100 & 7.7 & 48896 & 1.25 & 1.08 & Fail to Reject \\
\hline & 360 to $495 \mathrm{ft}$ & 7.7 & 4.1 & 80 & 7.4 & 3.7 & 46491 & 1.96 & 0.58 & Fail to Reject & 8.0 & 84 & 7.7 & 48896 & 1.27 & 1.07 & Fail to Reject \\
\hline & 250 to $360 \mathrm{ft}$ & 8.1 & 4.4 & 98 & 7.4 & 3.7 & 46491 & 1.96 & 1.58 & Fail to Reject & 8.2 & 100 & 7.7 & 48896 & 1.25 & 1.13 & Fail to Reject \\
\hline & 155 to $250 \mathrm{ft}$ & 7.9 & 5.8 & 58 & 7.4 & 3.7 & 46491 & 1.96 & 0.62 & Fail to Reject & 8.6 & 59 & 7.7 & 48896 & 1.32 & 1.24 & Fail to Reject \\
\hline & $<155 \mathrm{ft}$ & 8.5 & 2.9 & 12 & 7.4 & 3.7 & 46491 & 1.96 & 1.29 & Fail to Reject & 7.5 & 13 & 7.7 & 48896 & 1.72 & 1.05 & Fail to Reject \\
\hline \multirow{5}{*}{$\begin{array}{l}\mathrm{I}-64 \\
98 \mathrm{~W}\end{array}$} & 495 to $645 \mathrm{ft}$ & 8.7 & 5.6 & 92 & 7.9 & 4.6 & 46415 & 1.96 & 1.36 & Fail to Reject & 9.1 & 100 & 9.0 & 48773 & 1.25 & 1.01 & Fail to Reject \\
\hline & 360 to $495 \mathrm{ft}$ & 8.7 & 4.6 & 76 & 7.9 & 4.6 & 46415 & 1.96 & 1.38 & Fail to Reject & 9.2 & 84 & 9.0 & 48773 & 1.27 & 1.04 & Fail to Reject \\
\hline & 250 to $360 \mathrm{ft}$ & 8.8 & 4.7 & 94 & 7.9 & 4.6 & 46415 & 1.96 & 1.69 & Fail to Reject & 9.2 & 100 & 9.0 & 48773 & 1.25 & 1.03 & Fail to Reject \\
\hline & 155 to $250 \mathrm{ft}$ & 9.2 & 5.2 & 55 & 7.9 & 4.6 & 46415 & 1.96 & 1.79 & Fail to Reject & 9.2 & 59 & 9.0 & 48773 & 1.32 & 1.03 & Fail to Reject \\
\hline & $<155 \mathrm{ft}$ & 10.4 & 6.5 & 12 & 7.9 & 4.6 & 46415 & 1.96 & 1.29 & Fail to Reject & 9.3 & 13 & 9.0 & 48773 & 1.72 & 1.05 & Fail to Reject \\
\hline \multirow{5}{*}{$\begin{array}{l}\mathrm{I}-64 \\
99 \mathrm{E}\end{array}$} & 495 to $645 \mathrm{ft}$ & 5.2 & 3.7 & 232 & 5.1 & 3.2 & 38906 & 1.96 & 0.47 & Fail to Reject & & & & & & & \\
\hline & 360 to $495 \mathrm{ft}$ & 5.2 & 3.6 & 249 & 5.1 & 3.2 & 38906 & 1.96 & 0.37 & Fail to Reject & & & & & & & \\
\hline & 250 to $360 \mathrm{ft}$ & 5.2 & 3.9 & 501 & 5.1 & 3.2 & 38906 & 1.96 & 0.50 & Fail to Reject & & & & & & & \\
\hline & 155 to $250 \mathrm{ft}$ & 5.0 & 4.0 & 1274 & 5.1 & 3.2 & 38906 & 1.96 & -1.47 & Fail to Reject & & & & & & & \\
\hline & $<155 \mathrm{ft}$ & 5.1 & 3.9 & 2619 & 5.1 & 3.2 & 38906 & 1.96 & -0.92 & Fail to Reject & & & & & & & \\
\hline
\end{tabular}




\begin{tabular}{|c|c|c|c|c|c|c|c|c|c|c|c|c|c|c|c|c|c|}
\hline \multirow{5}{*}{$\begin{array}{l}\mathrm{I}-64 \\
99 \mathrm{~W}\end{array}$} & 495 to $645 \mathrm{ft}$ & 7.3 & 4.5 & 229 & 7.8 & 4.4 & 37870 & 1.96 & -1.87 & Fail to Reject & & & & & & & \\
\hline & 360 to $495 \mathrm{ft}$ & 7.2 & 4.2 & 252 & 7.8 & 4.4 & 37870 & 1.96 & -2.55 & Reject & & & & & & & \\
\hline & 250 to $360 \mathrm{ft}$ & 7.4 & 4.2 & 485 & 7.8 & 4.4 & 37870 & 1.96 & -2.49 & Reject & & & & & & & \\
\hline & 155 to $250 \mathrm{ft}$ & 7.2 & 4.4 & 1228 & 7.8 & 4.4 & 37870 & 1.96 & -4.58 & Reject & & & & & & & \\
\hline & $<155 \mathrm{ft}$ & 6.9 & 4.8 & 2511 & 7.8 & 4.4 & 37870 & 1.96 & -9.56 & Reject & & & & & & & \\
\hline \multirow{5}{*}{$\begin{array}{c}\mathrm{I}-64 \\
101 \mathrm{E}\end{array}$} & 495 to $645 \mathrm{ft}$ & 2.4 & 4.9 & 145 & -0.2 & 5.7 & 38902 & 1.96 & 6.19 & Reject & & & & & & & \\
\hline & 360 to $495 \mathrm{ft}$ & 1.8 & 5.3 & 150 & -0.2 & 5.7 & 38902 & 1.96 & 4.54 & Reject & & & & & & & \\
\hline & 250 to $360 \mathrm{ft}$ & 1.3 & 5.7 & 283 & -0.2 & 5.7 & 38902 & 1.96 & 4.36 & Reject & & & & & & & \\
\hline & 155 to $250 \mathrm{ft}$ & 2.3 & 5.5 & 530 & -0.2 & 5.7 & 38902 & 1.96 & 10.11 & Reject & & & & & & & \\
\hline & $<155 \mathrm{ft}$ & 1.8 & 5.1 & 663 & -0.2 & 5.7 & 38902 & 1.96 & 9.84 & Reject & & & & & & & \\
\hline \multirow{5}{*}{$\begin{array}{c}\mathrm{I}-64 \\
101 \mathrm{~W}\end{array}$} & 495 to $645 \mathrm{ft}$ & 6.8 & 5.1 & 158 & 6.5 & 4.7 & 41150 & 1.96 & 0.68 & Fail to Reject & & & & & & & \\
\hline & 360 to $495 \mathrm{ft}$ & 6.7 & 6.1 & 153 & 6.5 & 4.7 & 41150 & 1.96 & 0.32 & Fail to Reject & & & & & & & \\
\hline & 250 to $360 \mathrm{ft}$ & 6.7 & 4.7 & 286 & 6.5 & 4.7 & 41150 & 1.96 & 0.61 & Fail to Reject & & & & & & & \\
\hline & 155 to $250 \mathrm{ft}$ & 6.2 & 5.0 & 564 & 6.5 & 4.7 & 41150 & 1.96 & -1.39 & Fail to Reject & & & & & & & \\
\hline & $<155 \mathrm{ft}$ & 5.9 & 5.0 & 781 & 6.5 & 4.7 & 41150 & 1.96 & -3.31 & Reject & & & & & & & \\
\hline \multirow{5}{*}{$\begin{array}{c}\mathrm{I}-64 \\
102 \mathrm{E}\end{array}$} & 495 to $645 \mathrm{ft}$ & 6.5 & 2.7 & 118 & 5.9 & 3.4 & 46417 & 1.96 & 2.59 & Reject & 7.2 & 119 & 6.5 & 48686 & 1.22 & 1.21 & Fail to Reject \\
\hline & 360 to $495 \mathrm{ft}$ & 6.6 & 3.2 & 150 & 5.9 & 3.4 & 46417 & 1.96 & 2.53 & Reject & 7.1 & 161 & 6.5 & 48686 & 1.19 & 1.17 & Fail to Reject \\
\hline & 250 to $360 \mathrm{ft}$ & 6.4 & 4.0 & 224 & 5.9 & 3.4 & 46417 & 1.96 & 1.93 & Fail to Reject & 7.5 & 230 & 6.5 & 48686 & 1.16 & 1.33 & Reject \\
\hline & 155 to $250 \mathrm{ft}$ & 6.5 & 3.5 & 338 & 5.9 & 3.4 & 46417 & 1.96 & 3.25 & Reject & 7.6 & 351 & 6.5 & 48686 & 1.13 & 1.36 & Reject \\
\hline & $<155 \mathrm{ft}$ & 6.1 & 3.6 & 196 & 5.9 & 3.4 & 46417 & 1.96 & 1.02 & Fail to Reject & 7.5 & 196 & 6.5 & 48686 & 1.17 & 1.33 & Reject \\
\hline \multirow{5}{*}{$\begin{array}{c}\mathrm{I}-64 \\
102 \mathrm{~W}\end{array}$} & 495 to $645 \mathrm{ft}$ & 5.8 & 2.4 & 124 & 4.8 & 3.2 & 45745 & 1.96 & 4.75 & Reject & 6.4 & 129 & 5.9 & 48070 & 1.22 & 1.19 & Fail to Reject \\
\hline & 360 to $495 \mathrm{ft}$ & 5.7 & 4.5 & 155 & 4.8 & 3.2 & 45745 & 1.96 & 2.51 & Reject & 6.6 & 169 & 5.9 & 48070 & 1.19 & 1.29 & Reject \\
\hline & 250 to $360 \mathrm{ft}$ & 5.6 & 3.5 & 231 & 4.8 & 3.2 & 45745 & 1.96 & 3.53 & Reject & 6.5 & 242 & 5.9 & 48070 & 1.16 & 1.22 & Reject \\
\hline & 155 to $250 \mathrm{ft}$ & 5.9 & 3.4 & 339 & 4.8 & 3.2 & 45745 & 1.96 & 6.17 & Reject & 6.8 & 351 & 5.9 & 48070 & 1.13 & 1.34 & Reject \\
\hline & $<155 \mathrm{ft}$ & 6.9 & 3.9 & 195 & 4.8 & 3.2 & 45745 & 1.96 & 7.86 & Reject & 7.3 & 196 & 5.9 & 48070 & 1.17 & 1.55 & Reject \\
\hline
\end{tabular}

